UNIVERSIDADE DE SÃO PAULO

FACULDADE DE CIÊNCIAS FARMACÊUTICAS DE RIBEIRÃO PRETO

\title{
“Complexos de rutênio com nitrosil como agentes doadores de óxido nítrico. \\ Aspectos químicos e físico-químicos de suas aplicações como agentes terapêuticos”
}

Wagner Luiz Heleno Marcus Bertolini 
UNIVERSIDADE DE SÃO PAULO

FACULDADE DE CIÊNCIAS FARMACÊUTICAS DE RIBEIRÃO PRETO

“Complexos de rutênio com nitrosil como agentes doadores de óxido nítrico. Aspectos químicos e físico-químicos de suas aplicações como agentes terapêuticos”

Dissertação de Mestrado apresentada ao Programa de Pós-Graduação em Ciências Farmacêuticas para a Obtenção de Título de Mestre em Ciências Farmacêuticas, área de Concentração: Fármacos e Medicamentos

Orientado: Wagner Luiz Heleno Marcus Bertolini

Orientador: Prof. Dr. Roberto Santana da Silva 


\section{FICHA CATALOGRÁFICA}

Preparada pela Biblioteca Central do Campus

Administrativo

de Ribeirão Preto / USP

Bertolini, Wagner Luiz Heleno Marcus

“Complexos de rutênio com nitrosil como agentes doadores de óxido nítrico. Aspectos químicos e físico-químicos de suas aplicações como agentes terapêuticos”.Ribeirão Preto, 2004 118 p. : il. ; $30 \mathrm{~cm}$

Dissertação de Mestrado, apresentada à Faculdade de Ciências Farmacêuticas de Ribeirão Preto/USP Área de concentração: Fármacos e Medicamentos. Orientador: Silva, Roberto Santana da

1. Complexos de rutênio. 2. Ligantes nitrosilos.

3. Permeação passiva. 4.Liberação controlada 
Wagner Luiz Heleno Marcus Bertolini

“Complexos de rutênio com nitrosil como agentes doadores de óxido nítrico.

Aspectos químicos e físico-químicos de suas aplicações como agentes terapêuticos”

Prof. Dr. Roberto Santana da Silva

Faculdade de Ciências Farmacêuticas-USP-RP

Trabalho defendido e aprovado pela Comissão Julgadora em / $\quad / 2004$ 


\section{DEDICATÓRIA}

\section{Ao Prof. Dr. Roberto Santana da Silva}

Depois de mais de uma década após minha graduação em 1990 deparei-me com o objetivo de buscar uma maior qualificação acadêmica. Após tantos anos na profissão de professor decidi fazer pós-graduação, também devido a algumas necessidades pessoais e profissionais. Muitas dúvidas açoitavam-me os pensamentos antes de encarar tal jornada. Como seria? Como me depararia com a Universidade novamente há tantos anos distante? Quem me aceitaria como orientado, em função de minha situação profissional não me propiciar muitas horas de dedicação aos desafios de um mestrado?

Nesses momentos de incertezas um rosto aparecia estampado em meus pensamentos. Um rosto que apesar de muitos anos distantes se fazia lembrar pelas qualidades da pessoa, encarnadas na figura de um excelente professor. Tal lembrança deveu-se ao fato de, durante minha graduação, ter sempre deste professor um sorriso amável, um jeito sereno, que nos transmitia tranqüilidade, perseverança e, principalmente, à qualidade de suas aulas.

Um professor que sempre demonstrou muito conhecimento, didática e paciência para com todos. A aura, a pessoa do professor Roberto, sem que ele às vezes nem soubesse, nos transmitia harmonia e um ambiente muito agradável num momento de vida difícil para a maioria dos graduandos. E mesmo passados tantos anos é muito gratificante saber que ele continua a mesma pessoa simples, cordial, amável e conhecedor dos assuntos tratados.

Ao procurá-lo para discutir minha aceitação como orientado, sei que busquei a pessoa certa e fui extremamente bem recebido. 
Durante o decorrer do mestrado, sempre o tive a meu lado, discutindo os problemas decorrentes, ensinando-me muitas novas coisas; propondo alternativas a alguns passos, enfim: sempre presente e sempre com seu jeito amável, sábio e cordial, Uma rocha. Uma fortaleza. Como poderiam estas minhas simples palavras estar à altura necessária para te agradecer ? Meu muitíssimo obrigado, Roberto.

\section{À minha esposa LUCIMARA}

Dizer o que esta pessoa representa em minha vida é resumir minha vida em sua existência.

Feliz é a pessoa que pode contar e ter ao seu lado uma mulher como ela. Uma mulher que desde os tempos de namoro, no início da graduação, sempre me norteou, guiou-me pelos caminhos evitando os descaminhos quando estes se mostravam próximos.

Tempos tão difíceis para mim, mas uma mão estendida, confiante, me encorajando a enfrentar todas as batalhas. Coragem que nunca me faltara mas, às vezes, parecia se esconder.

Dedicação de amor e de carinho, trilhando comigo lado a lado os momentos difíceis, me ajudando a superá-los e vivenciando minhas vitórias, nossos momentos felizes, bem como sofrendo comigo quando das derrotas (que a vida sempre nos impõe), das dúvidas, das dificuldades encontradas. Mas sempre presente e sempre presente...

Uma guerreira incansável com sua força ímpar para crescer, para superar dificuldades. Como uma bússola a nortear meu caminho, mesmo em momentos dissonantes, mas, sempre uma pessoa vertical. Mulher de princípios mui bem definidos, fruto da 
excelente educação e carinho recebidos de seus pais (meus excelentes sogros).

Uma guerreira com coração leve, manso, de uma sensibilidade emocionante. Para quem a conhece, lealdade e atenção são outras de suas várias virtudes.

\section{À minha MÃE}

Tão longe fisicamente por muitos anos de minha vida. É difícil falar dela sem me emocionar ao relembrar nossas vidas.

Quando criança encontramo-nos distantes de uma vivência familiar, que se resumia a poucas horas por dia (alguns dias, nem isso) devido às situações impostas pela vida. Ela sempre teve que trabalhar muito para nosso sustento, para o sustento meu e de minhas duas irmãs, suprindo a ausência de um pai (falecido) trabalhando arduamente para que nada nos faltasse.

Decorridos alguns anos eu me tornara um adulto (?) e a ausência fez-se necessária para que eu pudesse cursar faculdade em Ribeirão Preto.

Durante os tempos de faculdade, as dificuldades foram uma constante. Porém, ao me lembrar das lições ensinadas por minha mãe e, tendo-a como um espelho, eu não desanimava e encarava estas dificuldades tendo que lutar pela superação na maioria das vezes.

Já graduado, a vida profissional teimou em manter tal distanciamento. Porém, distância física não nos separa daqueles que gostamos, daqueles a quem amamos. Muitas vezes bate a saudade... 


\section{AGRADECIMENTOS ESPECIAIS}

Gostaria de agradecer a todos que contribuíram direta ou indiretamente para com a realização deste meu trabalho.

Entre estes, gostaria de agradecer à Marília, Renata e Fabiana por serem sempre prestativas em me ajudar nas dificuldades, ensinando-me muitas técnicas, discutindo comigo aspectos inerentes ao meu trabalho, enfim: ajudaram-me muito desde o primeiro dia em que iniciei no laboratório até os últimos.

Ao Marião pelo auxílio e convivência nos experimentos farmacotécnicos, tendo a paciência e boa vontade de sacrificar alguns sábados auxiliando-me nesta jornada.

À Prof ${ }^{\mathrm{a}}$ Dr $^{\mathrm{a}}$ Renata Fonseca Vianna Lopez, um agradecimento muitíssimo especial, pela tão estimada ajuda nos experimentos farmacotécnicos, sempre discutindo os conceitos e objetivos de meu trabalho. Agradecimento extensivo a seu grupo de pós-graduandos, pela atenção dedicada e ajuda dispensada. Em especial à Haluka e Léo.

À Maria Perpétua , Rosana Tavares, Luiz Carlos Feiteiro e Solange De Santis meu agradecimento pela colaboração técnica e pelas conversas do nosso dia-a-dia.

Ao casal de professores de nosso laboratório: Rose e Zeki Naal pelos bate-papos e pelos momentos de descontração que tivemos.

Às minhas irmãs, Rosangela e Dulcinéia; meus sobrinhos: Gabi, Carol, Camila e Lucas e meu cunhado Wagner. 
À comissão de Pós-Graduação e seus funcionários. pelo apoio a mim deferido, que foi de grande valia. Sempre me socorrendo em minhas dúvidas e auxiliando nas necessidades de aporte técnico.

Ao Eduardo Bortolin, por sempre me oferecer aquele cafezinho, que na verdade servia de disfarce para nos atrair para um animado bate-papo...e sempre deixando aquele sorriso espontâneo e gratuito para os amigos. Obrigado, meu camarada, pelo incentivo para sempre persistir e não desanimar. E esse sorriso amigo vem desde os meus tempos de graduação.Valeu muito !!!!

Como se pode perceber, em minha vida sempre tive a felicidade de conviver com pessoas maravilhosas. Muitas vezes me convenço que nem sempre faço o que deveria para merecê-las e mantê-las em minha vida. Creio que é Obra Dele para comigo. E só posso agradecer a cada novo dia por isto. Pena que em muitos dias das nossas vidas não falamos a estas pessoas que nos cercam o que sentimos por elas. Parece que temos medo de sermos frívolos...mas devíamos falar.
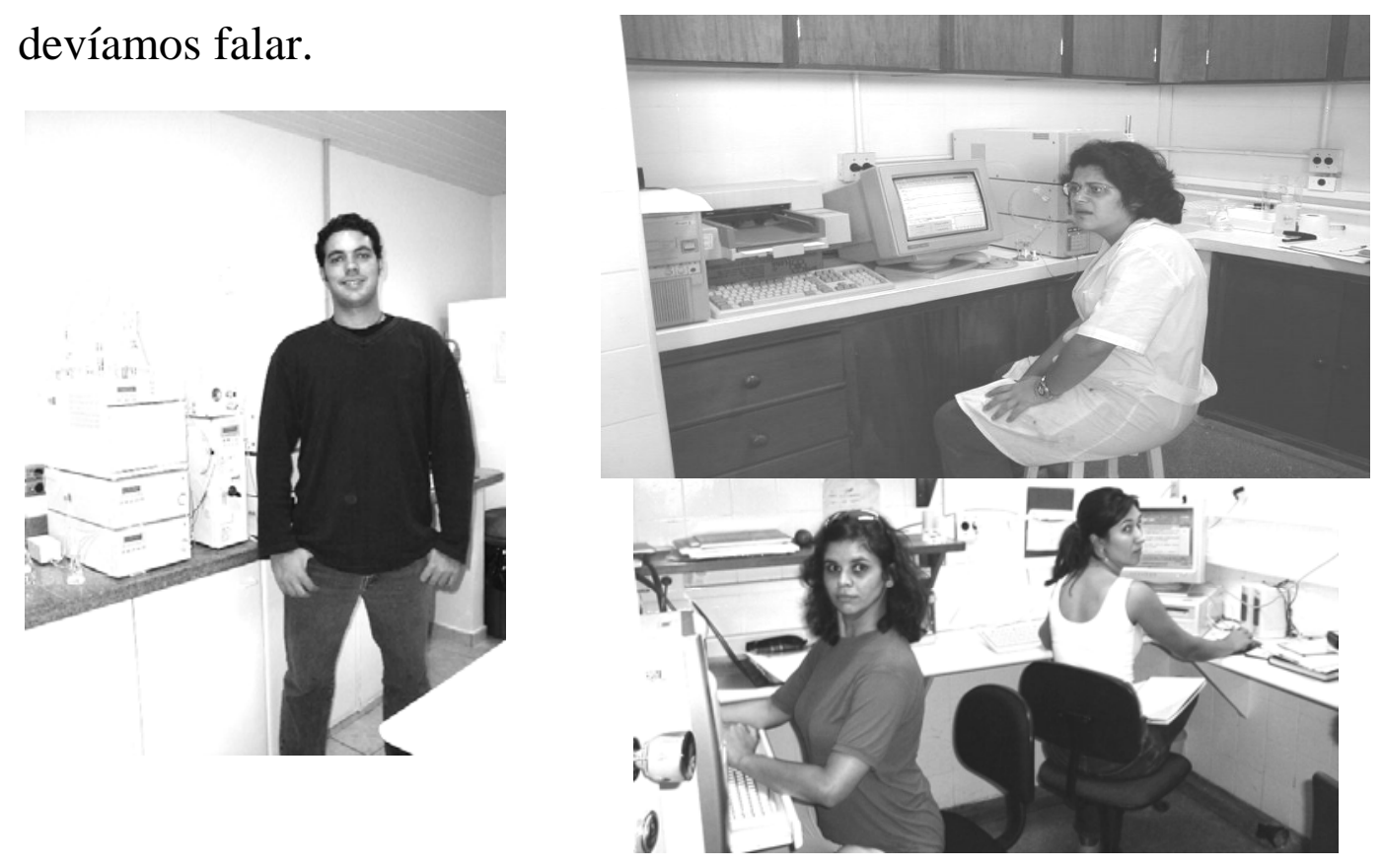
Lista de Esquemas e Equações I

Lista de Figuras

Lista de Tabelas $\quad$ IX

Lista de Abreviaturas $\quad \mathrm{X}$

Resumo XIII

$\begin{array}{ll}\text { Abstract } & \text { XV }\end{array}$

1. INTRODUÇÃO

1.1. Propriedades físico-químicas do óxido nítrico............................... 07

1.2. Aplicações farmacêuticas de complexos metálicos...................... 12

1.3. Complexos nitrosilos de rutênio................................................... 15

1.4. Permeação passiva...................................................................... 18

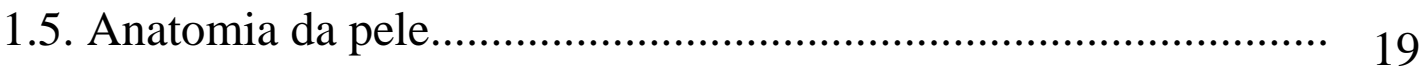

1.6. Penetração cutânea de fármacos................................................. 23

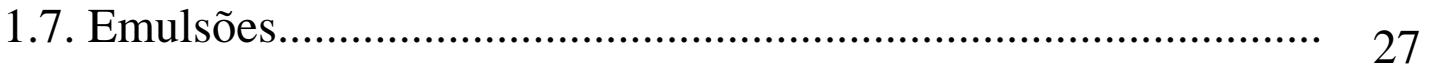

2. OBJETIVOS

3. MATERIAIS E MÉTODOS............................................................. 31

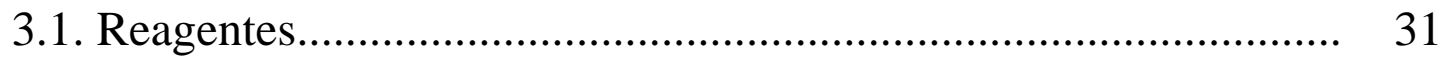

3.2. Materiais e equipamentos utilizados............................................ 32

3.2.1. Gás Argônio................................................................... 32

3.2.2. Espectroscopia na região do infravermelho..................... 33 
3.2.3. Espectroscopia na região do ultravioleta-visível.

3.2.4. Voltametria.

3.2.5. Medidas de $\mathrm{pH}$.

3.2.6. Preparação das emulsões............................................... 34

3.2.7. Outros equipamentos....................................................... 35

3.3. Sínteses dos compostos de rutênio.............................................. 35

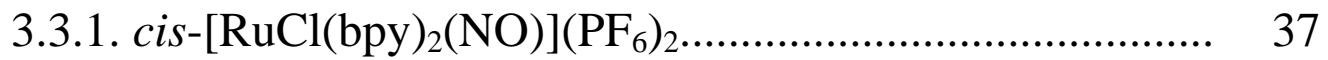

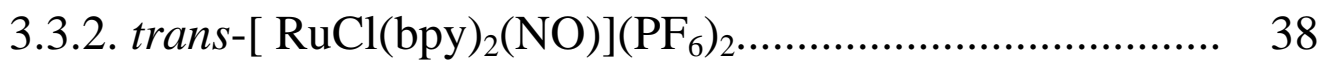

3.3.3. Purificação do complexo

$$
\left[\mathrm{RuCl}(\mathrm{bpy})_{2}(\mathrm{NO})\right]\left(\mathrm{PF}_{6}\right)_{2}
$$

3.4. Caracterização dos compostos de rutênio

3.4.1. Espectroscopia na região do ultravioleta-visível

3.4.2. Espectroscopia na região do infravermelho.

3.4.3. Voltametria cíclica.

3.5. Estudos de penetração passiva in vitro...

3.5.1. Célula de difusão

3.5.2. Determinação da permeação do fármaco através da pele in vitro. 45

3.5.3. Estudos de retenção 48 
3.6. Determinação dos parâmetros cinéticos de liberação de NO

3.6.1. Redução química

3.6.1.1. Redução química com solução redutora de ácido ascórbico

3.6.1.2. Redução química com amálgama de zinco.

3.6.1.3. Redução química com amálgama de cádmio.

3.6.1.4. Redução sob potencial controlado

3.6.1.5. Espectroeletroquímica

4. RESULTADOS E DISCUSSÃO

4.1. Sínteses.

4.2. Espectroscopia na região do UV-visível

4.2.1. Complexos $\left[\mathrm{RuCl}(\mathrm{bpy})_{2}(\mathrm{NO})\right]\left(\mathrm{PF}_{6}\right)_{2}$

4.3. Espectroscopia na região do Infravermelho.

4.4. Comportamento voltamétrico em meio não aquoso...... 68 4.5. Estudo da permeação passiva

4.5.1. Permeação passiva dos complexos a partir do tampão fosfato

4.5.2. Permeação passiva dos complexos a partir de emulsões 
4.5.2.2. Emulsão Paramul ${ }^{\circledR}$

4.5.2.3. Estudo de liberação utilizando-se membrana sintética.

4.5.2.4. Determinação da concentração liberada ou permeada através da membrana....

4.6. Estudo de liberação de NO por potencial controlado

4.7. Estudo cinético de labilização do NO

4.7.1. Redução química com solução redutora de ácido ascórbico

5. CONSIDERAÇÕES FINAIS 


\section{LISTA DE ESQUEMAS}

ESQUEMA

Pág.

Esquema 1: Principais formas de atuação do óxido nítrico na Medicina e na Química (Fonte: Informativo CRQIV Maio-Jun/2003; figura extraída do artigo do Prof. Etelvino Bechara, com modificações).............. 04

Esquema 2: $\quad$ Reação de dimerização do óxido nítrico..................... 08

Esquema 3: Etapas reacionais de oxidação do óxido nítrico formando ERONs.

Esquema 4: Representação esquemática da epiderme e seus estratos........................................... 22

Esquema 5: Rota sintética para os complexo cis$\left[\mathrm{RuCl}(\mathrm{bpy})_{2}(\mathrm{NO})\right]\left(\mathrm{PF}_{6}\right)_{2} \ldots \ldots \ldots \ldots \ldots \ldots \ldots \ldots \ldots . \quad 35$

Esquema 6: Rota sintética para os complexo trans-

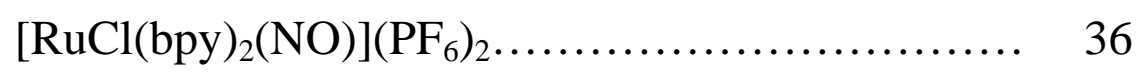

Esquema 7: Processos eletroquímicos centrados no ligante nitrosil para complexos do tipo $\left[\mathrm{RuL}(\mathrm{bpy})_{2}(\mathrm{NO})\right]^{\mathrm{n}+} . \quad 68$

\section{LISTA DE EQUAÇÕES}

Equações Pág.

Equação 1 Reação de adição de $\mathrm{HCl}$ com formação de $\mathrm{CO}_{2} \ldots \ldots$... 39

Equação 2 Método empírico de NICHOLSON \& SHAIN (1965) que determina a razão $\mathrm{I}_{\mathrm{pc}} / \mathrm{I}_{\mathrm{pa}}$

Equação 3: Equação da reação de oxi-redução do grupo nitrosil, referente ao processo eletroquímico 1a/1c, em acetonitrila. 


\section{LISTA DE FIGURAS}

FIGURA

Pág.

Figura 1: Número de publicações sobre NO de 1985 a 2003. Fonte: Web of Science............................................... 02

Figura 2: Diagrama simplificado de orbitais moleculares do óxido nítrico

Figura 3: Esquema dos orbitais moleculares envolvidos na ligação de um metal com o ligante nitrosil.

Figura 4: Fórmulas estruturais de complexos de rutênio denominados "scavengers" de NO, onde:

a) $\mathrm{K}\left[\mathrm{Ru}(\mathrm{Hedta}) \mathrm{OH}_{2}\right]$, b) $\mathrm{K}_{2}[\mathrm{Ru}($ Hedta)Cl $] \ldots \ldots \ldots \ldots . \quad 15$

Figura 5: Representação esquemática das camadas da pele.

Figura 6: Representação esquemática das vias de permeação de fármacos através da pele.

Figura 7: Fórmula estrutural do complexo cis-

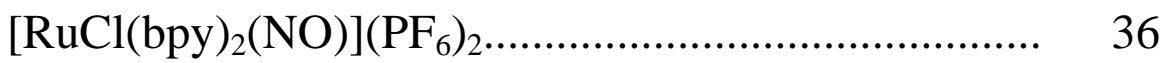

Figura 8: Fórmula estrutural do complexo trans$\left[\mathrm{RuCl}(\mathrm{bpy})_{2}(\mathrm{NO})\right]\left(\mathrm{PF}_{6}\right)_{2}$

Figura 9: Esquema da aparelhagem utilizada para a fotólise......

Figura 10: Ilustração dos parâmetros de um voltamograma cíclico

Figura 11: a) Célula de Franz montada; b) Pele da orelha de porco 
Figura 12: Célula de difusão de Franz utilizada nos estudos de 45 permeação cutânea in vitro

Figura 13: Esquema de montagem das células de difusão de Franz. Visão geral do sistema de difusão.

Figura 14: Bomba peristáltica (esquerda) e coletor automático....

Figura 15: Aparelho utilizado na técnica "stopped flow". 50

Figura 16: Frasco de Zwickel.........................................................

Figura 17: Esquema ilustrando a cela espectroeletroquímica....... 53

Figura 18: Esquema ilustrando eletrodo de referência $\mathrm{Ag} / \mathrm{AgCl}$.. 54

Figura 19: Aparato montado em capela para geração de óxido nítrico gasoso $\left(\mathrm{NO}^{0}\right)$. 56

Figura 20: Diagrama simplificado de orbitais moleculares e transições eletrônicas para compostos do tipo cis-[RuL(bpy $\left.)_{2}(\mathrm{NO})\right]^{\mathrm{n}+}$ 58

Figura 21: Espectro na região do UV-visível, em $\mathrm{HCl} \mathrm{0,10} \mathrm{mol.}$ $\mathrm{L}^{-1}$, do complexo cis-[RuCl(bpy $\left.)_{2}(\mathrm{NO})\right]\left(\mathrm{PF}_{6}\right)_{2}$ [complexo] $=6,30 \times 10^{-5} \mathrm{~mol} . \mathrm{L}^{-1}$ 60

Figura 22: Espectro na região do UV-visível, em $\mathrm{HCl}$ 0,10 mol. $\mathrm{L}^{-1}$, do complexo cis-[ $\left[\mathrm{RuCl}_{2}(\mathrm{bpy})_{2}\right] \cdot 2 \mathrm{H}_{2} \mathrm{O}$. [complexo] $=6,30 \times 10^{-5} \mathrm{~mol} . \mathrm{L}^{-1}$

Figura 23: Espectro na região do UV-visível, em $\mathrm{HCl} 0,10$ mol.L ${ }^{-1}$,do complexo trans-[RuCl(bpy $\left.)_{2}(\mathrm{NO})\right]\left(\mathrm{PF}_{6}\right)_{2}$. [complexo] $=6,30 \times 10^{-5} \mathrm{~mol} . \mathrm{L}^{-1}$

Figura 24: Espectro na região do UV-visível, em $\mathrm{HCl}$ 0,10 mol.

$\mathrm{L}^{-1}$, do complexo trans-[RuCl $\left.2(\text { bpy })_{2}\right] \cdot 2 \mathrm{H}_{2} \mathrm{O}$. [complexo] $=6,30 \times 10^{-5} \mathrm{~mol} . \mathrm{L}^{-1}$ 
Figura 25: Intervalos típicos de freqüência de estiramento na região do infravermelho para complexos metálicos nitrosilos

Figura 26: Espectro na região do infravermelho, em pastilha de $\mathrm{KBr}$, do complexo trans-[RuCl(bpy $\left.)_{2}(\mathrm{NO})\right]\left(\mathrm{PF}_{6}\right)_{2} \ldots \ldots$.

Figura 27: Espectro na região do infravermelho, em pastilha de $\mathrm{KBr}$, do complexo cis-[RuCl(bpy $\left.)_{2}(\mathrm{NO})\right]\left(\mathrm{PF}_{6}\right)_{2} \ldots \ldots \ldots .$.

Figura 28: Influência da posição do ligante L na energia de estiramento do ligante nitrosil. a) posição trans e b) posição cis.

Figura 29: Variação de $v \mathrm{NO}$ em função de $\Sigma \mathrm{E}_{\mathrm{L}}$ para complexos de rutênio de simetria trans. 1) $\mathrm{L}=i m \mathrm{~N}$, 2) $\mathrm{L}=$ py, 3) $\mathrm{L}=$ isc e 4) $\mathrm{L}=\mathrm{pz}$ para a série trans$\left[\mathrm{Ru}\left(\mathrm{NH}_{3}\right)_{4} \mathrm{~L}(\mathrm{NO})\right]^{3+}$. 5) $\left.\mathrm{L}=\mathrm{OH}^{-}, 6\right) \mathrm{L}=\mathrm{Cl}^{-}$e 7) $\mathrm{L}=$ $\mathrm{NH}_{3}$ para a série trans-[RuL(py) $\left.)_{4}(\mathrm{NO})\right]^{\mathrm{n}+}$

Figura 30: Voltamograma cíclico do complexo cis$\left[\mathrm{RuCl}(\mathrm{bpy})_{2}(\mathrm{NO})\right]\left(\mathrm{PF}_{6}\right)_{2}$ em acetonitrila,. Eletrólito de suporte: TBAH 0,10 mol. $\mathrm{L}^{-1}$. Potencial de reversão: $-1,12 \mathrm{~V}_{\text {vs Fc}}{ }^{+/ 0}$. [complexo] $=6,50 \times 10^{-5}$ mol. $\mathrm{L}^{-1} . ; \mathrm{v}=100 \mathrm{mV} / \mathrm{s} . \mathrm{T}=25^{\circ} \mathrm{C}$

Figura 31: IVoltamogramama cíclico do complexo, trans$\left[\mathrm{RuCl}(\mathrm{bpy})_{2}(\mathrm{NO})\right]\left(\mathrm{PF}_{6}\right)_{2}$ em acetonitrila Eletrólito de suporte: TBAH 0,10 mol.L ${ }^{-1}$. Potencial de reversão:

$-1,12 \mathrm{~V} \mathrm{vs} \mathrm{Fc}^{+/ 0}$. [complexo] $=6,50 \times 10^{-5} \mathrm{~mol}^{-\mathrm{L}^{-1}}$. $\mathrm{v}=100 \mathrm{mV} / \mathrm{s} . \mathrm{T}=25^{\circ} \mathrm{C}$

Figura 32: IVoltamogramas cíclicos do complexo cis$\left[\mathrm{RuCl}(\mathrm{bpy})_{2}(\mathrm{NO})\right]\left(\mathrm{PF}_{6}\right)_{2}$ em acetonitrila Eletrólito 
suporte: TBAH 0,10 mol. $\mathrm{L}^{-1}$

[complexo] $=1,00 \times 10^{-4} \mathrm{~mol}$. $\mathrm{L}^{-1}$. Velocidades de varredura (mV/s): 50, 100, 200, 300 e $400 \mathrm{~T}=25^{\circ} \mathrm{C}$.

Figura 33: Variação de $I_{p c}$ em função de $v^{1 / 2}$, em acetonitrila, para o complexo cis-[RuCl(bpy $\left.)_{2}(\mathrm{NO})\right]\left(\mathrm{PF}_{6}\right)_{2}$. $\mathrm{T}=25^{\circ} \mathrm{C}$.

Figura 34: Voltamogramas cíclicos do complexo, em acetonitrila, trans-[RuCl(bpy $\left.)_{2}(\mathrm{NO})\right]\left(\mathrm{PF}_{6}\right)_{2}$. Eletrólito de suporte: TBAH 0,10 mol. $\mathrm{L}^{-1}$. [complexo] $=1 \times 10^{-4}$ mol. $\mathrm{L}^{-1}$. Velocidades de varredura $(\mathrm{mV} / \mathrm{s}): 50,100$, 200, 300 e 400. $\mathrm{T}=25^{\circ} \mathrm{C}$

Figura 35: Variação de $I_{p c}$ em função de $v^{1 / 2}$, em acetonitrila, para o complexo trans-[RuCl(bpy $\left.)_{2}(\mathrm{NO})\right]\left(\mathrm{PF}_{6}\right)_{2} \cdot \mathrm{T}=74$ $25^{\circ} \mathrm{C}$.

Figura 36: Voltamogramas cíclicos do complexo cis$\left[\mathrm{RuCl}(\mathrm{bpy})_{2}(\mathrm{NO})\right]\left(\mathrm{PF}_{6}\right)_{2}$ em acetonitrila. Eletrólito de suporte: TBAH 0,10 mol. $\mathrm{L}^{-1}$. [Complexo] = $7,20 \times 10^{-4} \mathrm{~mol}$. L ${ }^{-1}$.Velocidades de varredura $(\mathrm{mV} / \mathrm{s})$ : $50,100,300$ e $400 . \mathrm{T}=25^{\circ} \mathrm{C}$

Figura 37: Voltamogramas cíclicos do complexo trans-[RuCl(bpy $\left.)_{2}(\mathrm{NO})\right]\left(\mathrm{PF}_{6}\right)_{2}$ em acetonitrila. Eletrólito de suporte: TBAH 0,10 mol.L ${ }^{-1}$. [Complexo] $=7,20 \times 10^{-4} \mathrm{~mol} . \mathrm{L}^{-1}$. Velocidades de varredura (mV/s): 50, 100, 200,300 e 400.. T $=25{ }^{\circ} \mathrm{C} \quad 76$

Figura 38: Relação entre $\mathrm{Ipc} / \mathrm{V}^{1 / 2}$ vs $\mathrm{V}^{1 / 2}$ para o complexo cis-[RuCl(bpy $\left.)_{2}(\mathrm{NO})\right]\left(\mathrm{PF}_{6}\right)_{2}$, em acetonitrila. 
Figura 39: Relação entre $\mathrm{Ipc} / \mathrm{V}^{1 / 2}$ vs $\mathrm{V}^{1 / 2}$ para o complexo trans-[RuCl(bpy $\left.)_{2}(\mathrm{NO})\right]\left(\mathrm{PF}_{6}\right)_{2}$, em acetonitrila... 78

Figura 40: Espectro UV-visível em acetonitrila no estrato córneo do complexo cis-[RuCl(bpy $\left.)_{2}(\mathrm{NO})\right]\left(\mathrm{PF}_{6}\right)_{2} \ldots \ldots .$. 79

Figura 41: Espectro UV-visível na epiderme viável do complexo cis-[RuCl(bpy $\left.)_{2}(\mathrm{NO})\right]\left(\mathrm{PF}_{6}\right)_{2}$. Em detalhe: $\begin{array}{llllll}\text { espectro na região de } 400 \mathrm{~nm} \text { a } & 79\end{array}$ $600 \mathrm{~nm}$

Figura 42: Espectro UV-visível no estrato córneo do complexo trans-[RuCl(bpy $\left.)_{2}(\mathrm{NO})\right]\left(\mathrm{PF}_{6}\right)_{2}$

Figura 43: Espectro UV-visível na epiderme viável do complexo trans- 80 $\left[\mathrm{RuCl}(\mathrm{bpy})_{2}(\mathrm{NO})\right]\left(\mathrm{PF}_{6}\right)_{2}$

Figura 44: Espectro UV-visível do complexo cis$\left[\mathrm{RuCl}(\mathrm{bpy})_{2}\left(\mathrm{H}_{2} \mathrm{O}\right)\right]^{+}$em solução tampão fosfato $\mathrm{pH}=5.0$ após redução do complexo cis$\left[\mathrm{RuCl}(\mathrm{bpy})_{2}(\mathrm{NO})\right]\left(\mathrm{PF}_{6}\right)_{2} \quad$ com amálgama de zinco.

Figura 45: Espectro UV-visível do complexo cis$\left[\mathrm{RuCl}(\mathrm{bpy})_{2}(\mathrm{NO})\right]\left(\mathrm{PF}_{6}\right)_{2}$ no estrato córneo

Figura 46: Espectro UV-visível do complexo trans$\left[\mathrm{RuCl}(\mathrm{bpy})_{2}(\mathrm{NO})\right]\left(\mathrm{PF}_{6}\right)_{2}$ no estrato córneo.................

Figura 47: Espectro UV-visível na epiderme viável do complexo cis-[RuCl(bpy $\left.)_{2}(\mathrm{NO})\right]\left(\mathrm{PF}_{6}\right)_{2}$. Em detalhe, região de $480 \mathrm{~nm}$. 
Figura 48: Espectro UV-visível do complexo trans$\left[\mathrm{RuCl}(\mathrm{bpy})_{2}(\mathrm{NO})\right]\left(\mathrm{PF}_{6}\right)_{2}$ na epiderme viável.............. 85

Figura 49: Espectro UV-visível do complexo cis$\left[\mathrm{RuCl}(\mathrm{bpy})_{2}(\mathrm{NO})\right]\left(\mathrm{PF}_{6}\right)_{2}$ após permeação passiva em membrana de acetato de celulose após período de 12 horas

Figura 50: Espectro UV-visível do complexo trans$\left[\mathrm{RuCl}(\mathrm{bpy})_{2}(\mathrm{NO})\right]\left(\mathrm{PF}_{6}\right)_{2}$ após permeação passiva em membrana de acetato de celulose após período de 12 horas.

Figura 51: Perfil de liberação dos complexos em membrana de celulose. Complexo cis-[RuCl(bpy $\left.)_{2}(\mathrm{NO})\right]\left(\mathrm{PF}_{6}\right)_{2}$ (Azul) e trans-[RuCl(bpy) $\left.)_{2}(\mathrm{NO})\right]\left(\mathrm{PF}_{6}\right)_{2}$ (rosa)..........

Figura 52: Perfil de liberação das amostras do complexo em membrana de acetato de celulose.Complexo cis-

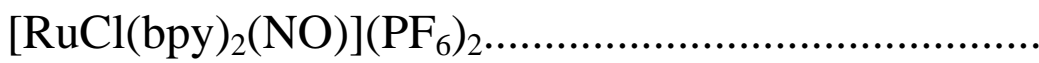

Figura 53: Perfil de liberação das amostras do complexo em membrana de acetato de celulose. Complexo trans-

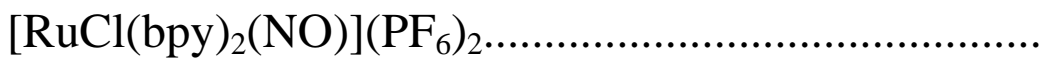

Figura 54: Perfil de liberação do complexo em membrana de acetato de celulose. Complexo cis-

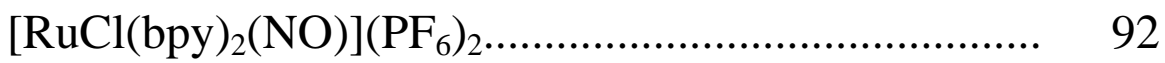

Figura 55: Perfil de liberação do complexo em membrana de acetato de celulose. Complexo trans-

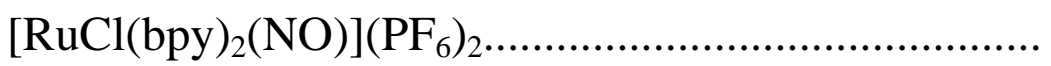


Figura 56: Cronoamperograma do NO liberado pela redução do complexo cis-[RuCl(bpy $\left.)_{2}(\mathrm{NO})\right]\left(\mathrm{PF}_{6}\right)_{2}$, em solução tampão fosfato, $\mathrm{pH}=5,0$ com potencial de $0,00 \mathrm{~V}$ vs

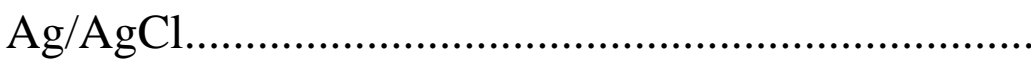

Figura 57: Cronoamperograma do NO liberado pela redução do complexo trans-[RuCl(bpy $\left.)_{2}(\mathrm{NO})\right]\left(\mathrm{PF}_{6}\right)_{2}, \quad$ em tampão fosfato, $\mathrm{pH}=5,0$ com potencial aplicado de 0,00 $\mathrm{V}$ vs $\mathrm{Ag} / \mathrm{AgCl}$ 


\section{LISTA DE TABELAS}

TABELA

Pág.

Tabela 1: Comparação entre o comprimento de ligação, energia vibracional na região do infravermelho e potencial redox das espécies $\mathrm{NO}^{+}, \mathrm{NO}^{0}$ e $\mathrm{NO}^{-}$

Tabela 2: Porcentagem de pureza e procedência dos reagentes utilizados durante as sínteses e a caracterização dos complexos.

Tabela.3: Formulação das emulsões estudadas.

Tabela 4: Resultados de análise de espectros na região do UVvisível para os complexos de rutênio em solução de $\mathrm{HCl}$ 0,1 mol. $\mathrm{L}^{-1}$,em 62 acetonitrila.

Tabela 5: Energia vibracional do $\mathrm{NO}^{+}$em complexos do tipo cis-[RuL(bpy) $\left.)_{2}(\mathrm{NO})\right]^{\mathrm{n}+}$ (CALLAHAN \& MEYER, 1977).

Tabela 6: Parâmetros eletroquímicos, em acetonitrila, para o complexo cis-[RuCl(bpy $\left.)_{2}(\mathrm{NO})\right]\left(\mathrm{PF}_{6}\right)_{2} . \mathrm{T}=25{ }^{\circ} \mathrm{C}$.

E (V vs Ag/AgCl).

Tabela 7: Parâmetros eletroquímicos, em acetonitrila, para o complexo trans-[RuCl(bpy $\left.)_{2}(\mathrm{NO})\right]\left(\mathrm{PF}_{6}\right)_{2} . \mathrm{T}=25^{\circ} \mathrm{C}$.

E (V vs Ag/AgCl)

Tabela 8: Concentração $\left(\mathrm{mol} . \mathrm{L}^{-1} / \mathrm{cm}^{2}\right)$ de fármaco liberado a partir de emulsão paramul em membrana de acetato de celulose.

Tabela 9: Parâmetros cinéticos das curvas de liberação dos complexos $\left(\mathrm{mol} / \mathrm{cm}^{2}\right)$ em função do tempo......................... 


\section{LISTA DE ABREVIATURAS E/OU SIGLAS}

\begin{tabular}{|c|c|}
\hline$\varepsilon$ & Coeficiente de absortividade molar (mol. $\left.\mathrm{cm}^{-1} \cdot \mathrm{L}^{-1}\right)$ \\
\hline$\lambda$ & Comprimento de onda (nm) \\
\hline$v(\mathrm{NO})$ & $\begin{array}{l}\text { Freqüência da banda de estiramento da ligação N-O na } \\
\text { região do infravermelho }\left(\mathrm{cm}^{-1}\right)\end{array}$ \\
\hline$\Delta \mathrm{G}$ & Variação da energia livre de Gibbs \\
\hline$\Delta \mathrm{H}$ & Variação da entalpia \\
\hline$\Delta \mathrm{S}$ & Variação da entropia \\
\hline [ ] & Concentração molar $\left(\mathrm{mol} . \mathrm{L}^{-1}\right)$ \\
\hline$\Pi$ * & Orbital pi-antiligante \\
\hline $\mathrm{ACN}$ & Acetonitrila \\
\hline $\mathrm{A} / \mathrm{O}$ & Emulsão água em óleo \\
\hline bpy & 2, 2'-bipiridina \\
\hline cGMP & Guanosina monofosfato cíclica \\
\hline CNTP & Condições normais de temperatura e pressão \\
\hline $\mathrm{EC}$ & Estrato córneo \\
\hline $\mathrm{E}_{1 / 2}$ & Potencial de meia onda \\
\hline $\mathrm{E}_{\mathrm{L}}$ & Parâmetro de Lever \\
\hline $\mathrm{E}_{\mathrm{pa}}$ & Potencial de oxidação \\
\hline $\mathrm{E}_{\mathrm{pc}}$ & Potencial de redução \\
\hline EPH & Eletrodo padrão de hidrogênio \\
\hline ERONs & Espécies reativas de óxido de nitrogênio \\
\hline $\mathrm{E}_{\mathrm{sp}}$ & Potencial de reversão \\
\hline $\mathrm{F}_{\mathrm{c}}$ & Ferroceno \\
\hline FRED & Fator de relaxamento do endotélio dependente \\
\hline
\end{tabular}




\begin{tabular}{|c|c|}
\hline GTP & Guanosina trifosfato \\
\hline IL & Intraligante \\
\hline $\mathrm{IFN} \gamma$ & Interferon gama \\
\hline $\mathrm{I}_{\mathrm{pa}}$ & Corrente máxima de oxidação \\
\hline $\mathrm{I}_{\mathrm{pc}}$ & Corrente máxima de redução \\
\hline isc & Isocotinamida \\
\hline $\mathrm{I}_{\mathrm{sp}}$ & Corrente de reversão \\
\hline K & Constante de equilíbrio \\
\hline $\mathrm{L}$ & Ligante genérico \\
\hline LPS & Lipossacarídeo \\
\hline M & Metal \\
\hline NADP & Nicotinamida adenina dinucleotídeo fosfato \\
\hline NADPH & $\begin{array}{l}\text { Nicotinamida adenina dinucleotídeo fosfato em sua } \\
\text { forma reduzida }\end{array}$ \\
\hline NOS & Óxido nítrico sintase \\
\hline NOSe & Óxido nítrico sintase endotelial \\
\hline NOSi & Óxido nítrico sintase induzível \\
\hline NOSn & Óxido nítrico sintase neural \\
\hline $\mathrm{O} / \mathrm{A}$ & Emulsão óleo em água \\
\hline py & Piridina \\
\hline qsp & Quantidade suficiente para \\
\hline rpm & Rotação por minuto \\
\hline sh & Ombro \\
\hline $\mathrm{T}$ & Temperatura \\
\hline TBAH & Hexafluorfosfato de tetrabutilamônio \\
\hline TCML & Transferência de carga metal ligante \\
\hline
\end{tabular}


TNF $\alpha \quad$ Fator de necrose tumoral alfa

uv Ultravioleta

$\mathrm{v}$

Velocidade de varredura $(\mathrm{mV} / \mathrm{s})$

vs

Versus

$\mathrm{Zn} / \mathrm{Hg}$

Amálgama de Zinco

$\Delta \mathrm{Ep}$

Variação de potencial 


\section{RESUMO}

A atividade do óxido nítrico na Química e Biologia não é completamente conhecida. Centenas de artigos são publicados por ano, somente sobre este assunto. Muito mais estudos necessitam ser feitos nesta área.

Cientistas no campo da Biologia que queiram estudar como o óxido nítrico se comporta em diferentes sistemas necessitam de algum tipo de composto modelo que libera NO, para auxiliá-los em seus estudos farmacocinéticos.

O óxido nítrico (NO) é tão importante que há um grande desejo da sociedade cientifica em obter compostos que possibilitem liberá-lo. Ele apresenta aplicações diversificadas. Investigando a cinética de liberação de NO, poderemos saber como o mesmo pode ser aplicado nas mais diversas atividades, tais como: controlar a relaxação cardiovascular, pressão sanguínea ou mesmo o desenvolvimento do câncer.

Neste trabalho sintetizamos e caracterizamos cis$\left[\mathrm{RuCl}(\mathrm{NO})(\mathrm{bpy})_{2}\right]\left(\mathrm{PF}_{6}\right)_{2}$ e trans-[RuCl(NO)(bpy)$\left.)_{2}\right]\left(\mathrm{PF}_{6}\right)_{2}$. Os valores obtidos para o complexo cis-[RuCl(NO)(bpy $\left.)_{2}\right]\left(\mathrm{PF}_{6}\right)_{2}$ por voltametria cíclica foram: $\mathrm{E}_{1 / 2}=0,21 \mathrm{~V}$ vs Fe ;UV-vis(298nm,332nm); FTIR:vNO= $1930 \mathrm{~cm}^{-1}$; para o complexo trans-[RuCl(NO)(bpy $\left.)_{2}\right]\left(\mathrm{PF}_{6}\right)_{2}$ a voltametria cíclica apresentou $\mathrm{E}_{1 / 2}=0,19 \mathrm{~V}$ vs Fe ;UV-vis (298nm,312nm); FTIR:vNO= 1921 $\mathrm{cm}^{-1}$.

O desenvolvimento de sistemas de liberação de NO a partir de complexos nitrosilos de rutênio podem ser discutidos com particular referencia ao produto de necessidade médica. Uma compreensão apropriada das propriedades da molécula doadora de NO, em um sistema 
de liberação de fármaco, é essencial antes do uso de interesse na terapia clinica.

Foram estudadas as propriedades físico-quimicas dos compostos cis / trans-[RuCl(NO)(bpy) $\left.)_{2}\right]\left(\mathrm{PF}_{6}\right)_{2}$ em emulsão água / óleo (A/O) e avaliadas as taxas de liberação de NO encapsulado na fase aquosa interna da emulsão.

O perfil de liberação de NO pelos complexos cis / trans[RuCl(NO)(bpy $\left.)_{2}\right]\left(\mathrm{PF}_{6}\right)_{2}$ também foi estudada utilizando-se membrana de acetato de celulose, cujos resultados mostram um comportamento não linear com taxa de $4,53 \times 10^{-4} \mathrm{~mol} / \mathrm{cm}^{2}$ para a espécie cis-[RuCl(bpy) $\left.{ }_{2} \mathrm{NO}\right]^{2+}$ e $3,33 \times 10^{-4} \mathrm{~mol} / \mathrm{cm}^{2}$ para a espécie trans-[RuCl(bpy) $\left.{ }_{2} \mathrm{NO}\right]^{2+}$.

A permeação transdérmica e a acumulação dos complexos cis /trans$\left[\mathrm{RuCl}(\mathrm{bpy})_{2} \mathrm{NO}\right]^{2+}$ sobre a pele foi também estudada utilizando-se pele da orelha de porco.

Os dados obtidos por espectro de absorção UV-visível exibiram aumentos da concentração acumulada dos complexos sobre a pele quando os mesmos foram formulados em emulsão na forma livre, para ambos os isômeros. Tais resultados mostraram que os complexos ficaram acumulados principalmente na epiderme.

Também foram observados espectros UV-visível, utilizando-se acoplado um sensor seletivo para NO, que demonstraram que é possível liberar $\mathrm{NO}$ a partir dos complexos cis / trans-[RuCl(NO)(bpy $\left.)_{2}\right]\left(\mathrm{PF}_{6}\right)_{2}$ através da eletro-redução em meio aquoso ou em emulsão A/O, quando um potencial de $0,00 \mathrm{~V}$ vs $\mathrm{Ag} / \mathrm{AgCl}$ foi aplicado.

Estes resultados nos sugerem que o sistema de complexos de rutênio nitrosil veiculados em emulsão A/O poderia ser utilizado com sucesso no desenvolvimento de um sistema de liberação prolongada de NO 


\section{ABSTRACT}

Nitric oxide activity in chemistry and biology is not yet fully discovered. There are more than 5,000 papers alone on this subject each year. A lot more work needs to be done in this area.

For people in biology who want to study how nitric oxide works in different systems, they need some kind of model compound to release nitric oxide to help them do their pharmacokinetic studies.

Nitric oxide (NO) is very important, there is a great need in the scientific society to have a compound that can release it. There are many applications. By investigating the nitric oxide releasing kinetics, we will know if it can be applied to any of these activities such as controlling cardiovascular relaxation, blood pressure or cancer growth.

We have synthesized and characterized cis-[RuCl(NO)(bpy $\left.)_{2}\right]\left(\mathrm{PF}_{6}\right)_{2}$ and trans-[RuCl(NO)(bpy $\left.)_{2}\right]\left(\mathrm{PF}_{6}\right)_{2}$. We found that cis-[RuCl(NO)(bpy)$\left.)_{2}\right]\left(\mathrm{PF}_{6}\right)_{2}$ show by cyclic voltammetry $E_{1 / 2}=0,21 \mathrm{~V}$ vs $\mathrm{Fe} ; \mathrm{UV}$-vis(298nm,332nm); FTIR:vNO $=1930 \mathrm{~cm}^{-1}$ and trans- $\left[\mathrm{RuCl}(\mathrm{NO})(\mathrm{bpy})_{2}\right]\left(\mathrm{PF}_{6}\right)_{2}$ show by cyclic voltammetry $\mathrm{E}_{1 / 2}=0,19 \mathrm{~V}$ vs Fe ;UV-vis(298nm,312nm); FTIR:vNO= 1921 $\mathrm{cm}^{-1}$.

The development of delivery systems for nitric oxide release from nitrosyl ruthenium complexes could be discussed with particular reference to the products of unmet medical needs. A proper understanding of the properties of the NO donor molecule in a drug delivery system is essential before an appropriate use in clinical therapy. We have studied the physical and chemical properties of cis/trans-[RuCl(bpy $\left.)_{2} \mathrm{NO}\right]\left(\mathrm{PF}_{6}\right)_{2}$ in a water/oil emulsion (W/O) 
and evaluate release rates of nitric oxide encapsulated in internal aqueous phase.

The cis/trans-[RuCl(bpy) $\left.{ }_{2} \mathrm{NO}\right]^{2+}$ release was also studied with a cellulose membrane, which show non-linear behavior with rate of $4,53 \times 10^{-4}$ $\mathrm{mol} / \mathrm{cm}^{2}$ for cis-[RuCl(bpy) $\left.)_{2} \mathrm{NO}\right]^{2+}$ and $3,33 \times 10^{-4} \mathrm{~mol} / \mathrm{cm}^{2}$ for trans$\left[\mathrm{RuCl}(\mathrm{bpy})_{2} \mathrm{NO}\right]^{2+}$. The transdermal permeation and skin accumulation of cis/trans-[RuCl(bpy $\left.)_{2} \mathrm{NO}\right]^{2+}$ on the percutaneous penetration was also studied through pig skin.

Data showed that UV-vis absorber exhibited increases in skin accumulation when is formulated in emulsions in free form for both isomers. Those results showed that the complexes were mainly accumulated on epidermis. We also found by UV-visible and using a NO sensor that the cis/trans-[RuCl(bpy $\left.)_{2} \mathrm{NO}\right]^{2+}$ can release $\mathrm{NO}$ by electro-reduction in aqueous solution or in $\mathrm{W} / \mathrm{O}$ emulsion when a potential of $0.0 \mathrm{~V}$ vs $\mathrm{Ag} / \mathrm{AgCl}$ was applied.

Those results suggest us that a W/O emulsion system bearing nitrosyl ruthenium complex could successfully be used in the development of long acting nitric oxide release system. 


\section{INTRODUÇÃO}

O óxido nítrico (NO) apresenta surpreendente onipresença em seres vivos. É uma das moléculas mais estudadas na Química, na Biologia e na Medicina.

A molécula de NO é a menor molécula classificada como mensageiro biológico. Nessa função, não depende de transportadores específicos nem de canais de passagem intracelulares. A molécula de NO difunde-se livremente pela célula, com a mesma facilidade em meio hidrófilo e em meio lipófilo. Sua ação fisiológica depende muito mais de suas propriedades físico-químicas do que de sua conformação espacial (FELDMAN et al., 1993).

Há duas décadas, aproximadamente, o que se conhecia sobre o óxido nítrico era sua ocorrência nos subprodutos da queima de combustíveis fósseis, sua contribuição para a chuva ácida e para a destruição da camada de ozônio. Sabia-se, também, que em processos industriais, a formação do óxido nítrico era uma etapa importante durante a oxidação da amônia em ácido nítrico (FELDMAN et al., 1993).

Pode-se ter uma idéia do crescente interesse em conhecer melhor esta molécula e suas propriedades, analisando-se o número de publicações referentes ao óxido nítrico no período de 1985 a 2003 (Figura 1). 


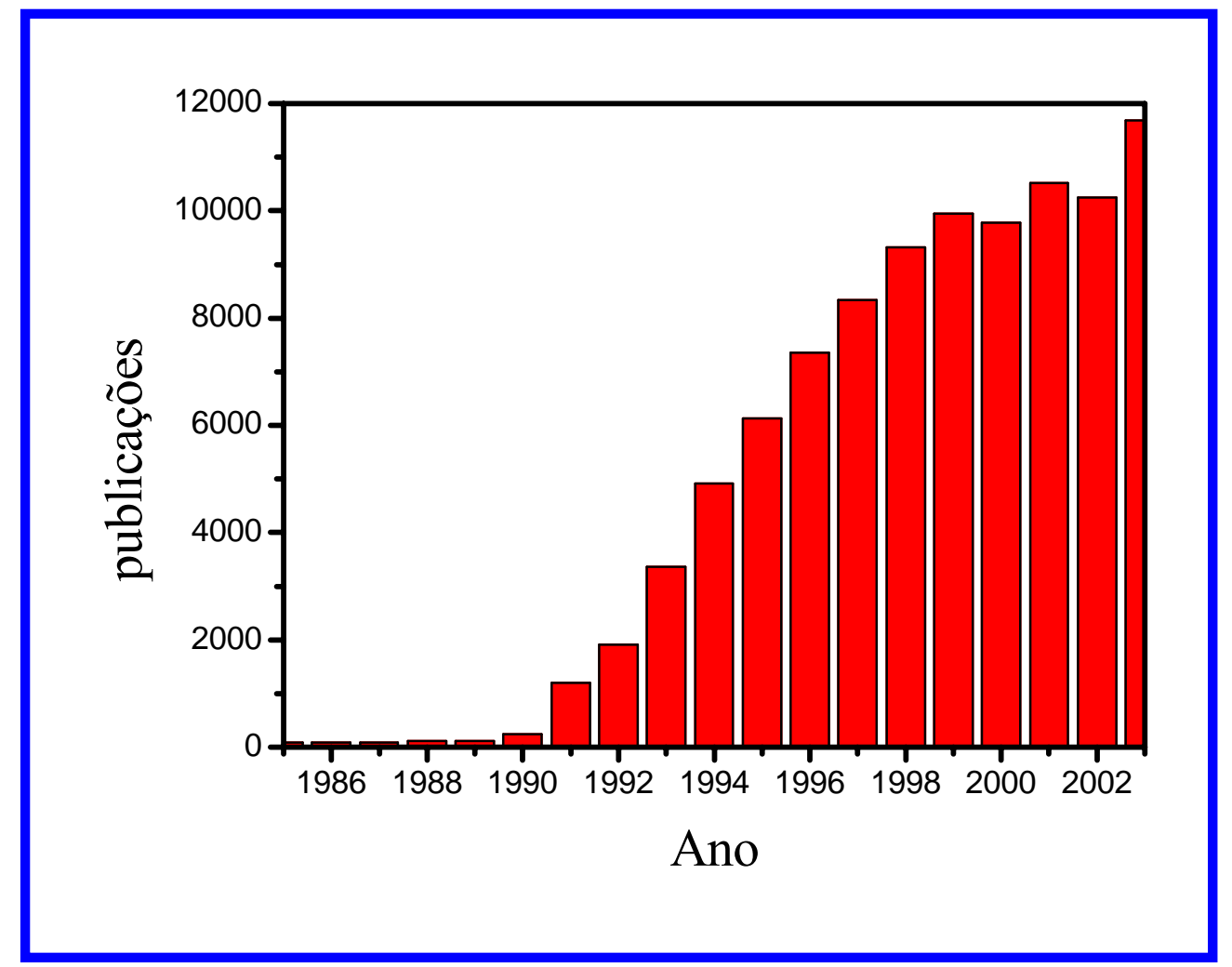

Figura 1: Número de publicações sobre NO de 1985 a 2003. Fonte: Web of Science

Em 1981, Tannenbaum e colaboradores, pesquisando a toxicologia de nitroaminas, demonstraram que óxidos de nitrogênio eram produzidos em quantidade significativa pelo metabolismo de mamíferos e que sua concentração aumentava em condições inflamatórias (GREEN et al., 1981). Assim, durante a década de 1980, algumas descobertas sobre a bioquímica do NO mudaram o conceito que se tinha sobre essa molécula.

Quatro destas descobertas tiveram grande repercussão e aumentaram muito o interesse pela bioquímica do óxido nítrico (TRAYLOR \& SHARMA, 1992):

- O envolvimento do $\mathrm{NO}$ em vários processos biológicos, incluindo vasodilatação, inibição da agregação plaquetária e comunicação neural. 
A ativação da enzima guanilato ciclase, que catalisa a conversão de guanosina trifosfato (GTP) em guanosina monofosfato cíclica (cGMP).

O efeito citotóxico do óxido nítrico após ser eliminado por macrófagos ou por outras células do sistema de defesa de seres vivos.

A produção endógena do NO a partir da conversão do aminoácido L-arginina por um mecanismo enzimático que envolve uma família de enzimas denominadas Óxido Nítrico Sintase (NOS).

Em 1992, a American Association for the Advancement of Science elegeu o NO como a molécula do ano (Science, 1992). Em 1996 Ignarro, Murad e Furchgott receberam o Albert Lasker Award, em reconhecimento aos seus trabalhos com o NO e em 1998, foram agraciados com o prêmio Nobel de Medicina.

O NO já era conhecido por Faraday e Gay Lussac, no século XIX, como um gás facilmente difusível no ar e líquidos, paramagnético (portanto um radical livre), cerca de dez vezes mais solúvel em solventes orgânicos que em água, tal como o oxigênio molecular $\left(\mathrm{O}_{2}\right)$.

Sua alta reatividade química com compostos tiólicos (R-SH), leva à formação de S-nitrosotióis (R-SNO) e à rápida coordenação a metais de transição tais como íons de ferro e cobre que, associados ao antigo uso de medicamentos nitrados $\left(\mathrm{R}-\mathrm{NO}_{2}\right)$ e nitrosados (R-NO), do tipo de nitroprussiato de sódio, nitrito de amila e mesmo a nitroglicerina como anti-hipertensivos. Estas foram pistas importantes para a descoberta da natureza química do "endothelium derived relaxing factor" (FRED), identificado como o NO (Informativo CRQ-IV Maio-Jun/2003).

$\mathrm{O}$ achado de Ignarro e Moncada foi o início para a revelação do rico e sofisticado repertório de funções biológicas do NO, algumas benéficas e outras deletérias. 
O NO regula o tônus e a permeabilidade vascular, a adesão celular, a neurotransmissão, a adesão plaquetária, a broncodilatação, o sistema imunológico e a função renal, mas inibe a atividade de várias metaloenzimas; induz a peroxidação das membranas das células e lesão química do DNA; diminui os estoques de antioxidantes e aumenta a suscetibilidade de tecidos à radiação, metais pesados e agentes alquilantes. Portanto, tal como o oxigênio molecular, o NO comporta-se como uma faca de dois gumes: provê vida, mas também pode matar. Uma idéia geral sobre as principais formas de atuação do NO na Medicina e na Química pode ser visualizada através do Esquema 1.

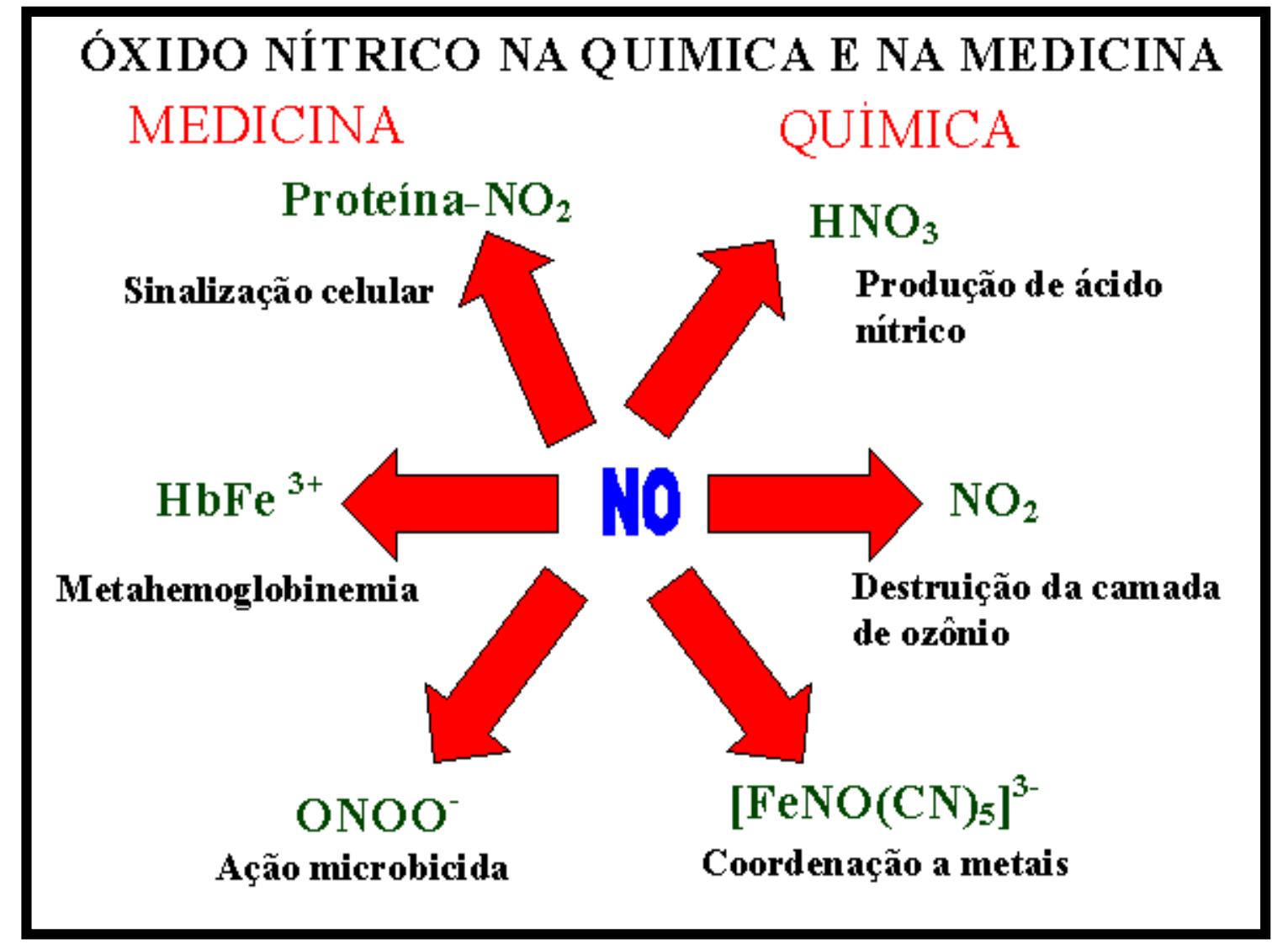

Esquema 1: Principais formas de atuação do óxido nítrico na Medicina e na Química ( Fonte: Informativo CRQ-IV Maio-Jun/2003; figura extraída do artigo Prof. Etelvino Bechara, com modificações) 
De modo geral, o óxido nítrico é a única molécula endógena que reúne as propriedades de neurotransmissor, de mediador constitutivo e indutível e de agente citotóxico, podendo atuar na regulação da pressão sangüínea, no sistema imunológico e nas atividades do cérebro, fígado, pâncreas, útero e pulmões (IGNARRO, 2000; WINK et al.,1996; AINSCOUGH \& BRODIE, 1995; FELDMAN, 1993; CULOTTA \& KOSHLAND JUNIOR, 1992; RICHTER-ADDO \& LEGZDINS, 1992; STAMLER, 1992).

Atualmente, uma linha de trabalho que tem recebido muita atenção está relacionada com a atuação do óxido nítrico como neurotransmissor. Acredita-se que a compreensão do mecanismo de atuação desta molécula possa ser usada para elucidar questões relacionadas à memorização, bem como possibilitar o tratamento de certas doenças neurológicas (KHAN et al., 2004 M; SHUKLA et al., 2003; SNYDER \& BREDT, 1992; SHIMOKAWA et al., 1983).

Talvez a área de pesquisa sobre a bioquímica do NO que mais temse desenvolvido esteja relacionada com sua ação vasodilatadora. Em 1987, constatou-se ser o $\mathrm{NO}$ o fator de relaxamento endotélio dependente (FRED). Nas células endoteliais o NO é produzido pela isoforma constitutiva da enzima Óxido Nítrico Sintase Endotelial (NOSe). Simplificadamente: esta enzima produz NO e o aminoácido L-citrulina a partir do aminoácido L-arginina e de oxigênio $\left(\mathrm{O}_{2}\right)$. Este processo envolve a transferência de 5 elétrons e conversão de NADPH em NADP.

No meio celular, mesmo em concentrações menores que $5 \mu \mathrm{M}$, o NO reage com o íon metálico de ferro(III), presente na enzima guanilato ciclase, ativando-a. Esta enzima produz um segundo mensageiro biológico, a guanosina monofosfato cíclica, que é responsável por desencadear uma série de processos fisiológicos, inclusive o relaxamento da musculatura lisa das artérias (BUTLER, 1995). 
A NOSe é uma enzima que faz parte das células endoteliais e produz NO constantemente e em baixa quantidade. As células do sistema nervoso possuem outra isoforma dessa enzima, a Óxido Nítrico Sintase Neural (NOSn), que também gera NO pelo mesmo mecanismo. A concentração intracelular de NO deve ser baixa, para que não ocorram reações paralelas que consistem na oxidação do $\mathrm{NO}$, as quais geram espécies radicalares altamente reativas, que podem desnaturar macromoléculas. Esta concentração de NO é controlada pelo consumo mitocondrial e por "scavengers", como a oxihemoglobina (WINK, 1996).

A isoforma indutível da Óxido Nítrico Sintase (NOSi) pode ser expressa em uma variedade de células, em resposta à estimulação por lipossacarídeos (LPS) de bactérias e certas citocinas inflamatórias, tais como: Fator de Necrose Tumoral $\alpha$ (TNF $\alpha$ ), Interferon $\gamma$ (IFN $\gamma)$ e Interleucinas (IL) 1 e 2 . Uma vez expressa, a NOSi permanece ativada por várias horas, gerando altos níveis de NO. A ativação desse processo implica em algumas patogenias, como, por exemplo, choque séptico (FRICKER et al., 1997), no qual ocorre uma superprodução de NO por macrófagos e outras células brancas ativados por citocinas. Uma quantidade elevada de NO pode levar a uma súbita queda na pressão arterial e a uma disfunção renal.

Apesar dos numerosos estudos sobre a ação do óxido nítrico no organismo, há muitas questões de natureza química a serem respondidas. Como já foi mencionada, a atuação do óxido nítrico está mais relacionado com as suas propriedades físico-químicas do que com a sua conformação espacial. Portanto, é necessário que se tenha um bom conhecimento das propriedades químicas da molécula de NO. 


\subsection{Propriedades físico-químicas do óxido nítrico}

O óxido nítrico é uma molécula paramagnética, uma vez que nas condições normais de temperatura e pressão (CNTP) é um gás incolor e termodinamicamente menos estável, quando comparado aos gases $\mathrm{N}_{2}$ e $\mathrm{O}_{2}$ (RICHTER-ADDO \& LEGZDINS, 1992). Sua solubilidade em meio aquoso é $1,9 \times 10^{-3} \mathrm{~mol}$. $\mathrm{L}^{-1}$. Em sistemas biológicos sua velocidade média de difusão é cerca de $50 \mu \mathrm{m} / \mathrm{s}$ (WINK et al., 1996).

O comprimento de ligação dessa molécula é 1,15 Å, valor intermediário entre o comprimento de uma dupla ligação $(1,18 \AA$ ) e de uma tripla (1,06 $\AA$ ) (RICHTER-ADDO \& LEGZDINS, 1992). A ordem de ligação da molécula de NO corresponde a 2,5 ligações, pois essa molécula possui um elétron desemparelhado no orbital pi antiligante $\left(\pi^{*}\right)$, como mostra o diagrama de orbitais moleculares, representado na Figura 2.

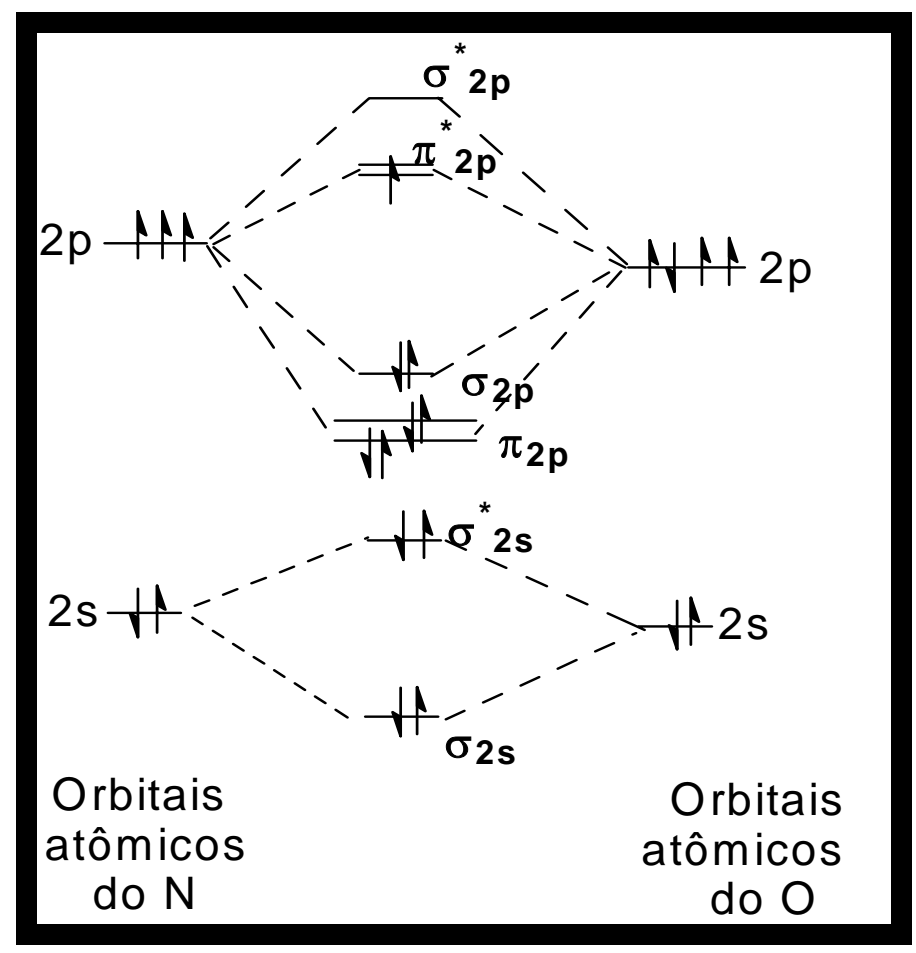

Figura 2: Diagrama simplificado de orbitais moleculares do óxido nítrico. 
Com base na configuração eletrônica, sempre surge a questão sobre o motivo pelo qual os elétrons desemparelhados de duas moléculas de NO não se combinam, à temperatura ambiente, para formar o dímero $\mathrm{N}_{2} \mathrm{O}_{2}$, conforme a reação representada no Esquema 2. A formação de dímero ocorre, porém, em condições especiais: é necessário que o NO esteja no estado sólido sob temperatura de nitrogênio líquido.

\section{$2 \mathrm{NO} \longrightarrow \mathrm{N}_{2} \mathrm{O}_{2}$}

Esquema 2: Reação de dimerização do óxido nítrico.

Nas condições normais de temperatura e pressão a dimerização não é termodinamicamente favorável. $\mathrm{O}$ dímero $\mathrm{O}=\mathrm{N}-\mathrm{N}=\mathrm{O}$ possui uma ordem de ligação de 5 ligações, que é a mesma para duas moléculas de NO. O calor envolvido $(\Delta \mathrm{H})$ neste processo foi determinado experimentalmente e corresponde à cerca de $-2,6 \mathrm{kcal} / \mathrm{mol}$.

A entropia $(\Delta \mathrm{S})$ diminui, pois uma molécula é menos desordenada do que duas, uma vez que sob 1 atm e $300{ }^{\circ} \mathrm{C}$, o termo $-\mathrm{T} \Delta \mathrm{S}$ é $+4,3$ $\mathrm{kcal} / \mathrm{mol}$. Assim, a energia livre de Gibbs $(\Delta \mathrm{G}=\Delta \mathrm{H}-\mathrm{T} \Delta \mathrm{S})$ é positiva, ou seja, a reação não ocorre espontaneamente nessas condições (BECKMAN, 1996). Em baixas temperaturas, o termo $-\mathrm{T} \Delta \mathrm{S}$ é minimizado e a energia livre passa a ser negativa, tornando a reação espontânea.

As reações de óxido nítrico com moléculas orgânicas, cineticamente não são favoráveis apesar da sua natureza radicalar. A maioria das moléculas orgânicas no estado fundamental possui orbitais com um par de elétrons de spins opostos. A reação com o NO faria com que essas moléculas ficassem com um elétron desemparelhado, formando um radical orgânico intermediário de alta energia. Essas reações requerem uma alta energia de ativação e são bastante lentas. Porém, o NO reage 
rapidamente com radicais orgânicos que já possuam um elétron desemparelhado (BECKMAN, 1996).

Com alguns metais de transição, o óxido nítrico tende a reagir rapidamente. A ligação entre o metal e a molécula de óxido nítrico é estável porque existe uma doação de densidade eletrônica dos orbitais $\sigma$ do NO para o metal. Em alguns casos, e dependendo do íon metálico, além da ligação $\sigma$, há uma doação de densidade eletrônica dos orbitais d do metal para o orbital $\pi^{*}$ do $\mathrm{NO}\left(\mathrm{d}_{\pi}(\mathrm{M}) \rightarrow \pi^{*}(\mathrm{NO})\right)$, constituindo-se em uma retrodoação (Figura 3).

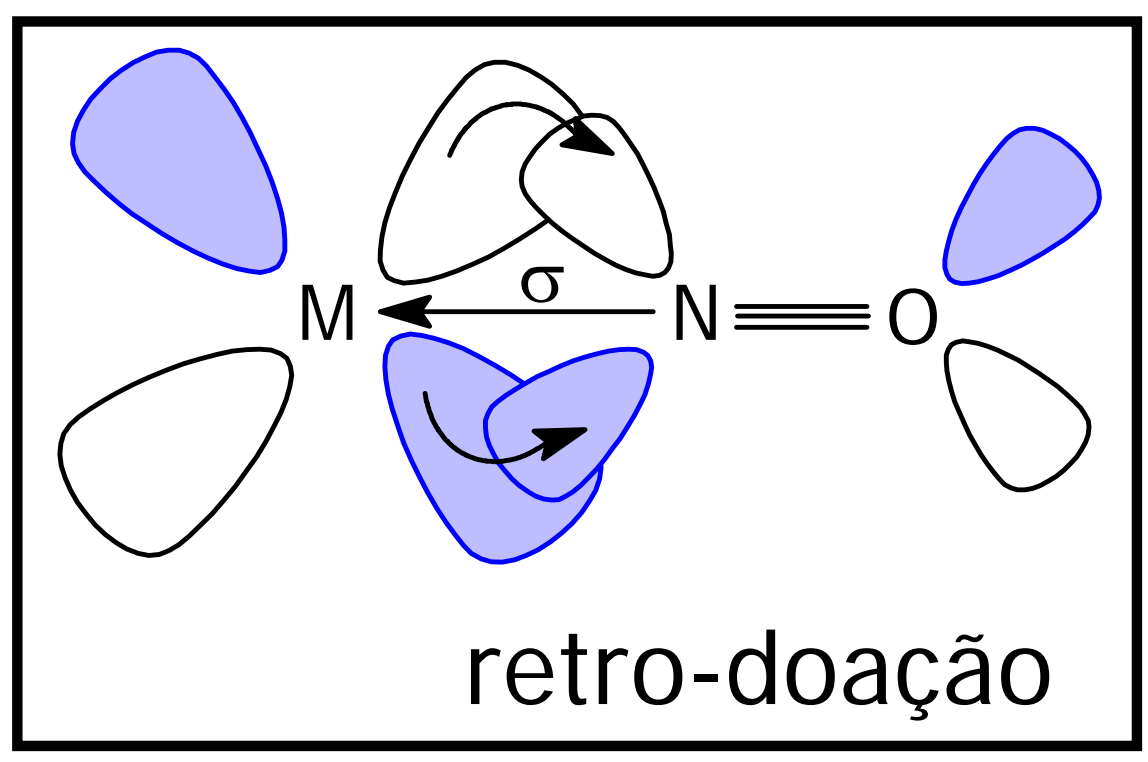

Figura 3: Esquema dos orbitais moleculares envolvidos na ligação de um metal com o ligante nitrosil.

A princípio, a molécula de NO pode ligar-se ao metal (M) tanto pelo átomo de nitrogênio como pelo átomo de oxigênio, originando as formas nitrosil ou isonitrosil, respectivamente. A forma nitrosil é a mais comum, uma vez que a forma isonitrosil deve ocorrer em compostos com íosn metálicos de razão carga/raio menor do que a razão para os metais de transição, como os do bloco "s", Li e Na (RICHTER-ADDO \& LEGZDINS, 1992). 
Complexos nitrosilos são normalmente caracterizados por espectroscopia na região do infravermelho por meio da banda de estiramento do $\mathrm{NO}\{v(\mathrm{NO})\}$. Essa energia vibracional é influenciada pela intensidade da retro-doação. Quanto maior a retro-doação, menor é a força de ligação do NO e, portanto, menor a energia vibracional da molécula. De acordo com RICHTER-ADDO \& LEGZDINS (1992) existem vários fatores que afetam a intensidade da retro-doação, tais como o efeito eletrônico dos ligantes e a estrutura do complexo (efeito estéreo). Os valores da energia vibracional para o óxido nítrico não coordenado em seus três possíveis estado de oxidação estão relacionados na Tabela 1.

Tabela 1: Comparação entre o comprimento de ligação, energia vibracional na região do infravermelho e potencial redox das espécies $\mathrm{NO}^{+}, \mathrm{NO}^{0}$ e $\mathrm{NO}^{-}$.

\begin{tabular}{cccc}
\hline & NO $^{+}$ & NO $^{\mathbf{0}}$ & NO $^{-}$ \\
Distância N-O $(\AA)$ & 1,06 & 1,15 & 1,26 \\
v (NO) $\left(\mathrm{cm}^{-1}\right)$ & 2377 & 1875 & 1470 \\
Potencial vs EPH $(\mathrm{V})$ & $-1,20^{\mathrm{a}}$ & - & $-0,33^{\mathrm{b}}$
\end{tabular}

a) $\mathrm{NO}^{0 /+}$, b) $\mathrm{NO}^{0 /-}$. (KOPPENOL, 1996)

Atribui-se a riqueza da bioquímica do óxido nítrico à diversidade de suas espécies, ou seja, a espécie $\mathrm{NO}^{+}$(íon nitrosônio), que é formada pela retirada do elétron desemparelhado no orbital $\pi^{*}$, e a espécie $\mathrm{NO}^{-}$(ânion nitróxido), que é formada pela adição de um elétron ao orbital $\pi^{*}$. Os potenciais em que ocorrem a oxidação e redução do óxido nítrico, em solução aquosa, podem ser observados na Tabela 1.

$\mathrm{O}$ ânion nitróxido é isoeletrônico ao gás oxigênio $\left(\mathrm{O}_{2}\right)$ e, como ele, pode existir no estado singlete, de maior energia, ou no estado triplete, de 
menor energia. O íon nitrosônio é isoeletrônico ao monóxido de carbono (CO). O íon nitrosônio reage rapidamente com água e outros nucleófilos.

Embora seja esperado que o produto direto da oxidação do óxido nítrico seja o íon nitrosônio, pode ocorrer formação de várias espécies reativas de óxido de nitrogênio (ERONs), produtos das reações representadas nas equações do no Esquema 3. O oxigênio molecular possui dois elétrons desemparelhados e reage com $\mathrm{NO}^{0}$ produzindo $\mathrm{NO}_{2}$ (reações 1 e 2). Este pode reagir com outra molécula de $\mathrm{NO}$ e formar $\mathrm{N}_{2} \mathrm{O}_{3}$ (reação 3). Essa espécie é instável e é convertida pela água em nitrito (reação 4) (IGNARRO, 2000).

\begin{tabular}{|c|c|}
\hline $\mathrm{NO}^{0}+\mathrm{O}_{2} \rightarrow \mathrm{ONOO}^{\bullet}$ & (1) \\
\hline $\begin{array}{l}\mathrm{NO}^{0}+\mathrm{ONOO}^{\circ} \rightarrow \mathrm{ONOONO} \rightarrow 2 \mathrm{NO}_{2} \\
2 \mathrm{NO}_{2}+2 \mathrm{NO}^{0} \rightarrow 2 \mathrm{~N}_{2} \mathrm{O}_{3}\end{array}$ & $\begin{array}{l}(2) \\
(3)\end{array}$ \\
\hline $2 \mathrm{~N}_{2} \underline{\mathrm{O}}_{3}+2 \mathrm{H}_{2} \underline{\mathrm{O}} \rightarrow 4 \mathrm{NO}_{2}-$ & $-(4)$ \\
\hline $4 \mathrm{NO}^{0}+\mathrm{O}_{2}+2 \mathrm{H}_{2} \mathrm{O} \rightarrow 4 \mathrm{NO}_{2}^{-}+4 \mathrm{H}^{+}$ & $(5)$ \\
\hline
\end{tabular}

Esquema 3: Etapas reacionais de oxidação do óxido nítrico formando ERONs.

De acordo com IGNARRO (2000), dados experimentais mostraram que a reação global (reação 5) representada no Esquema 3 é de terceira ordem, mesmo em concentrações micromolares de NO. A velocidade de reação pode ser expressa pela equação $\frac{\mathrm{d}[\mathrm{NO}]}{\mathrm{dt}}=\mathrm{k}[\mathrm{NO}]^{2}\left[\mathrm{O}_{2}\right]$, onde $\mathrm{k}=$ $8 \times 10^{6}\left(\mathrm{~mol}^{-1} \mathrm{~L}^{-1}\right)^{-2} \cdot \mathrm{s}^{-1}$. Portanto, a degradação do NO em meio aquoso e aeróbico não é linearmente dependente da sua concentração.

Um dos aspectos mais intrigantes dessa reação é que sua constante de velocidade $(\mathrm{k})$ é pouco dependente do solvente, do $\mathrm{pH}$ e da temperatura, 
quando esta se encontra entre $20,0{ }^{\circ} \mathrm{C}$ e $37,0{ }^{\circ} \mathrm{C}$. Assim, em ambiente fisiológico, conforme o NO é produzido e difundido no meio intracelular, sua concentração diminui e, conseqüentemente, há uma queda na formação de ERONs, aumentando assim o tempo necessário para que ele seja degradado. Isto colabora para que o $\mathrm{NO}$ exerça suas funções e minimize a interferência fornecida pela reação com o oxigênio. Por outro lado, quando ocorre uma superprodução de NO, a reação é acelerada exponencialmente, acarretando maior formação de ERONs (WINK et al., 1996).

Posto que as propriedades físico-químicas do óxido nítrico governam suas atividades fisiológicas e que sua falta no organismo acarreta graves danos, o uso terapêutico de compostos que sirvam como fonte de NO parece ser bastante promissor. Dentre esses compostos, os complexos metálicos são sui generis, pois o óxido nítrico reage facilmente com alguns metais, produzindo compostos estáveis. Tais compostos são, porém, susceptíveis à ação de certos estímulos químicos que promovem a liberação de NO.

\subsection{Aplicações farmacêuticas de complexos metálicos}

A história nos conta que metais preciosos vêm sendo utilizados há mais de 3500 anos no tratamento de certas doenças. O ouro, por exemplo, já teve seu valor terapêutico na Arábia e na China. Ferro, zinco, cobre, mercúrio e bismuto foram usados em práticas médicas desde a Antiguidade até a Idade Média (ABRAMS \& MURRER, 1993). Embora se saiba que certos metais sejam benéficos para o organismo, seu mecanismo de ação ainda continua obscuro na maioria dos casos, principalmente, naqueles relacionados a metais de transição.

A atividade farmacológica dos complexos metálicos, em geral, depende do metal, do ligante, ou de ambos. Porém, o mecanismo de ação 
de certos fármacos envolvendo metais é complexo, e a maioria ainda necessita de melhor entendimento. É importante que esses mecanismos sejam bem esclarecidos para que seja aumentada a eficiência dos fármacos e diminuídos seus efeitos indesejados.

A modelagem molecular de complexos metálicos para fins terapêuticos envolve o delineamento de algumas etapas que possibilitam a absorção do fármaco pelo organismo: hidrólise do composto, ligação em sítio protéico, transporte pela membrana celular e interação com alvo molecular (SCHWIETER \& McCUE, 1999). O desenvolvimento dessas etapas possibilitou a aplicação de uma série de compostos em que geralmente o metal está associado a substâncias orgânicas, tais como certos suplementos minerais, como: manganês, cromo, ferro, cobalto, níquel, cobre e molibdênio (GUO \& SADLER, 2000; ABRAMS \& MURRER, 1993; SADLER, 1991). Como aplicação farmacológica, entre outros exemplos, pode-se citar: os compostos de platina, utilizados no tratamento do câncer; assim como os compostos de ouro, utilizados no tratamento de artrite reumatóide; os compostos de prata, usados como agentes antimicrobianos; e os compostos de mercúrio, foram utilizados como diuréticos (ALLARDYCE \& DYSON, 2001; BAKHTIAR \& OCHIAI, 1999; BERNERS-PRICE \& SADLER, 1996).

Alguns complexos de nitrosil com aplicação médica são também conhecidos desde o século XIX e muitos deles continuam úteis (SZCZEPURA \& TAKEUCHI, 1990). O nitroprussiato de sódio, $\mathrm{Na}_{2}\left[\mathrm{Fe}(\mathrm{CN})_{5}(\mathrm{NO})\right] \cdot 2 \mathrm{H}_{2} \mathrm{O}$ - vasodilatador útil no controle da pressão arterial, especialmente em casos de emergência - é um exemplo de complexo metálico que carrega um ligante ativo (ligante nitrosil) (STOCHEL et al., 1998; MONCADA et al., 1991). O uso desses compostos encontra, às vezes, limitação, devido às reações secundárias 
indesejadas. No caso dos compostos nitrosilos, a reação desejada é a liberação de óxido nítrico.

Algumas alternativas para o controle da liberação seletiva de NO a partir de compostos de coordenação são viáveis clinicamente, como a indução luminosa (terapia fotodinâmica) e a redução eletroquímica do $\mathrm{NO}^{+}$ coordenado. Ambas as técnicas levam em consideração a baixa afinidade observada entre o ligante $\mathrm{NO}^{0}$ e alguns íons metálicos. Tal fato mostra que a fotoquímica e os processos eletroquímicos podem ser utilizados para modelar diferentes processos bioquímicos (STOCHEL et al., 1998).

Fármacos, cujo centro metálico é o rutênio, possuem boa aplicação clínica, principalmente por ser baixa a toxicidade do íon metálico. Isto se deve, em parte, à semelhança das propriedades físico-químicas desse íon metálico com as do íon ferro. $\mathrm{O}$ organismo consegue proteger-se dos efeitos causados por um excesso de ferro, através do aumento da produção de proteínas captadoras de ferro, como a transferrina e a albumina. Alguns autores acreditam que o mecanismo de proteção contra a toxicidade do rutênio seria o mesmo (ALLARDYCE \& DYSON, 2001).

Lembrando que a toxicidade do metal também está relacionada ao estado de oxidação, pode-se afirmar que outro fator da baixa toxicidade do rutênio é sua habilidade de atingir vários estados de oxidação (II, III e IV) em meio fisiológico. Talvez o envolvimento de complexos de rutênio em reações redox em ocorra de maneira similar às dos compostos de ferro, ou seja, na enzima citocromo oxidase, ou pela participação da glutadiona ou pelo ascorbato, entre outros (ALLARDYCE \& DYSON, 2001). As características de complexos nitrosilos de rutênio e a vasta literatura a eles referente (AU \& WONG, 1997; SEDDON \& SEDDON, 1984) tornam esses compostos propícios para a busca de novas substâncias que funcionem como agentes liberadores de NO. 


\subsection{Complexos nitrosilos de rutênio}

Compostos nitrosilos com metais de transição podem ser úteis como agentes liberadores de óxido nítrico e, em particular, na liberação redutimétrica de NO em alvos biológicos (TFOUNI et al., 2003).

Em altas concentrações, o óxido nítrico torna-se prejudicial à saúde, podendo reagir com oxigênio ou superóxido presente no meio e provocar a formação de espécies reativas de óxido de nitrogênio (ERONs). Essas espécies possuem uma natureza radicalar e são altamente maléficas porque danificam lipídeos, proteínas e DNA. Altas concentrações de NO estão associadas a alguns quadros clínicos, como hipotensão, diabetes, derrame cerebral, artrite, epilepsia, inflamação intestinal e choque séptico.

Para casos em que o objetivo é diminuir a concentração de óxido nítrico no organismo, desenvolveu-se uma série de complexos, chamados de "scavengers", que formam um complexo estável com o NO, removendoo do meio (CHEN \& SHEPHERD et al., 1999; CHEN \& SHEPHERD, 1997). Como exemplo destes complexos, pode-se citar o $\mathrm{K}\left[\mathrm{Ru}(\mathrm{Hedta}) \mathrm{OH}_{2}\right]$ e $\mathrm{K}_{2}[\mathrm{Ru}($ Hedta)Cl], que são as espécies a e $\underline{\mathrm{b}}$, respectivamente, representadas na Figura 4 (FRICKER et al., 1997).

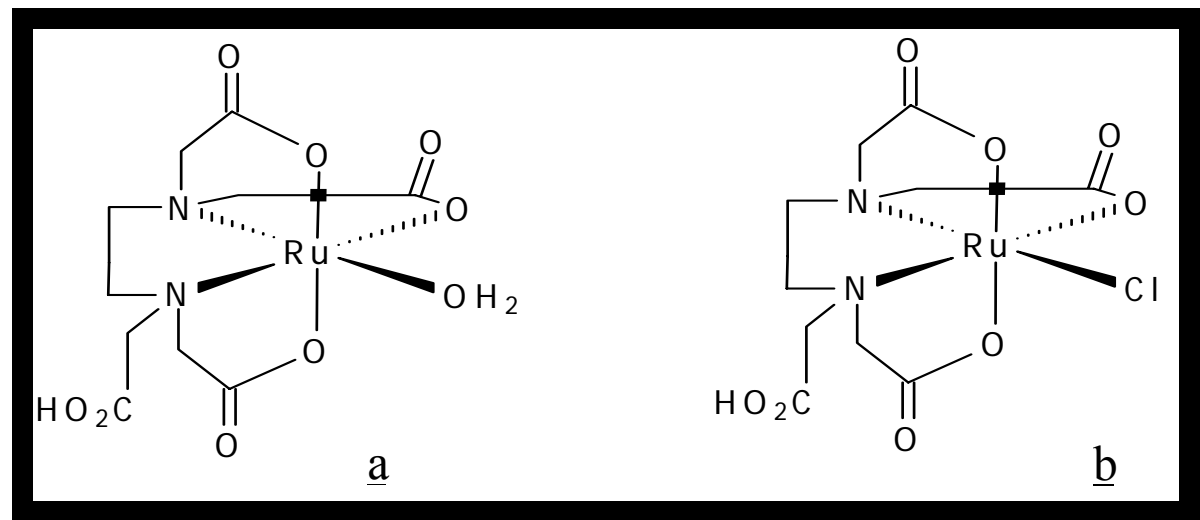

Figura 4: Fórmulas estruturais de complexos de rutênio denominado "scavengers" de $\mathrm{NO}$, onde: a) $\mathrm{K}\left[\mathrm{Ru}(\mathrm{Hedta}) \mathrm{OH}_{2}\right] \mathrm{e}$

b) $\mathrm{K}_{2}[\mathrm{Ru}(\mathrm{Hedta}) \mathrm{Cl}]$. 
A princípio, o NO presente no meio coordenar-se-ia ao rutênio substituindo a molécula de água em a e o cloreto em $\underline{b}$. O novo complexo formado seria eliminado pelo organismo.

A habilidade de compostos de coordenação de rutênio atuarem como "consumidores" ou como provedores de óxido nítrico tem despertado muito interesse no estudo de suas propriedades. Buscando conhecer estas propriedades, muitos cientistas desenvolveram e estudaram uma série de compostos nitrosilos de rutênio, como por exemplo, complexos do tipo $\left[\mathrm{RuCl}_{\mathrm{n}}(\mathrm{NO}) \mathrm{L}\right]$, em que L são ligantes fosfínicos, estudados por Batista e colaboradores (VON POELHSITZ et al., 2002; ZAMPIERE et al., 2002; PAULA, et al., 2002; BATISTA, 2001; BATISTA, 1997), e complexos do tipo trans-[Ru( $\left.\left.\mathrm{NH}_{3}\right)_{4} \mathrm{~L}(\mathrm{NO})\right]\left(\mathrm{BF}_{4}\right)_{3}$, em que $\mathrm{L}$ é imidazol, L-histidina, piridina e nicotinamida, amplamente investigados por Franco, Tfouni e colaboradores (CARLOS et al., 2004; TFOUNI et al., 2003; de BARROS et al., 2002; MARCONDES et al., 2002; KRIEGER et al., 2002; TOLEDO et al., 2002; TORSONI et al., 2002; BAGATIN et al., 2002; KRIEGER et al., 2001; GORELSKY et al., 2000; BORGES, 1998).

Com o intuito de minimizar reações paralelas à liberação de NO, Tfouni e colaboradores dedicaram-se também ao desenvolvimento e estudo de complexos com ligantes macrocícliclos, do tipo trans$\left[\mathrm{RuCl}(\text { cyclam)(NO) }]^{2+}\right.$, em que cyclam é 1,4,8,11-tetraazaciclotetradecano (LANG et al., 2000; McGARVEY et al., 2000), e trans$[\mathrm{RuCl}(\mathrm{imcyclen})(\mathrm{NO})]^{2+}$ (FERREIRA et al., 2004). Os macrociclos conferem aos compostos de coordenação diferentes propriedades e, devido a sua inércia, compostos desse tipo podem ser de grande interesse para o desenvolvimento de substâncias que possam apresentar atividade biológica (FERRO, 2000; MARTINEZ, 1997; SILVA \& TFOUNI, 1992; SILVA et al., 1992; CHI et al., 1985). 
A busca de métodos capazes de liberar óxido nítrico nos organismos, a partir de complexos nitrosilos de rutênio, tem sido alvo de muita pesquisa. Atualmente, uma das estratégias é utilizar compostos que sejam termicamente estáveis e fotoquimicamente ativos, ou seja, liberam NO quando submetidos a algum tipo de indução fotoquímica. Visando esta perspectiva, Ford e colaboradores sintetizaram e estudaram compostos do tipo $[\mathrm{Ru}(\mathrm{P})(\mathrm{ONO})(\mathrm{NO})]$, em que $\mathrm{P}$ é um anel porfirínico (FORD et al., 1998) e mais recentemente compostos do tipo [ $\mathrm{RuCl}(\mathrm{salen})(\mathrm{NO})]$, em que o ligante salen é um derivado do diânion N,N'-bis(salicilidina)etilenodiamina (WORKS et al., 2001; WORKS \& FORD, 2000).

Ainda visando à reatividade fotoquímica de complexos nitrosilos de rutênio, TOGNIOLO et al. (2001) constataram a liberação de óxido nítrico em meio aquoso a partir do complexo cis-[RuCl(bpy $\left.)_{2}(\mathrm{NO})\right]\left(\mathrm{PF}_{6}\right)_{2}$, em que bpy é 2,2'-bipiridina. Durante as duas últimas décadas complexos polipiridínicos de rutênio vêm sendo intensamente investigados, principalmente devido a suas propriedades químicas e fotoquímicas (TOMA et al., 2000; JURIS \& BALZANI, 1988; DURHAM et al., 1980).

Particularmente, os complexos nitrosilos de rutênio com co-ligantes piridínicos começaram a ser estudados por Meyer e colaboradores desde o início da década de setenta (CALLAHAN \& MEYER, 1977; GODWIN \& MEYER, 1971a; GODWIN \& MEYER, 1971b), porém muitos aspectos do comportamento químico desses compostos ainda necessitam de esclarecimento. Alguns autores mostraram, por exemplo, que a reatividade do grupamento nitrosil depende das características de co-ligantes como 2,2'-bipiridina e piridina (OOYAMA et al., 1995).

Outra maneira, também amplamente estudada, de se conseguir a liberação de óxido nítrico é submeter estes complexos a um estímulo eletroquímico que consiga provocar a descoordenação do ligante nitrosil. Fundamentado nisto, alguns pesquisadores estudaram a ação biológica de 
vários tipos de complexos nitrosilos de rutênio aquo-solúveis (WIERASZKO et al., 2001; MARCONDES et al., 2001).

Recentemente, trabalhos publicados pelo nosso grupo mostraram claramente a influência dos co-ligantes em relação à liberação do NO. Nesses artigos, a produção de NO foi constatada in situ tanto por processos redutimétricos quanto fotoquímicos. Para aumentar a possibilidade da utilização desses complexos, como metalo-drogas, é preciso conhecer mais sobre seu comportamento químico e seu mecanismo de ação em sistemas biológicos. O efeito de co-ligantes nas espécies contendo Ru-NO, o acoplamento eletrônico entre os orbitais do metal e do ligante e o controle da reatividade do ligante nitrosil coordenado são alguns aspectos que intrigam e direcionam os estudos de pesquisadores. Neste contexto, o trabalho desenvolvido pelo nosso grupo (OLIVEIRA et al., 2004; FERREIRA et al., 2004; SAUAIA et al., 2003a; SAUAIA et al., 2003b SAUAIA \& SILVA, 2003; TOGNIOLO et al., 2001) e este aqui proposto visam contribuir para o conhecimento e descrição das propriedades físicoquímicas de complexos nitrosilos de rutênio. Além disso, estudos relacionados à reatividade desses compostos, quando submetidos à interação com meio biológico, serão necessários no que tangem à possibilidade de seu uso como fármaco. Tal estudo será principalmente realizado avaliando-se o efeito ocasionado na interação do composto metalo-nitrosil com a pele, num processo conhecido como permeação passiva.

\subsection{Permeação Passiva}

A administração de fármacos através da pele tem despertado um crescente interesse em muitas indústrias farmacêuticas. A liberação de fármacos por via transdérmica vem apresentando vantagens visíveis, uma 
vez que esta evita o metabolismo hepático de primeira passagem, mantendo constante o nível sangüíneo do fármaco por um longo período de tempo e diminuindo os efeitos colaterais, bem como os efeitos gastrintestinais, que podem ocorrer devido ao contato deste com a mucosa gástrica (KSHIRSAGAR, 2000; BERTI \& LIPSKY, 1995; RANADE, 1991; GUY \& HADGRAFT, 1990). O fármaco veiculado pode ter ação tópica ou transdérmica, dependendo das características da formulação.

Para avaliar a biodisponibilidade de fármacos incorporados em bases dermatológicas deve-se levar em consideração, principalmente, a sua liberação do veículo, pois uma rápida liberação e solubilização nas camadas da pele, geralmente levam a uma disponibilidade adequada do fármaco (LOPEZ et al., 2003; UEKAMA et al., 1992; GLOMOT et al., 1988; UEKAMA et al., 1985). Como o estudo envolvendo liberação transdérmica de complexos metalo-nitrosil é inovador, serão abordados alguns aspectos gerais sobre a pele, no intuito de situar o trabalho a uma possível utilização desses compostos como fármacos.

\subsection{Anatomia da pele}

A pele é o maior órgão do corpo humano, revestindo, num adulto, uma área média de superfície de $2 \mathrm{~m}^{2}$ e recebendo um terço da circulação sanguínea do corpo. Ela é constituída de uma estrutura complexa de tecidos de natureza variada, dispostos e inter-relacionados de modo a adequar-se de maneira harmônica ao desempenho de suas funções (Figura 5). Ela atua como uma barreira protetora natural contra a penetração de compostos exógenos tóxicos, ataques físicos, excessiva perda de água ou de outro componente natural do corpo (CHIEN, 1992). Na pele observam-se várias estruturas anexas, que são os pêlos, unhas e glândulas sudoríparas e sebáceas (JUNQUEIRA et al., 1999 ). 


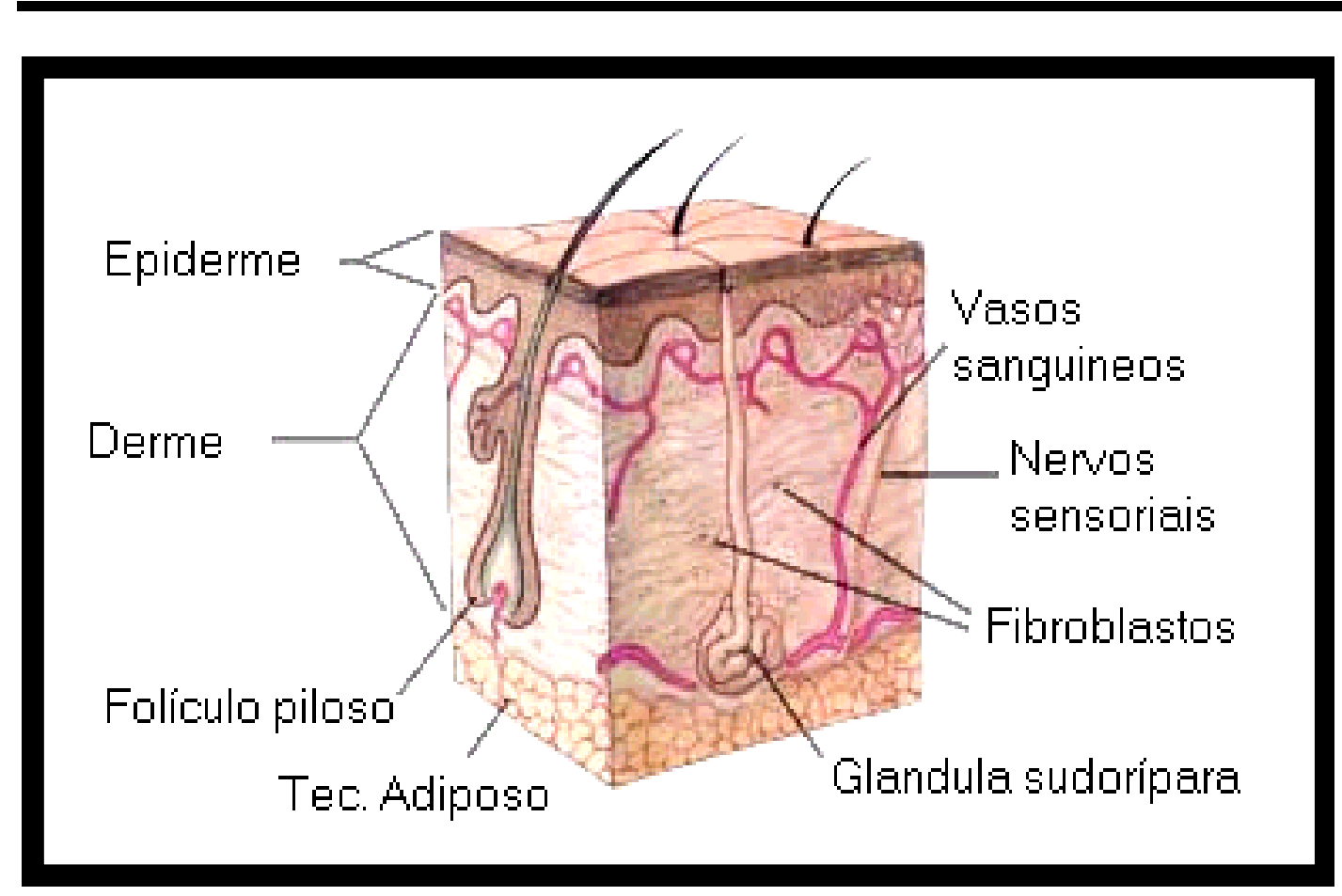

Figura 5: Representação esquemática das camadas da pele.

É, portanto, uma barreira biológica composta de três camadas principais: (i) epiderme, (ii) derme e (iii) hipoderme, que apresentam como principais características básicas:

(i)

epiderme: é a camada mais externa, porção epitelial de origem ectodérmica, avascular, composta de epitélio pavimentoso estratificado. Local de renovação celular contínua. As células epiteliais são mantidas juntas principalmente por pontes interligadas que são responsáveis pela integridade da pele (JACOB \& FRANCONE, 1970). Ela é composta de cinco camadas de tipos de células: estrato córneo (EC), estrato lúcido, estrato granuloso, estrato espinoso e estrato basal (BERTI \& LIPSKY, 1995). O limite entre a epiderme e a derme não é 
regular, apresentando saliências e reentrâncias das duas camadas, que imbricam e se ajustam entre si.

(ii) derme: uma porção conjuntiva de origem mesodérmica, é formada por uma rede de fibras de colágeno de uma espessura aproximadamente uniforme, que é responsável pelas propriedades elásticas da pele. A camada superior da derme é formada por papilas que se projetam em direção à epiderme e que contém vasos sanguíneos e linfáticos, as terminações nervosas e os apêndices cutâneos como os folículos pilosos, glândulas sebáceas e sudoríparas (CHIEN,1992). A camada mais profunda é formada por muitas estruturas com características elásticas (denso estroma fibroelástico de tecido conjuntivo), grandes quantidades de vasos sangüíneos (redes vasculares) e fibras nervosas. O transporte de solutos nesta área é rápido.

(iii) a hipoderme (tecido subdermal adjacente ou tecido subcutâneo) é situada abaixo e em continuidade com a derme, e embora tenha a mesma origem desta, não faz parte da pele, mas apenas lhe serve de suporte e união com órgãos subjacentes. O tecido subcutâneo está localizado abaixo da derme e funciona como uma reserva de gordura, com propriedades isolantes e protetoras; ele não possui um papel na penetração cutânea porque se situa abaixo do sistema vascular, que está localizado na derme (SINGH \& SINGH, 1999).

Como anteriormente mencionado, a epiderme é composta de cinco camadas de tipos de células: estrato córneo (EC), estrato lúcido, estrato granuloso, estrato espinoso e estrato basal (Esquema 4). 


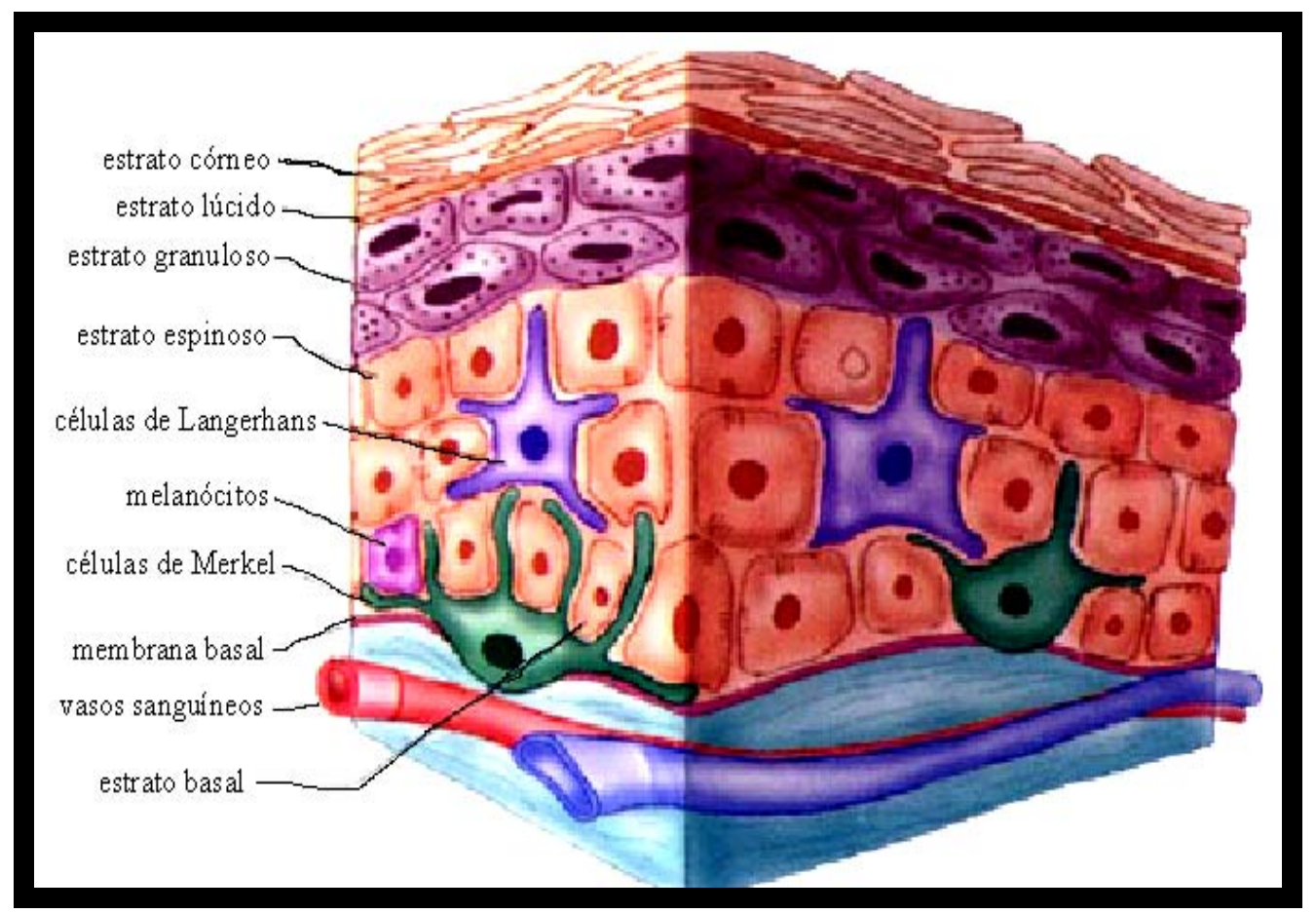

Esquema 4: Representação esquemática da epiderme e seus estratos

A epiderme pode ser dividida em duas partes principais:

(i) Estrato germinativo, parte mais interna, onde são produzidos os corneócitos (células queratinizadas), que se proliferam, sofrem alterações e dão origem às células mortas do estrato córneo. À medida que essas células migram do estrato germinativo para a superfície da pele seu conteúdo de água vai diminuindo, tornando-se uma camada seca;

(ii) Estrato córneo, também chamado "camada de descamação", pois as suas células queratinizadas vão se destacando do epitélio, sendo substituídas por outras. É uma camada constituída de células mortas ou em vias de degenerescência, muito ricas em queratina. É a camada mais externa da pele e de grande importância para os estudos de penetração cutânea, constituindo a principal barreira para a passagem de fármacos (ABRAHAM, et al., 
1994). O estrato córneo apresenta uma estrutura bifásica de lipídeo-proteína e tem aproximadamente 10 a $20 \mu \mathrm{m}$ de espessura (PIROT et al., 1997). A parte protéica dessa camada é formada por queratina, a qual é composta de células anucleadas (corneócitos) dispersas em uma matriz lipídica (parte lipídica). Esta matriz é constituída por lipídios como as ceramidas (18\%), triglicérides (25\%) ácidos graxos livres (19\%) e esteróis (14\%) (SZNITOWSKA et al., 2002), os quais formam uma matriz continua ao redor dos corneócitos, o que faz com que o estrato córneo acentue sua "função barreira". O estrato córneo é comumente descrito como uma parede de "cimento e tijolos" em que as células queratinizadas representam os tijolos e os espaços intersticiais entre as células, ou seja, a matriz lipídica representa o cimento (AGUILELLA et al., 1997). Por isso, o estrato córneo é normalmente responsável pela função de "barreira da pele" limitando a difusão percutânea de fármacos através dela.

\subsection{Penetração cutânea de Fármacos}

O estrato córneo, com a película lipídica que o reveste externamente e as camadas da epiderme subseqüentes, é uma barreira que impede ou dificulta a penetração dos fármacos. Se a substância ativa vencer essa barreira, atinge os tecidos subjacentes podendo, eventualmente, passar à corrente sanguínea.

Três mecanismos têm sido sugeridos para a permeação de solutos através do estrato córneo (Figura 6): 


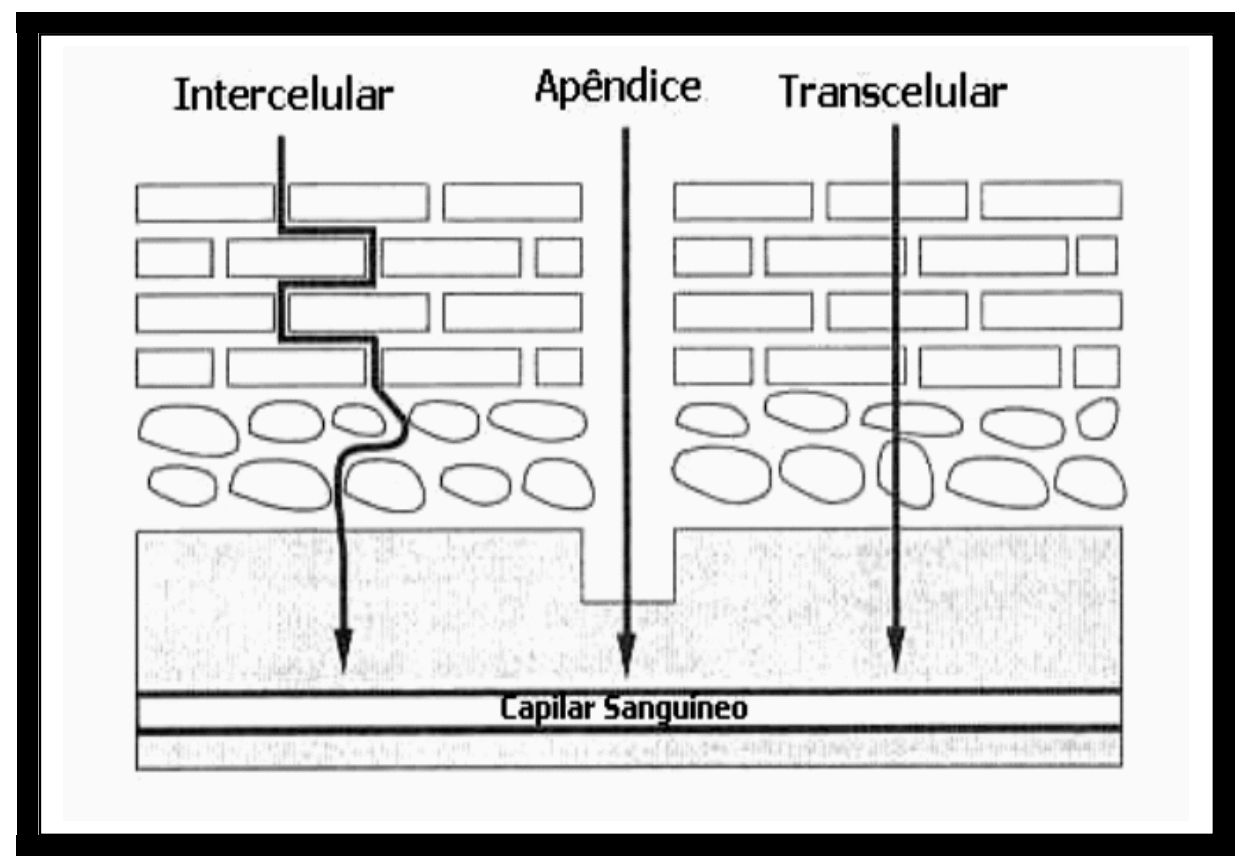

Figura 6: Representação esquemática das vias de permeação de fármacos através da pele

* penetração transcelular (através das células): o soluto difunde-se ao redor dos corneócitos permanecendo constantemente dentro da matriz lipídica;

* penetração intercelular ( entre as células ): o soluto passa diretamente através dos corneócitos e da matriz lipídica intercelular intermediária;

* penetração transanexial: rota paralela na qual o soluto pode ser absorvido através dos folículos pilosos, glândulas sebáceas e sudoríparas (MOSER et al.,2001; KITSON \& THEWALT, 2000; ANSEL et al., 2000).

A resistência ao transporte através do estrato córneo depende das propriedades e arranjo de suas camadas alternadas hidrófobas e hidrófilas, bem como de sua espessura, a qual varia de espécie para espécie e de região do corpo em um mesmo indivíduo.Variáveis adicionais, como a 
concentração local de folículos pilosos e glândulas sudoríparas, fornecem uma possível rota alternativa para difusão (PEREIRA, 1999).

Alguns fatores devem ser considerados no estudo da penetração cutânea de fármacos segundo ALENCASTRE, (2001) e ANSEL et al., (1999):

$\checkmark$ A concentração do fármaco: de modo geral, a quantidade absorvida por via percutânea por unidade de área de superfície por intervalo de tempo aumenta à medida que a concentração do fármaco aumenta;

$\checkmark$ Uma quantidade maior do fármaco é absorvida pela via percutânea quando a substância é aplicada em uma grande área;

$\checkmark$ A hidrossolubilidade do fármaco determina a concentração apresentada no local de absorção, e o coeficiente de partição tem forte influência na velocidade de transporte através dos locais de absorção;

$\checkmark$ A absorção parece ser aumentada por veículos que se espalham facilmente sobre a superfície da pele, misturam-se rapidamente com o sebo, colocando a substância ativa em contato com as células do tecido;

$\checkmark$ Os veículos oleosos e/ou os curativos oclusivos agem como barreira à umidade, através dos quais o suor da pele não pode passar, o que geralmente resulta em aumento da hidratação cutânea;

$\checkmark \mathrm{O}$ tempo e a intensidade de fricção na aplicação tópica têm influência sobre a quantidade absorvida: quanto maior o período e a intensidade, maior a absorção;

$\checkmark$ O local de aplicação pode ter um efeito sobre o grau de absorção;

$\checkmark$ Geralmente, quanto maior o período de contato com a pele, maior será a absorção. Entretanto, alterações da hidratação ou a 
saturação da pele com a substância ativa podem impedir o aumento significativo da absorção com o tempo;

$\checkmark$ Doses múltiplas de aplicação podem aumentar a biodisponibilidade da substância ativa.

A absorção de fármacos através da pele pode ser avaliada utilizandose metodologias in vitro e in vivo. Os modelos experimentais in vitro apresentam vantagens com relação aos in vivo, por serem mais simples e rápidos. Para avaliar a permeação e a retenção de fármacos in vitro através da pele de animais ou humana são utilizados sistemas compostos de células de difusão, onde uma membrana (pele inteira ou estrato córneo) separa as fases doadora e receptora.

Alguns fatores devem ser considerados nos estudos in vitro: a preparação da pele, a escolha da fase receptora e do sistema de agitação adequado, e a manutenção da temperatura fisiológica. A pele humana é preferível nos estudos de absorção e metabolismo de fármacos. Entretanto, seu uso é limitado devido à dificuldade de aquisição e variabilidade das amostras de pele. Desta maneira, faz-se necessário o uso de pele de animais para estudos repetitivos ou mecanísticos que requerem grandes quantidades.

SCHMOOK et al. (2001) realizaram um estudo comparativo entre (i) pele humana, (ii) um equivalente de pele humana viva (Graftskin ${ }^{\mathrm{TM}}$ LSE ${ }^{\mathrm{TM}}$ ), (iii) epiderme humana reconstituída ( Skinethic ${ }^{\mathrm{TM}} \mathrm{HRE}$ ), (iv) pele de rato, e (v) pele de porco, para estudos in vitro de absorção percutânea.

A pele humana é o modelo ideal para esses estudos, contudo não é acessível para a maioria dos pesquisadores. A princípio, modelos reconstituídos de pele poderiam ser uma alternativa promissora, no entanto, esses autores mostraram que produtos comercializados de derme e epiderme reconstituída têm as propriedades "barreira" mais fracas, quando comparadas com pele humana fresca ou congelada. Ao final dos estudos 
observou-se que a pele de porco foi a que obteve menor disparidade comparada com a pele humana, demonstrando assim, uma opção para estudos em desenvolvimentos de formulações de uso tópico e transdérmico, quando não se tem pele humana disponível.

\subsection{Emulsões}

O transporte de fármacos pela pele é complexo, pois, além da estrutura e propriedades distintas da pele, muitos outros fatores influenciam a penetração cutânea dos mesmos. Estes fatores são: 1) a molécula penetrante e suas propriedades físico-químicas; 2) o sistema de liberação do fármaco; e 3) a combinação de pele, fármaco e sistema de liberação (RANADE, 1991).

A penetração cutânea de fármacos pode ser descrita em três fases principais: 1) liberação da molécula do fármaco da formulação para a superfície da pele; 2) partilha e difusão da molécula pela pele; e 3) distribuição da molécula no local de ação pela circulação sistêmica. Qualquer um dos dois primeiros passos é limitante para a taxa de permeação. Modificações nas propriedades do fármaco (coeficiente de partilha, solubilidade, etc) e/ou na formulação ou sistema de liberação podem facilitar a penetração de ativos de interesse.

Os complexos de $\mathrm{Ru}^{\mathrm{II}}-\mathrm{NO}^{+}$sintetizados no presente trabalho são moléculas de grande massa molecular, que provavelmente teriam dificuldades na absorção pela pele. A escolha de uma formulação que facilite a sua interação com a mesma, e ao mesmo tempo desorganize a matriz lipídica do estrato córneo, torna-se fundamental para a ação tópica do NO. Ou seja, a formulação de escolha deve facilitar a penetração cutânea dos complexos mencionados, os quais, uma vez dentro da pele, 
devem ser reduzidos por substâncias ali presentes, ocasionando a liberação do NO ativo. Assim, a forma farmacêutica mais simples que pode propiciar a penetração desejada é a emulsão.

Emulsão consiste num sistema heterogêneo de pelo menos um líquido imiscível disperso internamente em outro na forma de gotículas, através do auxílio de um terceiro componente, o agente emulsificante. $\mathrm{O}$ diâmetro da fase dispersa em gotículas geralmente está entre 0,1 e $10 \mathrm{~mm}$ embora gotículas menores de $0,01 \mathrm{~mm}$ e maiores de $100 \mathrm{~mm}$ sejam comuns.

Quando a fase dispersa é apolar (oleosa) e a fase dispersante é polar (aquosa), a emulsão é conhecida como emulsão óleo em água (O/A). Quando a fase dispersa é aquosa e a fase dispersante é oleosa, a emulsão é do tipo água em óleo (A/O).

As emulsões água em óleo $(\mathrm{A} / \mathrm{O})$ são insolúveis em água; não são laváveis em água; podem absorver água; e são oclusivas. As emulsões óleo em água (O/A) são miscíveis em água; são laváveis em água; podem absorver água; e não são oclusivas (ALLEN, 1999).

As emulsões do tipo O/A podem comprometer a estrutura do estrato córneo e incrementar a penetração do fármaco (GLOOR, 2003). A solubilidade do ativo e dos componentes do veículo dependem da composição da matriz lipídica, que predominantemente controla a permeabilidade da barreira. Ceramidas e colesterol reduzem a permeabilidade e a solubilidade, enquanto que triglicérides têm o efeito oposto (JAECKLE, 2003).

Para aplicações tópicas a composição do veículo pode acarretar um significante impacto na permeação cutânea do fármaco. A possível razão para tal fato deve-se ao fenômeno da partição e difusão do mesmo (HADGRAFT,2003). 
Novos testes para se determinar a eficácia de antiestamínicos tópicos em diferentes formulações de géis e emulsões, de modo a otimizar veículos aumentando a eficácia das preparações foram desenvolvidos. Os excipientes utilizados nos dois tipos de forma farmacêutica tópica mencionados podem evitar tratamentos dispendiosos e insatisfatórios, pois alteram a performance de liberação e permeação de um mesmo princípio ativo empregado (HEINEMANN, 2003).

Estudos com emulsões apresentando diferentes formulações foram realizados para se analisar a permeação de ditranol, tendo-se observado que ocorre maior permeação quando se utiliza excipientes mais hidrófobos, comparando-se à permeação obtida quando a emulsão é preparada utilizando-se excipientes mais hidrófilos, em que se obteve uma pobre permeação (KAMMERAU, 1975).

Parte do trabalho apresentado neste Mestrado visa analisar a liberação de NO a partir de tampão fosfato e emulsões e a possibilidade de usá-las como sistema liberador de $\mathrm{NO}$ em complexos do tipo $\mathrm{Ru}^{\mathrm{II}}-\mathrm{NO}^{+}$. 


\section{OBJETIVOS}

Os objetivos deste trabalho, ora apresentado, visam:

* Síntese dos complexos cis-[RuCl(bpy $\left.)_{2}(\mathrm{NO})\right]\left(\mathrm{PF}_{6}\right)_{2}$ e trans$\left[\mathrm{RuCl}(\mathrm{bpy})_{2}(\mathrm{NO})\left(\mathrm{PF}_{6}\right)_{2}\right.$.

Caracterização por espectroscopia uv-visível, infravermelho e voltametria dos complexos mencionados.

* Avaliação do efeito estereoquímico no processo relacionado à liberação de NO.

* Estudo farmacotécnico visando:

1- Desenvolvimento de formulação para aplicação cutânea

2- Determinação da penetração passiva dos complexos para avaliar se os mesmos apresentam a possibilidade de se difundirem através do estrato córneo, com a finalidade de verificar a possibilidade desses compostos terem ação tópica. 


\section{Materiais e Métodos}

\subsection{Reagentes}

Os reagentes utilizados, bem como as porcentagens de pureza e procedência estão relacionadas na Tabela 2.

Tabela 2: Porcentagem de pureza e procedência dos reagentes utilizados durante as sínteses e a caracterização dos complexos.

\begin{tabular}{l|c|c}
\hline \multicolumn{1}{c|}{ Reagentes } & $\begin{array}{c}\text { \% de } \\
\text { pureza }\end{array}$ & Procedência \\
\hline 2, 2'-bipiridina & 99,0 & Aldrich Chemicals \\
Acetona & 99,5 & Carlo Erba \\
Acetonitrila & 99,9 & Mallinckrodt \\
Ácido ascórbico & 99,7 & Synth \\
Ácido clorídrico & & Quimex \\
Ácido nítrico & & Merck \\
Brometo de potássio & 99,5 & Reagen \\
Carbonato de sódio & 99,5 & Reagen \\
Cloreto de amônio & 98,0 & Nuclear \\
Cloreto de hexaaminrutênio(III) & 95,0 & Aldrich Chemicals \\
Cloreto de lítio & 99,0 & Aldrich Chemicals \\
Cloreto de potássio & 99,0 & Aldrich Chemicals \\
Cloreto de rutênio(III) & 99,9 & Scream Chemicals \\
Cloreto de tetrabutilamônio & 99,0 & Aldrich Chemicals \\
croda base & 99,0 & Croda \\
Dimetilformamida & 99,7 & Synth \\
Etanol & 99,8 & Vetec \\
\hline
\end{tabular}




\begin{tabular}{l|c|c}
\hline \hline Éter & 99,0 & Merck \\
Graxa de silicone & 99,0 & Synth \\
Hexafluorfosfato de amônio & 95,0 & Aldrich Chemicals \\
Hidróxido de sódio & 97,0 & Synth \\
Metanol & 99,5 & Merck \\
Monohidrogenofosfato de sódio & 99,5 & Merck \\
Nitrito de sódio & 99,0 & Merck \\
Paramul & 99,5 & Galena \\
Propilenoglicol & 99,5 & Synth \\
Tetrafluorborato de sódio & 98,0 & BDH Chemicals \\
Tetrafluorborato de tetrabutilamônio & 99,0 & Aldrich Chemicals \\
Vaselina líquida & 99,0 & Tec Lab \\
\hline
\end{tabular}

\subsection{Materiais e equipamentos utilizados}

\subsubsection{Gás Argônio}

O gás argônio utilizado foi borbulhado em uma solução de perclorato de crômo (II), contida em um frasco lavador, para retenção de traços de oxigênio eventualmente presentes no encanamento. As soluções de $\operatorname{Cr}(\mathrm{II})$ são obtidas por redução do correspondente sal de Cr(III) por amálgama de zinco.

A troca de cor azul $\{\mathrm{Cr}(\mathrm{II})\}$ para verde $\{\mathrm{Cr}(\mathrm{III})\}$ indica a presença de oxigênio. A solução redutora é mantida em contato permanente com zinco amalgamado para sua constante regeneração. Em seguida o argônio passa por um frasco lavador contendo água destilada para lavagem e saturação do gás com vapor d’água. 


\subsubsection{Espectroscopia na região do infravermelho}

Os espectros na região do infravermelho foram obtidos com espectrofotômetro FTIR Nicolet modelo Protege 460, fazendo-se a varredura no intervalo de 400 a $4.000 \mathrm{~cm}^{-1}$.

\subsubsection{Espectroscopia na região do ultravioleta-visível}

As medidas de absorção na região do ultravioleta e do visível foram efetuadas usando um espectrofotômetro UV-visível-NIR Hitachi modelo U-3501, utilizando celas de quartzo de 1,000 cm de caminho óptico. Os espectros foram obtidos num intervalo de varredura de 200 a $800 \mathrm{~nm}$.

\subsubsection{Voltametria}

Medidas de voltametria cíclica e de pulso diferencial foram realizadas utilizando um potenciostato / galvanostato AUTOLAB ${ }^{\circledR}$, modelo PGSTAT 30. Como eletrodo de trabalho utilizou-se: eletrodo de carbono vítreo para soluções aquosas e de platina para as não aquosas. Como eletrodo auxiliar e de referência utilizou-se eletrodo de platina e de $\mathrm{Ag} / \mathrm{AgCl}$, respectivamente.

\subsubsection{Medidas de $\mathrm{pH}$}

As medidas de $\mathrm{pH}$ foram realizadas utilizando-se o pHmetro Digimed modelo DM-20. 


\subsubsection{Preparação das emulsões}

Foram preparadas duas emulsões de acordo com as formulações descritas na Tabela 3.

Tabela 3: Formulação das emulsões estudadas

\begin{tabular}{|l|c|c|}
\hline \multicolumn{1}{|c|}{ Matérias-primas } & \multicolumn{2}{c|}{ \% massa/massa } \\
\hline & $\begin{array}{c}\text { Emulsão 1 } \\
\text { Paramul }{ }^{\circledR}\end{array}$ & $\begin{array}{c}\text { Emulsão 2 } \\
\text { Croda }{ }^{\circledR}\end{array}$ \\
\hline Paramul ${ }^{\circledR}$ & 8 & - \\
\hline Croda Base ${ }^{\circledR}$ & - & 16 \\
\hline Vaselina líquida & 5 & 3 \\
\hline Propilenoglicol & 4 & 5 \\
\hline Água destilada & Qsp 100 & Qsp 100 \\
\hline
\end{tabular}

Onde:

Paramul ${ }^{\circledR}$ : álcool cetilestearílico e ceteareth-20. (Paramul@)

Croda Base ${ }^{\circledR}$ : álcool cetilestearílico, ceteareth-20, óleo mineral, álcool de lanolina, petrolato-Croda base CR2®.

As formulações descritas na Tabela 3 foram preparadas aquecendose a fase aquosa à aproximadamente $50,0{ }^{\circ} \mathrm{C}$ até total solubilização dos componentes e vertendo-a lentamente, sob agitação manual, sobre a fase oleosa previamente aquecida até completa fusão dos componentes. Esta mistura foi agitada com bastão de vidro até resfriamento do sistema (temperatura ambiente), ocorrendo formação da emulsão. A emulsão formada foi deixada em repouso por pelo menos 48 horas antes do uso.

Não foram utilizados conservantes e antioxidante, pois os mesmos poderiam interferir na quantificação dos fármacos. 


\subsubsection{Outros equipamentos}

-Agitador de tubos (PHOENIX - Mod AP56)

-Banho de ultra-som (THORNTON - Mod T14)

-Bomba peristáltica (Fisaton - Mod 820)

-Células de difusão (LG - Mod 1088-IC USA)

-Chapa de aquecimento/agitador (CORNING - Mod PC-420)

-Coletor de fração (PHARMA TEST - Mod TYP PTFC2, Alemanha)

-Agitador magnético-MAG-1K-modelo MB01.15

-Banho Termostatizado (LAUDA - Ecoline E100)

\subsection{Sínteses dos compostos de rutênio}

A rota sintética do complexo de rutênio do tipo cis$\left[\operatorname{RuCl}(\mathrm{bpy})_{2}(\mathrm{NO})\right]\left(\mathrm{PF}_{6}\right)_{3}$ e trans-[RuCl(bpy $\left.)_{2}(\mathrm{NO})\right]\left(\mathrm{PF}_{6}\right)_{3}$, bem como suas fórmulas estruturais estão apresentadas pelas Figuras e Esquemas abaixo:

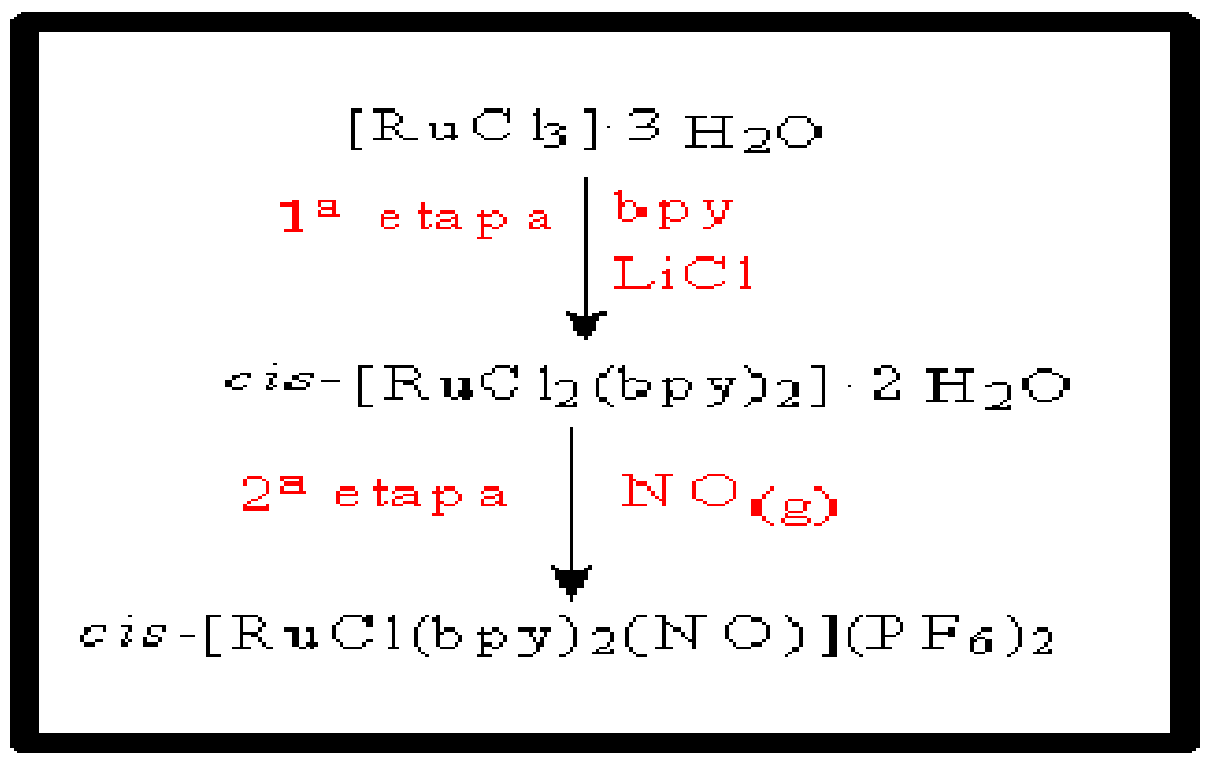

Esquema 5: Rota sintética para o complexo cis-[RuCl(bpy $\left.)_{2}(\mathrm{NO})\right]\left(\mathrm{PF}_{6}\right)_{2}$ 


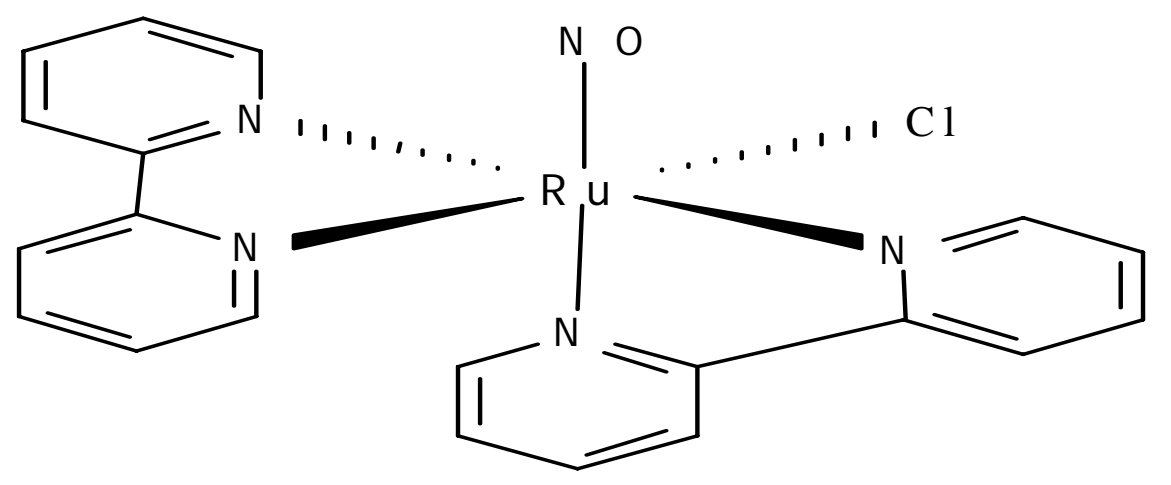

Figura 7: Fórmula estrutural do complexo cis-[RuCl(bpy $\left.)_{2}(\mathrm{NO})\right]\left(\mathrm{PF}_{6}\right)_{2}$

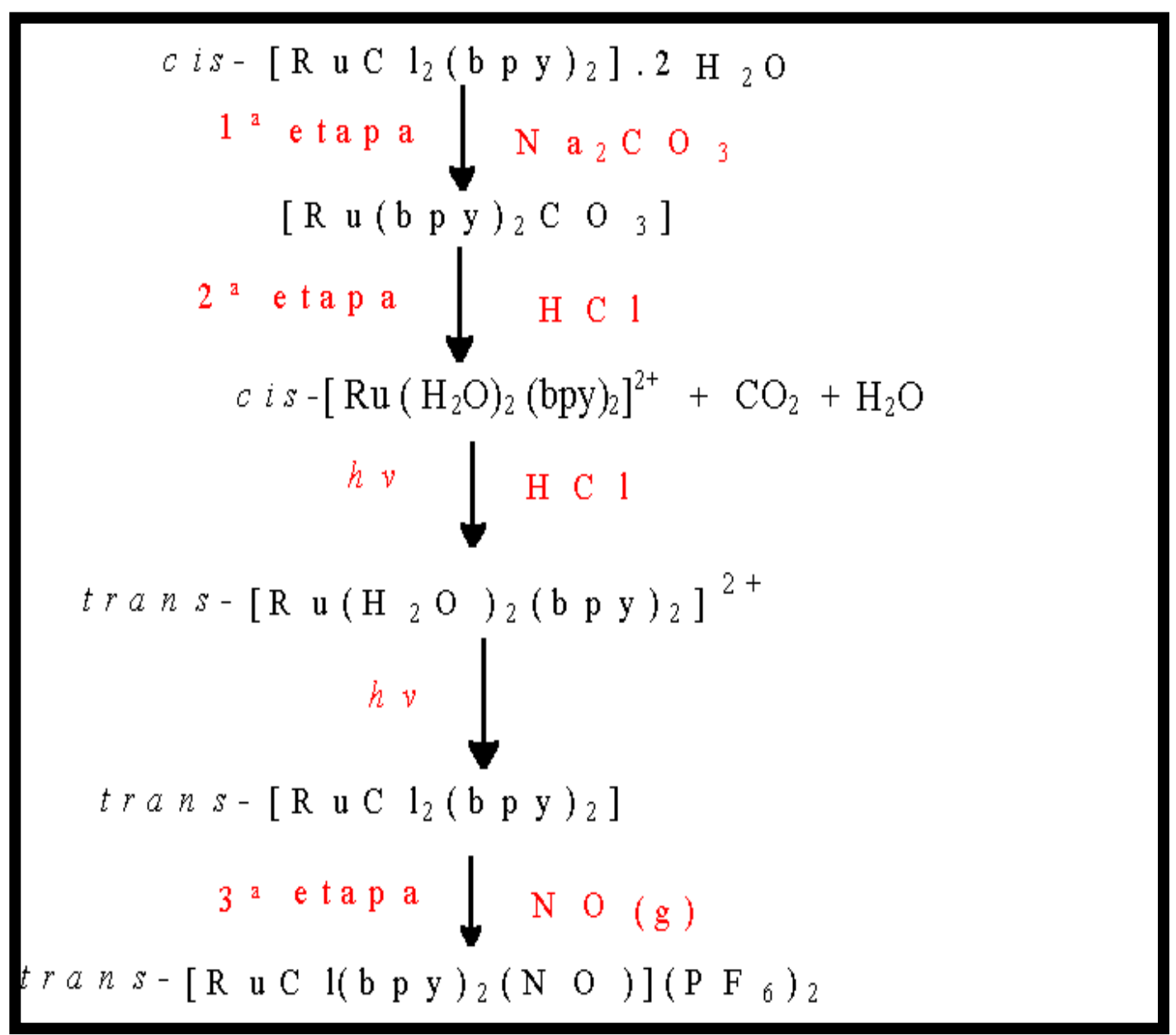

Esquema 6: Rota sintética para o complexo trans-[RuCl(bpy $\left.)_{2}(\mathrm{NO})\right]\left(\mathrm{PF}_{6}\right)_{2}$ 


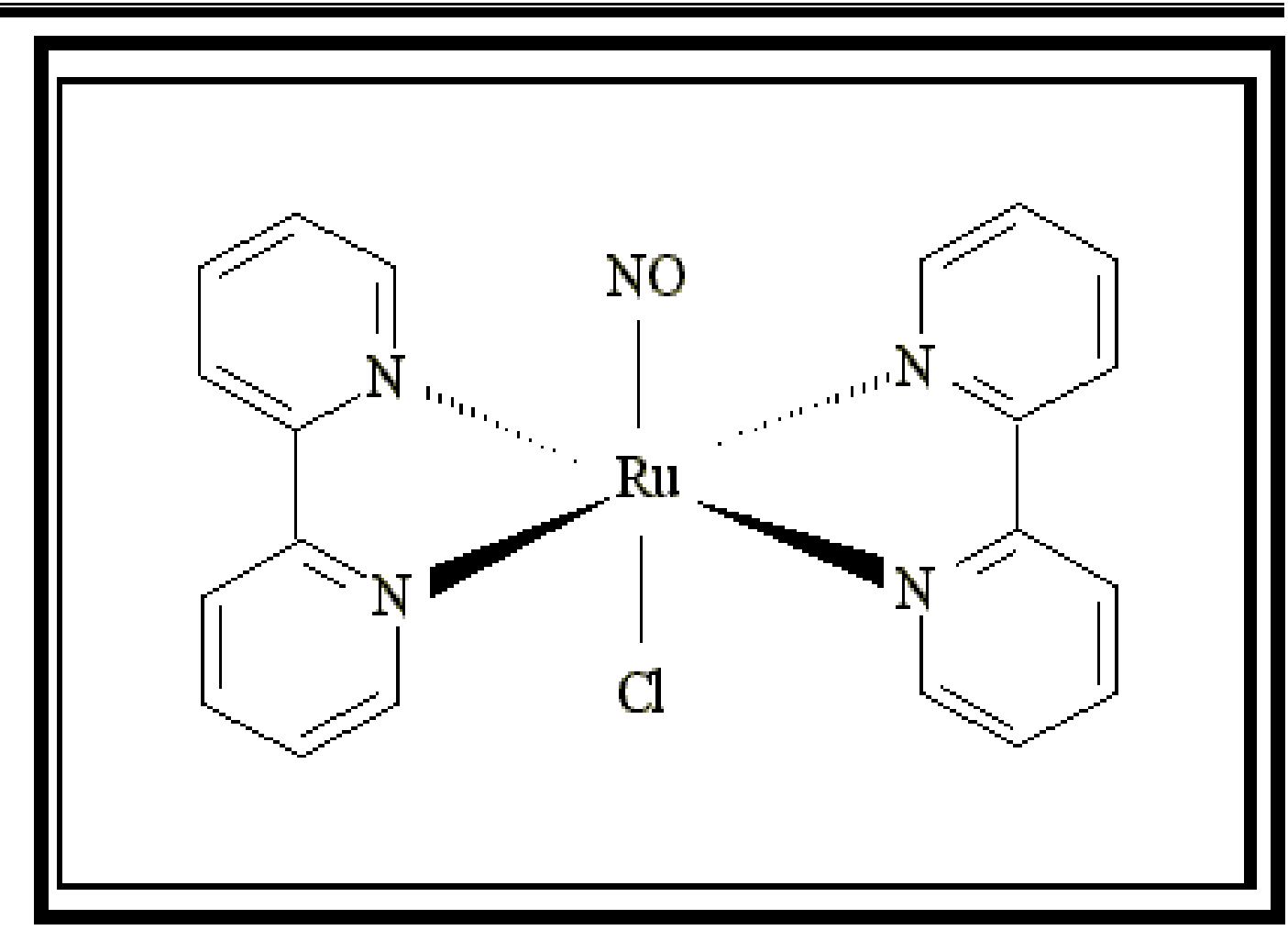

Figura 8: Fórmula estrutural do complexo trans-[RuCl(bpy $\left.)_{2}(\mathrm{NO})\right]\left(\mathrm{PF}_{6}\right)_{2}$

\subsection{1. cis-[RuCl(bpy $\left.)_{2}(\mathrm{NO})\right]\left(\mathrm{PF}_{6}\right)_{2}$}

- Etapa 1: cis-[RuCl $\left.\mathbf{R}_{2}(\mathbf{b p y})_{2}\right] \cdot 2 \mathbf{H}_{2} \mathbf{O}$ (DWYER et al., 1963)

Em um balão de $50 \mathrm{~mL}$ contendo $8 \mathrm{~mL}$ de dimetilformamida, adicionou-se 1,000 g de cloreto de rutênio (III) $\left(\mathrm{RuCl}_{3} \cdot 3 \mathrm{H}_{2} \mathrm{O}\right), 1,200 \mathrm{~g}$ de 2,2'-bipiridina (bpy) e 1,100 g de cloreto de lítio (LiCl). Acoplou-se um condensador ao balão que foi submetido a aquecimento por banho de glicerina. A solução atingiu o refluxo a uma temperatura de $135,0{ }^{\circ} \mathrm{C}$ e permitiu-se a reação por um tempo de 8 horas.

Ao término da reação, desligou-se o aquecimento e, em seguida, o balão foi levado à geladeira por 20 horas. A solução foi filtrada e o sólido escuro coletado foi lavado com várias porções de éter. Foi obtido 1,450 g de composto, com rendimento de 73\%. 
- Etapa 2: cis-[RuCl(NO)(bpy) $\left.)_{2}\right]\left(\mathbf{P F}_{6}\right)_{2}$ (GODWIN \& MEYER, 1971a)

Um volume de $60 \mathrm{~mL}$ de água destilada, contida em um balão de 250 $\mathrm{mL}$ de 3 bocas, foi submetido a borbulhamento de argônio por um período de 20 minutos para retirada de oxigênio. Foram dissolvidos, neste balão, 0,500 g do composto cis-[RuCl$\left.{ }_{2}(\mathrm{bpy})_{2}\right] \cdot 2 \mathrm{H}_{2} \mathrm{O}$, e a solução foi submetida a aquecimento a $65,0^{\circ} \mathrm{C}$. Deixou-se o sistema em refluxo por uma hora, sob atmosfera de argônio.

Posteriormente adicionou-se, lentamente, $6 \mathrm{~mL}$ de $\mathrm{HCl} 2 \mathrm{~mol} . \mathrm{L}^{-1}$ ao sistema ainda sob aquecimento, agitação e atmosfera de argônio. Depois de 10 minutos da adição do $\mathrm{HCl}$, adicionou-se, gota a gota, $3 \mathrm{~mL}$ de solução de nitrito de sódio $\left(0,070 \mathrm{~g}\right.$ de $\mathrm{NaNO}_{2}$ previamente dissolvido em água destilada e desaerada). Observou-se mudança da cor do sistema do vermelho para marrom. Deixou-se reagir por 15 minutos. Em seguida, foi desligado o aquecimento e o borbulhamento de argônio. Manteve-se a agitação e esperou-se que o sistema atingisse a temperatura ambiente.

Após resfriamento adicionou-se $1,0 \mathrm{~g}$ de $\mathrm{NH}_{4} \mathrm{PF}_{6}$ dissolvido em pequena quantidade de água desaerada (aproximadamente $4 \mathrm{~mL}$ ). Após adição do contra-íon formou-se um sólido de cor marrom opaco. Colocouse o balão sob refrigeração por volta de 24 horas.

Ao se retirar o material da refrigeração, filtrou-se e obteve-se um sólido marrom escuro, o qual foi lavado com várias porções de água gelada (total de $30 \mathrm{~mL}$ ) e, em seguida, com porção de éter. Obteve-se 0,682 g de sólido. Rendimento de $92 \%$.

\subsection{2. trans-[Ru Cl (NO) (bpy $\left.)_{2}\right]\left(\mathrm{PF}_{6}\right)_{2}$}

\section{- Etapa 1: síntese do [Ru (bpy) ${ }_{2}\left(\mathbf{C O}_{3}\right)$ ] ( NAGAO H.et al., 1989 )}

A massa de $0,500 \mathrm{~g}$ do complexo cis-[RuCl$\left.{ }_{2}(\text { bpy })_{2}\right] \cdot 2 \mathrm{H}_{2} \mathrm{O}$ foi adicionado a um balão de 3 bocas de $100 \mathrm{~mL}$, o qual continha $50 \mathrm{~mL}$ de água destilada previamente desaerada sob atmosfera de argônio. A mistura 
foi posteriormente mantida sob refluxo por cerca de 15 minutos. Em seguida, adicionou-se diretamente ao balão de 3 bocas 1,650 g de carbonato de sódio $\left(\mathrm{Na}_{2} \mathrm{CO}_{3}\right)$ e deixou-se sob refluxo nas condições mencionadas por 2 horas. Ao término desse período, o sistema de aquecimento foi desligado e deixou-se resfriar o sistema até atingir temperatura ambiente. O balão foi então tampado e conservado em refrigerador por 16 horas. Ocorreu a formação de um sólido. O material foi filtrado e o sólido obtido foi lavado com éter e guardado em dessecador. Obteve-se rendimento de $85 \%$.

\section{Etapa 2: Síntese do cis-[Ru( $\left.\left.\mathbf{H}_{2} \mathbf{O}\right)_{2}(\text { bpy })_{2}\right]^{2+}(\mathrm{NAGAO}$, et al, 1989 )}

A síntese desse composto foi realizada com algumas alterações em relação ao artigo mencionado.

Foi dissolvido 0,340 g de [Ru(bpy $\left.)_{2}\left(\mathrm{CO}_{3}\right)\right]$ em um béquer contendo $100 \mathrm{~mL}$ de $\mathrm{HCl}$ 0,5 mol. $\mathrm{L}^{-1}$. Houve efervescência da solução devido a liberação de $\mathrm{CO}_{2}$.

A equação a seguir representa o processo descrito anteriormente:

$$
\left[\mathrm{Ru}(\mathrm{bpy})_{2}\left(\mathrm{CO}_{3}\right)\right]+2 \mathrm{HCl} \longrightarrow \operatorname{cis}-\left[\mathrm{Ru}\left(\mathrm{H}_{2} \mathrm{O}\right)(\mathrm{bpy})_{2}\right]^{2+}+\mathrm{CO}_{2}+\mathrm{H}_{2} \mathrm{O}+2 \mathrm{Cl}^{-}
$$

Equação 1: Reação de adição de $\mathrm{HCl}$ com formação de $\mathrm{CO}_{2}$

Síntese do trans-[RuCl $\mathbf{R}_{\mathbf{2}}$ (bpy) $)_{2}$ (NAGAO, et al, 1989)

A síntese do composto trans- $\left[\mathrm{Ru}\left(\mathrm{H}_{2} \mathrm{O}\right)_{2}(\mathrm{bpy})_{2}\right]^{2+}$ foi realizada in situ e após a adição de $\mathrm{HCl}$ à solução de complexo carbonato (etapa 2) onde o sistema, após a mistura, foi colocado em uma cuba de gelo (banho de gelo), sob atmosfera de argônio, e fotolisada com lâmpada de 250W por 3 horas. A reação foi realizada em um fotoreator, construído conforme a Figura 9. 


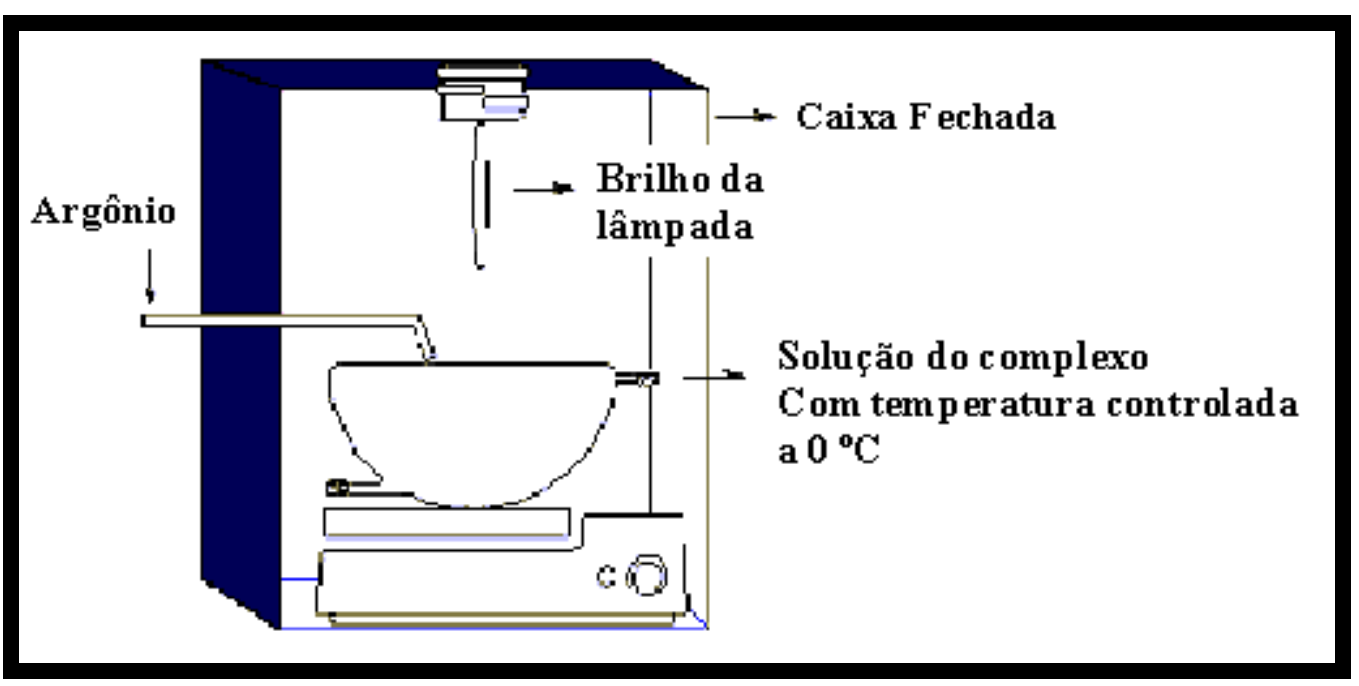

Figura 9: Esquema da aparelhagem utilizada para a fotólise.

Após ocorrer a formação do complexo trans-[Ru( $\left.\left.\mathrm{H}_{2} \mathrm{O}\right)_{2}(\mathrm{bpy})_{2}\right]^{2+}$ houve reação química com íons cloreto, o que acarretou a substituição do ligante aquo pelo ligante cloreto. A seguir, o material foi filtrado e o precipitado obtido foi lavado com éter e seco em dessecador. O procedimento foi repetido para o filtrado por mais duas vezes. Obteve-se 0,343 g do complexo, com rendimento de $99 \%$.

Etapa 3: Síntese do trans-[RuCl(bpy) $\left.)_{2}(\mathbf{N O})\right]\left(\mathbf{P F}_{6}\right)_{2}$ (NAGAO, et al, 1989)

Essa síntese foi feita com algumas alterações em relação ao artigo mencionado.Foi dissolvida uma massa de 0,200 g do complexo trans$\left[\mathrm{RuCl}_{2}(\mathrm{bpy})_{2}\right]$ em $50 \mathrm{~mL}$ de uma mistura de etanol e água (1:1), sem aquecimento. A solução foi então filtrada, para retirar possíveis impurezas insolúveis sendo, a seguir, desaerada com argônio por 15 minutos.

Depois de desaerada, e ainda sob atmosfera de argônio, a solução de coloração violeta foi borbulhada com óxido nítrico gasoso (NO) por 30 minutos. A mistura foi, então, novamente filtrada. 
Após a filtração da mistura, foi adicionado aproximadamente $1 \mathrm{~mL}$ de solução aquosa saturada com $\mathrm{NH}_{4} \mathrm{PF}_{6}$ preparada, dissolvendo-se o sal em água previamente desaerada com argônio (o preparo da solução foi feito dissolvendo-se o sal em aproximadamente $1 \mathrm{~mL}$ de água até saturação). A solução do complexo foi mantida em refrigeração por 12 horas.

Observou-se uma mudança radical da coloração da fase líquida da mistura, passando de cor violeta para salmão, com a formação de precipitado de cor amarela-opaco. O material foi filtrado, e o sólido foi lavado com $30 \mathrm{~mL}$ de éter e levado ao dessecador. Nessa etapa, o rendimento obtido foi de $70 \%$.

\subsubsection{Purificação do complexo $\left[\mathrm{RuCl}(\mathrm{bpy})_{2}(\mathrm{NO})\right]\left(\mathrm{PF}_{6}\right)_{2}$}

A purificação do complexo foi realizada através da recristalização. Dissolveu-se o sólido em pequeno volume de água $(\approx 1,0 \mathrm{~mL})$ e acrescentou-se uma solução aquosa $(\approx 2,0 \mathrm{~mL})$, contendo $0,500 \mathrm{~g}$ do sal hexafluorfosfato de amônio $\left(\mathrm{NH}_{4} \mathrm{PF}_{6}\right)$. Após duas horas na geladeira, o sólido foi coletado por filtração e seco a vácuo.

\subsection{Caracterização dos compostos de rutênio}

Os experimentos realizados durante a caracterização dos complexos sintetizados foram conduzidos sob luz difusa.

\subsubsection{Espectroscopia na região do ultravioleta-visível}

A caracterização por espectroscopia na região UV-visível dos complexos foi realizada em solução de $\mathrm{HCl} 0,1 \mathrm{~mol} . \mathrm{L}^{-1}$. Foram preparadas soluções com diferentes concentrações $\left(1 \times 10^{-5}, 2 \times 10^{-5}\right.$ e $3 \times 10^{-5}$ mol. $\left.\mathrm{L}^{-1}\right)$ dos 
compostos e submetidas à varredura espectrofotométrica de $800 \mathrm{~nm}$ a 200 nm, utilizando uma cubeta de quartzo de 1,000 cm de caminho óptico. Os máximos de absorção foram determinados diretamente nos espectros obtidos e utilizados para calcular o coeficiente de absortividade molar ( $($ ).

\subsubsection{Espectroscopia na região do infravermelho}

Para a obtenção dos espectros na região do infravermelho, prepararam-se amostras sólidas, em pastilhas de brometo de potássio $(\mathrm{KBr})$.

\subsubsection{Voltametria Cíclica}

Os voltamogramas cíclicos foram obtidos em meio aquoso e em meio de acetonitrila, à temperatura ambiente. Em meio aquoso utilizou-se solução tampão de acetato $(\mathrm{pH}=4,5)$, contendo cloreto de potássio $(\mathrm{KCl})$ 0,1 mol. $\mathrm{L}^{-1}$ como eletrólito de suporte. O eletrodo de trabalho foi de carbono vítreo; o eletrodo auxiliar foi de platina e o eletrodo de referência foi de $\mathrm{Ag} / \mathrm{AgCl}$. Em acetonitrila, o eletrólito de suporte utilizado foi hexafluorfosfato de tetrabutilamônio (TBAH) 0,1 mol.L ${ }^{-1}$. O eletrodo de trabalho e o eletrodo auxiliar foram de platina e o eletrodo de referência foi de Ag/AgCl. Para corrigir os potenciais, utilizaram-se como padrões interno cloreto de hexaaminrutênio (III) para meio aquoso e ferroceno para meio não aquoso. Essas espécies apresentam, respectivamente, potencial de $-0,142 \mathrm{~V}$ vs $\mathrm{Ag} / \mathrm{AgCl}$ (ELSON et al., 1975) e de 0,466 V vs $\mathrm{Ag} / \mathrm{AgCl}$ (LEVER, 1990).

Para um processo reversível, os potenciais e as correntes de picos anódico e catódico $\left(\mathrm{E}_{\mathrm{pa}}, \mathrm{E}_{\mathrm{pc}}, \mathrm{I}_{\mathrm{pa}}, \mathrm{I}_{\mathrm{pc}}\right)$, o potencial de meia onda de um processo redox $\left(E_{1 / 2}\right)$ e o potencial e a corrente de inversão de varredura $\left(E_{\mathrm{sp}}, \mathrm{I}_{\mathrm{sp}}\right)$ foram obtidos conforme a Figura 10. 


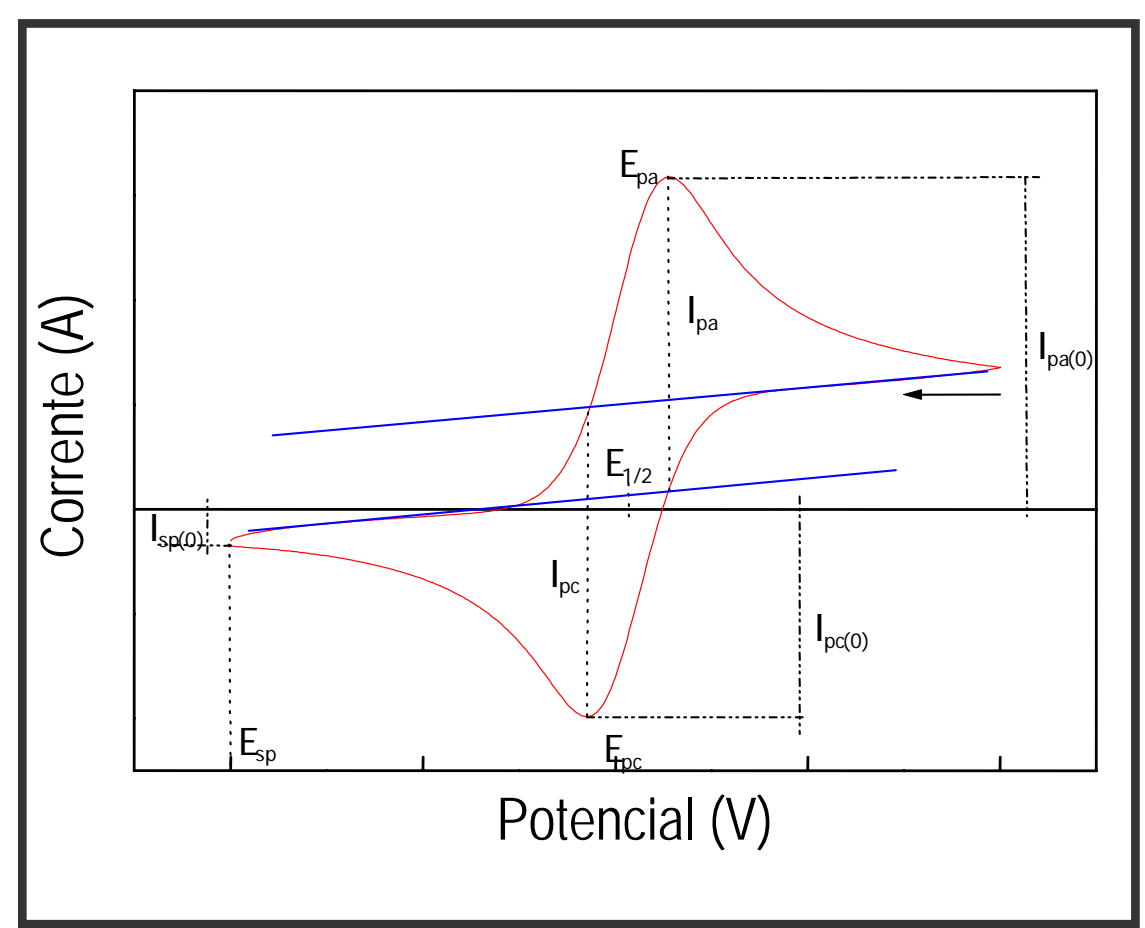

Figura 10: Ilustração dos parâmetros de um voltamograma cíclico completo.

Caso o sistema não exiba linha de base catódica definida na redução (ou anódica na oxidação), utiliza-se o método empírico de NICHOLSON \& SHAIN (1965) que determina a razão $\mathrm{I}_{\mathrm{pc}} / \mathrm{I}_{\mathrm{pa}}$ pela Equação 2.

$$
\frac{I_{p a}}{I_{p c}}=\frac{I_{p a(0)}}{I_{p c(0)}}+0,485\left(\frac{I_{s p(0)}}{I_{p c(0)}}\right)+0,086
$$

Equação 2: Método empírico de NICHOLSON \& SHAIN (1965) que determina a razão $\mathrm{I}_{\mathrm{pc}} / \mathrm{I}_{\mathrm{pa}}$ 


\subsection{Estudos de permeação passiva in vitro}

O fármaco é administrado na superfície da pele, onde poderá permeá-la (via intracelular, via intercelular ou via anexial) dependendo de suas características físico-químicas e das características da formulação em que ele se encontra. Foram realizados experimentos de penetração passiva, utilizando-se células de Franz (Figura 11) como equipamento. Como membrana, simulando a pele humana, foi utilizada a pele de orelha de porco branco (Figura 11), devido a sua semelhança com o tecido humano.
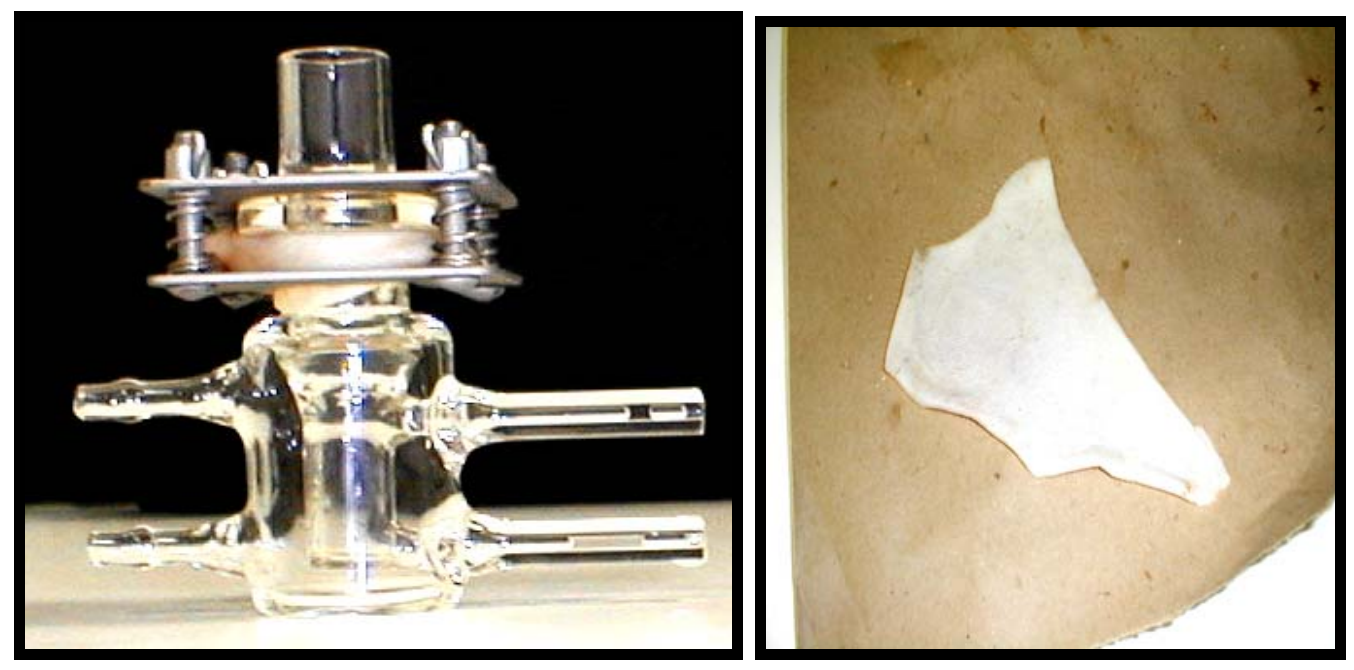

Figura 11: a) Célula de Franz montada ; b) Pele da orelha de porco.

\subsubsection{Célula de difusão}

O estudo de permeação cutânea passiva dos complexos cis$\left[\mathrm{RuCl}(\mathrm{bpy})_{2}(\mathrm{NO})\right]\left(\mathrm{PF}_{6}\right)_{2}$ e trans-[RuCl (bpy $\left.)_{2}(\mathrm{NO})\right]\left(\mathrm{PF}_{6}\right)_{2}$ foi feito in vitro utilizando-se células de difusão tipo Franz.

Essas células são divididas em duas partes de uma forma que uma metade fica sobre a outra (célula vertical). A pele é colocada entre as duas células horizontalmente, com a epiderme (área de $1,13 \mathrm{~cm}^{2}$ ) voltada para a metade superior da célula. A solução receptora $(6 \mathrm{~mL})$ é colocada na parte inferior da célula e nela existem "portas para perfusão”, que permitem que 
o fluido seja coletado continuamente (fluxo contínuo), além de "portas para banho circulante”, que permitem que a temperatura da solução receptora seja mantida a $37,0^{\circ} \mathrm{C}$.

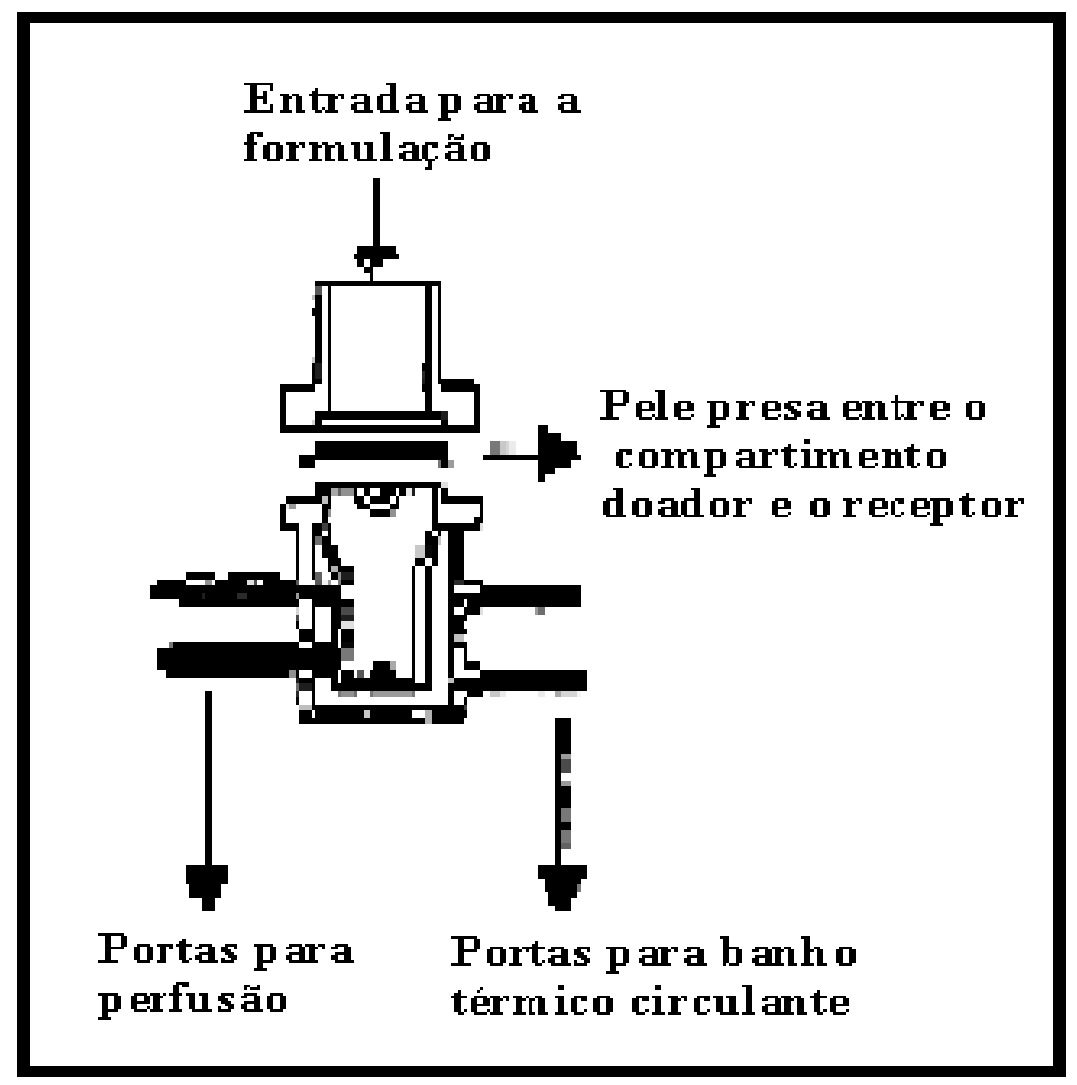

Figura 12: Célula de difusão tipo Franz utilizada nos estudos de permeação cutânea in vitro.(GLIKFELD et al, 1988).

\subsubsection{Determinação da permeação do fármaco através da pele in vitro}

A célula de difusão foi montada com a pele da orelha de porco separando o compartimento doador do compartimento receptor como descrito anteriormente.

A Figura 13 a seguir é referente ao sistema de difusão montado com sete células de Franz, conectadas ao coletor automático das amostras, à bomba peristáltica e, também, ao banho térmico. 


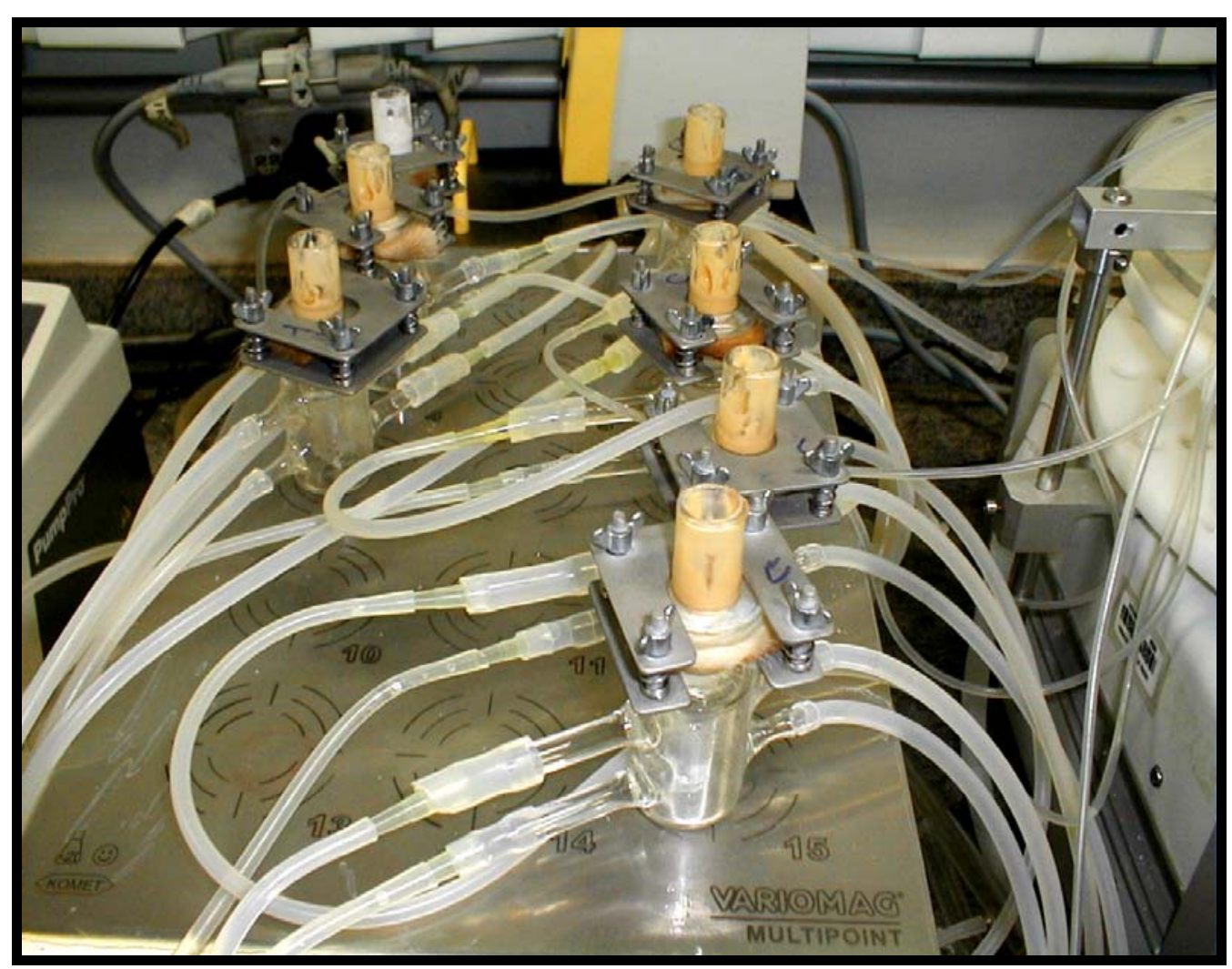

Figura 13: Esquema da montagem das células de difusão de Franz. Visão geral do sistema de difusão.

Foram testados os complexos cis-[RuCl(bpy $\left.)_{2}(\mathrm{NO})\right]\left(\mathrm{PF}_{6}\right)_{2}$ e trans$\left[\mathrm{RuCl}(\mathrm{bpy})_{2}(\mathrm{NO})\right]\left(\mathrm{PF}_{6}\right)_{2}$, em dois sistemas liberadores diferentes:

a) soluções saturadas dos complexos dissolvidos em tampão fosfato $0,01 \mathrm{~mol} . \mathrm{L}^{-1} \mathrm{com} \mathrm{pH}=5$. Os complexos foram individualmente dissolvidos em $10 \mathrm{~mL}$ do tampão mencionado até a saturação e, posteriormente, filtrados.

b) Emulsão Croda ${ }^{\circledR}$ (formulação 2 da Tabela 3), em que os complexos foram incorporados à emulsão através da técnica de espatulação. Complexos em concentração de saturação $\left(10^{-3} \mathrm{~mol} . \mathrm{L}^{-1}\right)$.

c) Emulsão Paramul ${ }^{\circledR}$ (formulação 1 da Tabela 3), em que os complexos foram incorporados à emulsão através da técnica 
de espatulação. Complexos em concentração de saturação $\left(10^{-3} \mathrm{~mol} . \mathrm{L}^{-1}\right)$.

Ao se utilizar a solução tampão como veículo dos complexos (fármacos) utilizou-se $1 \mathrm{~mL}$ do mesmo e, quando utilizou-se como veículo dos fármacos a emulsão, utilizou-se $1 \mathrm{~g}$ de emulsão com fármaco incorporado. Colocou-se estas formulações em contato com a epiderme (compartimento doador).

A solução receptora, que perfunde a derme, continha tampão fosfato 0,01 mol. $\mathrm{L}^{-1} \mathrm{com} \mathrm{pH}=5,0$ e foi mantida a $37,0^{\circ} \mathrm{C}$ por $12 \mathrm{~h}$, com agitação a $300 \mathrm{rpm}$ e fluxo de $2,7 \mathrm{~mL} / \mathrm{h}$, garantido pelo uso de bomba peristáltica (Figura 14)

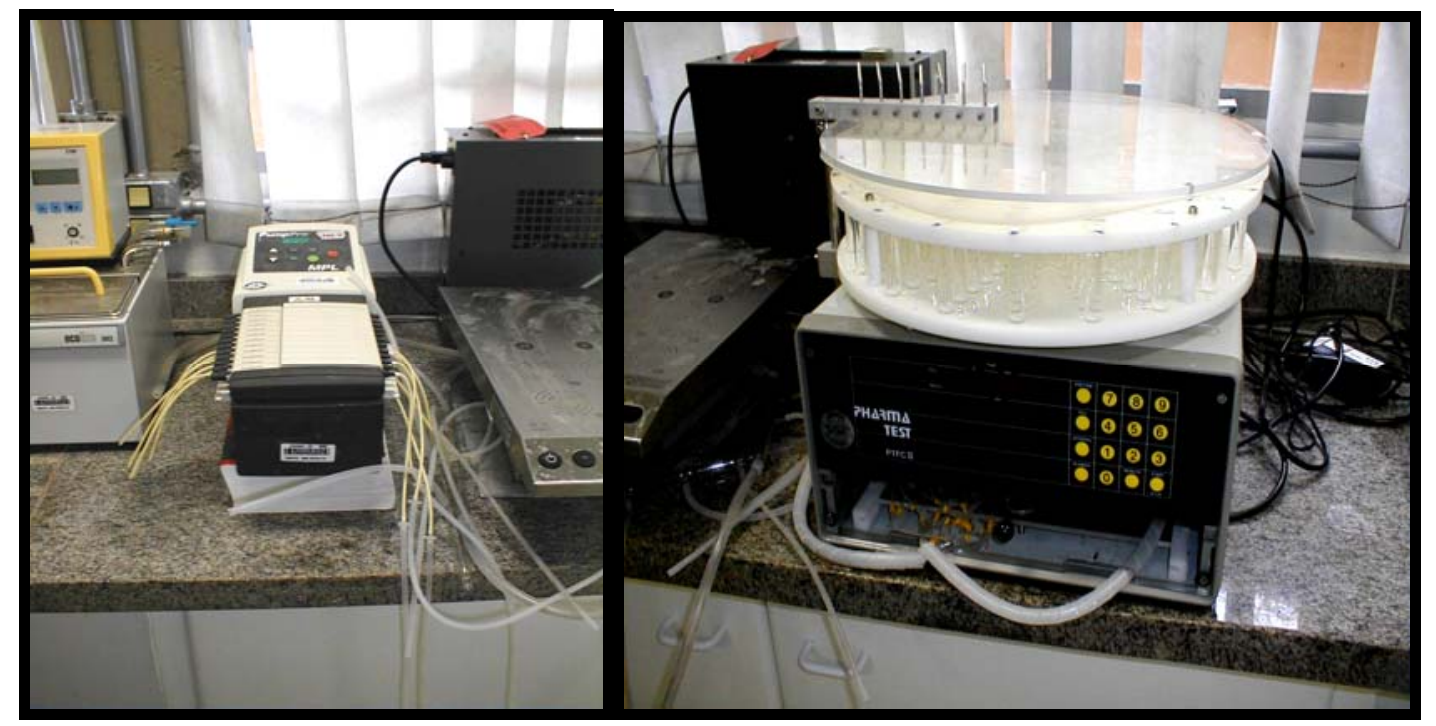

Figura 14: Bomba peristáltica (esquerda) e coletor automático.

Amostras da solução receptora foram coletadas por um coletor automático (Figura 14) nos intervalos de 1 hora até o período de 12 horas e analisadas por espectrometria UV-visível para determinação da concentração de fármaco que possa ter permeado a pele.

Paralelamente, foi realizado um experimento de permeação contendo, no compartimento doador, uma amostra da formulação (tampão fosfato ou emulsão), na ausência de fármaco, como branco. 


\subsubsection{Estudos de retenção}

Após o término do experimento de permeação, a pele foi removida da célula de difusão, o excesso de formulação removido com água destilada, e a pele presa a uma superfície lisa com o estrato córneo voltado para cima. A região da pele em contato com a solução tampão ou emulsão foi submetida à técnica de "tape stripping”.

Nessa técnica, o estrato córneo foi retirado utilizando-se 15 fitas adesivas. A remoção mais ou menos completa do estrato córneo é indicada pelo "brilho" da face exposta da pele (epiderme viável) (LOPEZ et al., 2003).

As 15 fitas adesivas, contendo partes do estrato córneo removido, foram colocadas em um tubo, e o fármaco aí contido foi extraído com 10 mL de acetonitrila, sob agitação em “mixer” por 5 min. Após esse período, os tubos contendo as fitas em acetonitrila foram novamente agitados por mais 5 minutos. As amostras foram filtradas e analisadas por espectrometria UV-visível para determinação da concentração de complexo presente no estrato córneo.

A pele remanescente (epiderme viável+derme) foi picotada, colocada em um tubo, e a quantidade de fármaco aí presente foi extraída com $5 \mathrm{~mL}$ de acetonitrila com o auxílio de um homogeneizador de tecidos (Turrax, por $3 \mathrm{~min}$ ) e, em seguida, com um sonicador, por $30 \mathrm{~min}$, para romper a membrana das células. Após a centrifugação e filtração, a solução foi analisada por espectro UV-visível para a determinação da quantidade de fármaco presente na epiderme viável (epiderme sem estrato córneo + derme). 


\subsection{Determinação dos parâmetros cinéticos de liberação de NO}

Foram realizados experimentos na tentativa de determinar a cinética de liberação de óxido nítrico a partir dos complexos mencionados, sob redução em meio aquoso, utilizando-se tampão fosfato $0,01 \mathrm{~mol} \cdot \mathrm{L}^{-1} \mathrm{pH}=5,0$.

A redução dos complexos foi realizada por diferentes metodologias: a redução química, utilizando-se solução de ácido ascórbico; redução química utilizando-se amálgama de zinco e também amálgama de cádmio; e redução potenciométrica, sob potencial controlado, em galvanostato/potenciostato.

\subsubsection{Redução química}

\subsubsection{Redução química com solução redutora de ácido ascórbico}

Inicialmente, buscou-se calcular a constante de velocidade de liberação do NO, a partir dos complexos, utilizando-se a espectrometria UV-visível, analisando-se o aparecimento da banda do complexo aquo, na região de $480 \mathrm{~nm}$, formado pela redução do complexo, em função do tempo decorrido.

Neste experimento preparou-se uma solução aquosa 0,1 mol. $\mathrm{L}^{-1}$ de ácido ascórbico e uma outra solução 0,01 mol.L ${ }^{-1}$ do complexo em estudo.

As soluções foram mantidas sob atmosfera de argônio por 10 minutos. Em seguida, foram misturados $2 \mathrm{~mL}$ da solução de ácido ascórbico com igual volume da solução de complexo. Após a adição da solução redutora, iniciou-se os registros dos espectros UV-visível.

Uma segunda técnica para o estudo cinético foi a "stopped flow". Para isto, utilizou-se um aparelho (Figura 15) que permite que ambas as soluções sejam misturadas simultaneamente dentro de uma cubeta e, a 
partir do momento em que as soluções são misturadas, aciona-se o registro do espectro UV-visível.

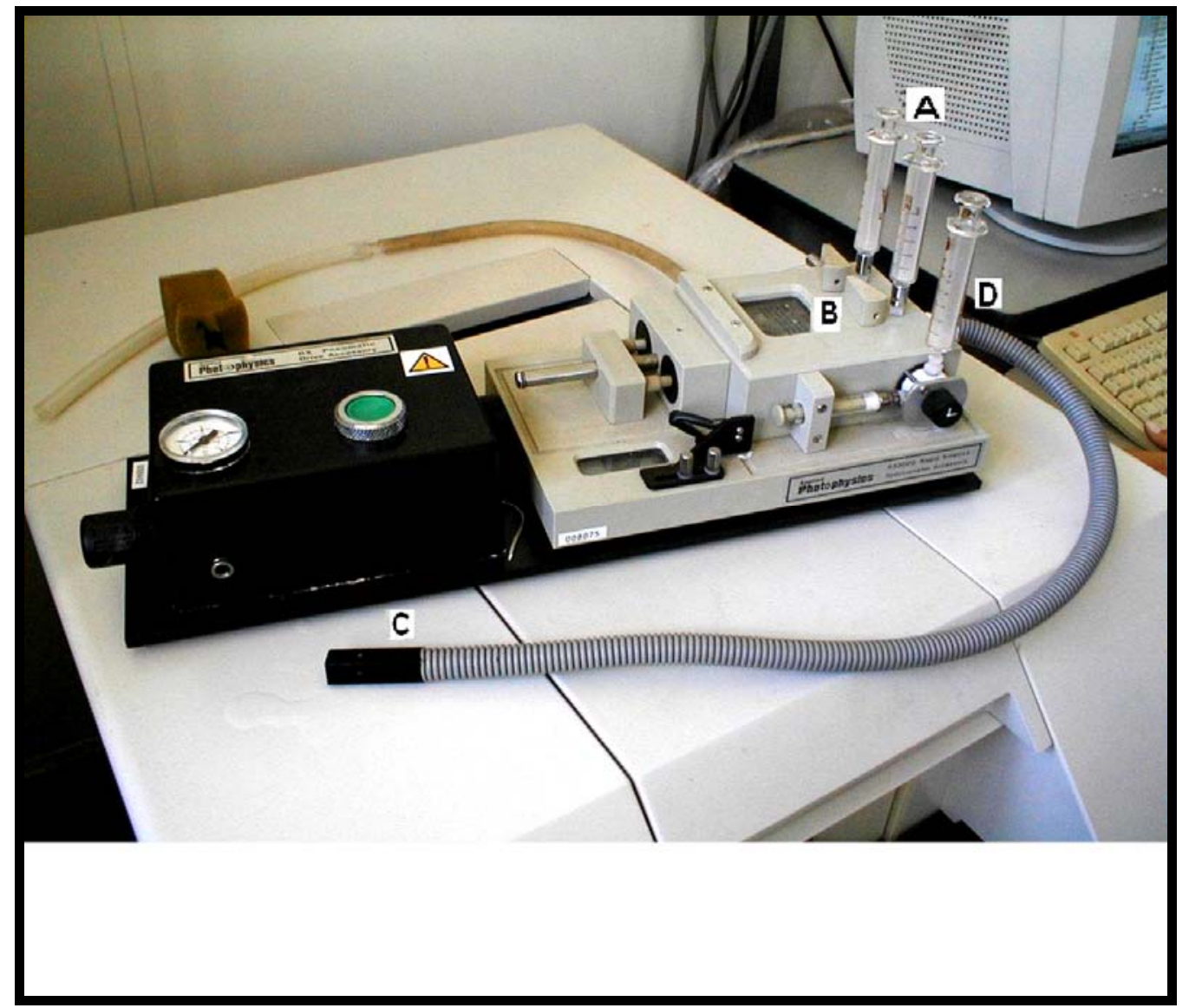

Figura 15: Aparelho utilizado na técnica "stopped flow"

Nesse aparelho, as soluções são colocadas em seringas de vidro (A), de forma independente e, através de um sistema de controle de sentido de fluxo (B), bombeia-se ambas as soluções, simultaneamente, em direção a uma cubeta de quartzo (C). Nessa cubeta, as soluções serão misturadas nas mesmas proporções volumétricas. O excesso de solução é enviado para uma outra seringa de vidro (D). O espectro UV-visível é então obtido, fazendo-se uma leitura de absorbância a $480 \mathrm{~nm}$ em função do tempo decorrido após a mistura das soluções. 


\subsubsection{Redução química com amálgama de zinco}

Os processos envolvendo a redução química dos complexos descritos neste trabalho foram feitos sob atmosfera de argônio. Para tanto, utilizou-se "Frasco de Zwickel” (Figura 16), o qual foi acoplado a uma cubeta de quartzo. Um volume de cerca de $10 \mathrm{~mL}$ de uma solução contendo o complexo nitrosilo foi adicionado a este recipiente e desaerado sob atmosfera de argônio por 15 minutos. Em seguida, adiciona-se amálgama de zinco à solução de complexo dentro do frasco e, através de um sistema de fluxo, faz-se a inversão do sentido de circulação dentro do frasco, ocorrendo o enchimento de uma cubeta de quartzo, que será introduzida no espectrofotometro UV-visível para posterior leitura. Dessa forma, o conteúdo da cubeta fica sem contato com o ar, impedindo ou minimizando reações paralelas de oxidação com oxigênio.

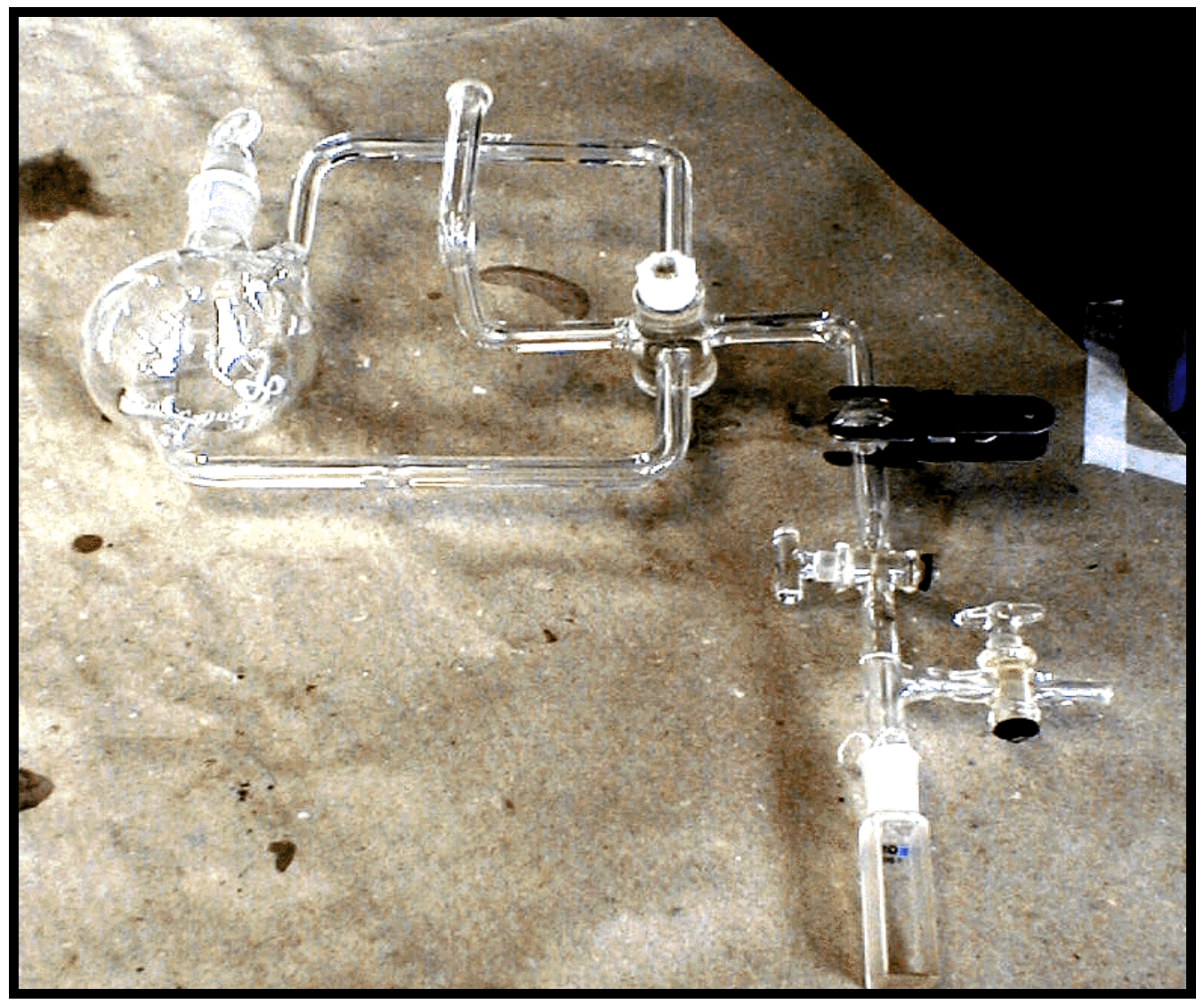

Figura 16: Frasco de Zwickel 


\subsubsection{Redução química com amálgama de cádmio}

A redução utilizando-se amálgama de cádmio foi semelhante à realizada com amálgama de zinco. Usou-se o cádmio devido ao potencial químico em que este poderia reduzir o complexo. Suspeitou-se que a amálgama de zinco, em função de seu potencial, poderia estar reduzindo o complexo, porém, numa região que poderia acarretar a redução do $\mathrm{NO}^{0}$ a NO`. Com o cádmio o potencial em que ocorre a redução $\left(E^{0}=-0,200 \mathrm{~V}\right.$ vs $\mathrm{Ag} / \mathrm{AgCl})$ não atinge valores suficientes para a redução do óxido nítrico para nitróxido.

\subsubsection{Redução sob potencial controlado}

Realizou-se a redução dos complexos utilizando-se um potenciostato/galvanostato, em cela voltamétrica, na qual foi também colocado um eletrodo seletivo para NO. O potencial foi mantido constante durante todo o experimento em $0,00 \mathrm{~V}$ vs $\mathrm{Ag} / \mathrm{AgCl}$. O eletrodo de $\mathrm{NO}$ mede a quantidade de NO liberado, através de um sensor desenvolvido pela WPI (NOmeter), baseado na determinação amperométrica direta do NO.

O sinal analógico do NOmeter foi digitalizado e registrado temporalmente utilizando-se um sistema DUO.18 versão 1.1, conversor analógico/digital.

As medidas foram efetuadas em solução tampão fosfato 0,01 mol. $\mathrm{L}^{-1}$ $\left(\mathrm{HPO}_{4}^{2-} / \mathrm{H}_{2} \mathrm{PO}_{4}^{-}\right)$. O pH foi mantido em 5,0.

\subsubsection{Espectroeletroquímica}

A espectroeletroquímica é uma técnica que envolve o acoplamento in situ da técnica espectroscópica com a técnica eletroquímica. No caso em 
questão, a técnica espectroscópica empregada foi a espectroscopia UVvisível.

Esta técnica consiste em incidir um feixe de luz UV-visível perpendicularmente ao eletrodo e medir as variações de absorbâncias decorrentes de espécies produzidas ou consumidas num processo eletródico.

A célula eletródica é colocada diretamente no compartimento do espectrofotômetro. A variação das concentrações das espécies oxidadas ou reduzidas é dada pela variação da absorbância em função do potencial aplicado em certo intervalo de tempo. As medidas foram efetuadas em solução tampão fosfato $0,01 \mathrm{~mol} . \mathrm{L}^{-1}\left(\mathrm{HPO}_{4}{ }^{2-} / \mathrm{H}_{2} \mathrm{PO}_{4}{ }^{-}\right)$. O pH foi mantido em 5,0.

Para manter uma força iônica constante utilizou-se tetrafluorborato de sódio $\left(\mathrm{NaBF}_{4}\right)$ na concentração 0,1 mol. $\mathrm{L}^{-1}$.

A cela para espectroeletroquímica é composta de um recipiente de quartzo de 0,500 $\mathrm{mm}$ de caminho óptico, com gargalo e provida de tampa de teflon. Como eletrodo de trabalho utilizou-se uma folha de ouro transparente, aderida sobre uma haste metálica, como eletrodo auxiliar e, como eletrodo de de referência, utilizou-se um fio de platina e $\mathrm{Ag} / \mathrm{AgCl}$, respectivamente, conforme está representado na Figura 17.

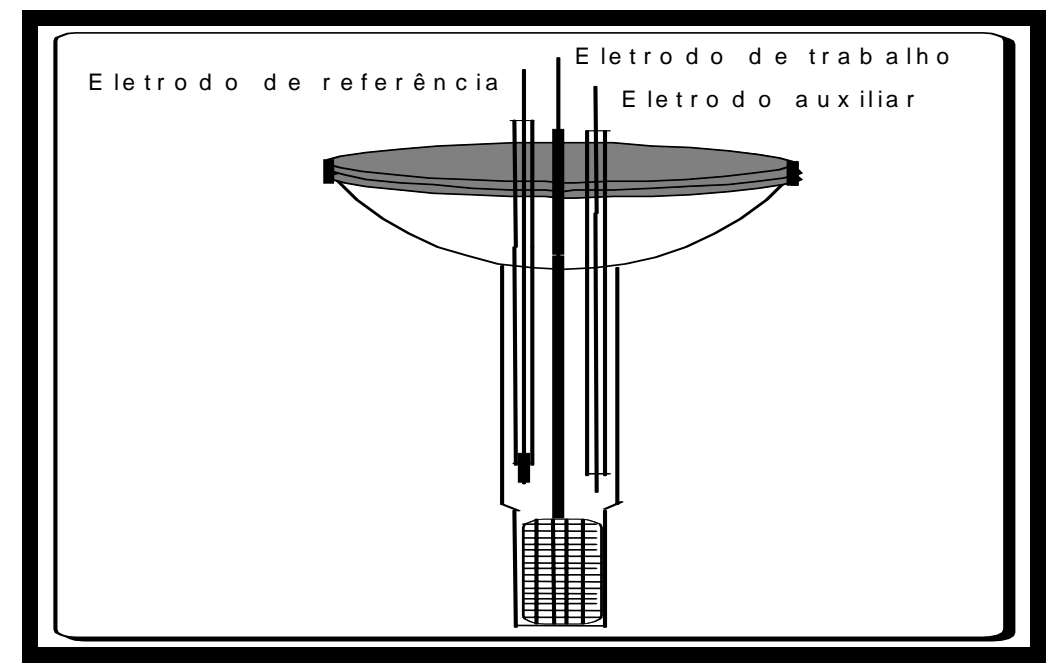

Figura 17: Esquema ilustrando a cela para espectroeletroquímica. 
O sistema foi mantido sob atmosfera de argônio e acoplado a um potenciostato/galvanostato AUTOLAB ${ }^{\circledR}$, modelo PGSTAT 30, juntamente com o espectrofotômetro UV-visível-infravermelho próximo Hitachi modelo U-3501. Durante a eletrólise, em potencial controlado, foram obtidos os espectros de absorção em tempos selecionados, à temperatura de $25{ }^{\circ} \mathrm{C}$.

O eletrodo de referência $\mathrm{Ag} / \mathrm{AgCl}$ foi construído em um capilar de vidro, sendo que uma das extremidades do capilar foi vedada com um pedaço de grafite, que serviu de contato entre a solução interna do capilar e a solução de análise. No interior do capilar foi usada uma solução saturada de cloreto de potássio e algumas gotas de solução de nitrato de prata que geram AgCl (Figura 18).

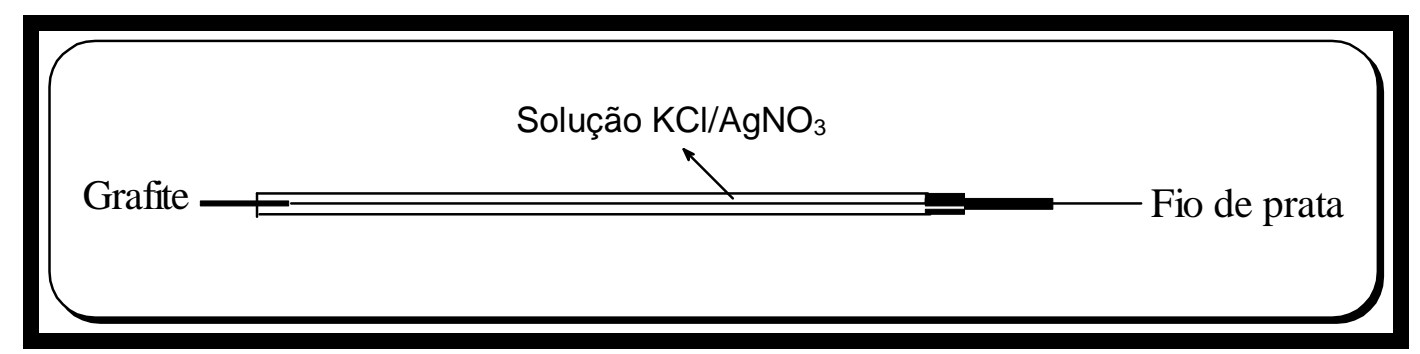

Figura 18: Esquema do eletrodo de referência Ag/AgCl. 


\section{RESULTADOS E DISCUSSÃO}

\subsection{Sínteses}

Complexos de rutênio, em que existe o ligante NO na esfera de coordenação do metal, são geralmente descritos como $R u(I I)$ e o ligante como $\mathrm{NO}^{+}$(BORGES et al., 1998; WALSH et al., 1980; GUENGERICH \& SCHUG, 1978; BOTTOMLEY, 1978). A síntese dessas espécies pode ser obtida de três maneiras:

- Borbulhamento do óxido nítrico gasoso em um precursor que contenha o fragmento $\mathrm{Ru}(\mathrm{II})$-aquo ou o $\mathrm{Ru}$ (III)-aquo (NAGAO et al., 1989; CHENEY \& ARMOR, 1977).

- Adição de nitrito de sódio a uma solução ácida de um complexo que contenha o fragmento $\mathrm{Ru}(\mathrm{II})-\mathrm{H}_{2} \mathrm{O}$ (TOGANO et al., 1992; WALSH \& DURHAM, 1982; GODWIN \& MEYER, 1971a).

- Oxidação do ligante amin $\left(\mathrm{NH}_{3}\right)$ coordenado ao íon metálico $\mathrm{Ru}$ (II) (ASSEFA \& STANBURY, 1997; MURPHY et al., 1986; MURPHY et al., 1982).

As sínteses dos complexos cis-[RuCl(bpy $\left.)_{2}(\mathrm{NO})\right]\left(\mathrm{PF}_{6}\right)_{2}$ e trans$\left[\mathrm{RuCl}(\mathrm{bpy})_{2}(\mathrm{NO})\right]\left(\mathrm{PF}_{6}\right)_{2}$, descritas nesse trabalho, foram feitas borbulhando-se NO gerado à partir de um aparato, conforme Figura 19 ou através da reação do nitrito de sódio em meio ácido, com os respectivos precursores.

Embora os complexos utilizados neste trabalho tenham sido anteriormente sintetizados, seus processos de sínteses não nos pareceram tão viáveis. Uma série de modificações foram realizadas visando a 
obtenção das espécies nitrosilas com maior rendimento e de uma forma mais pura.

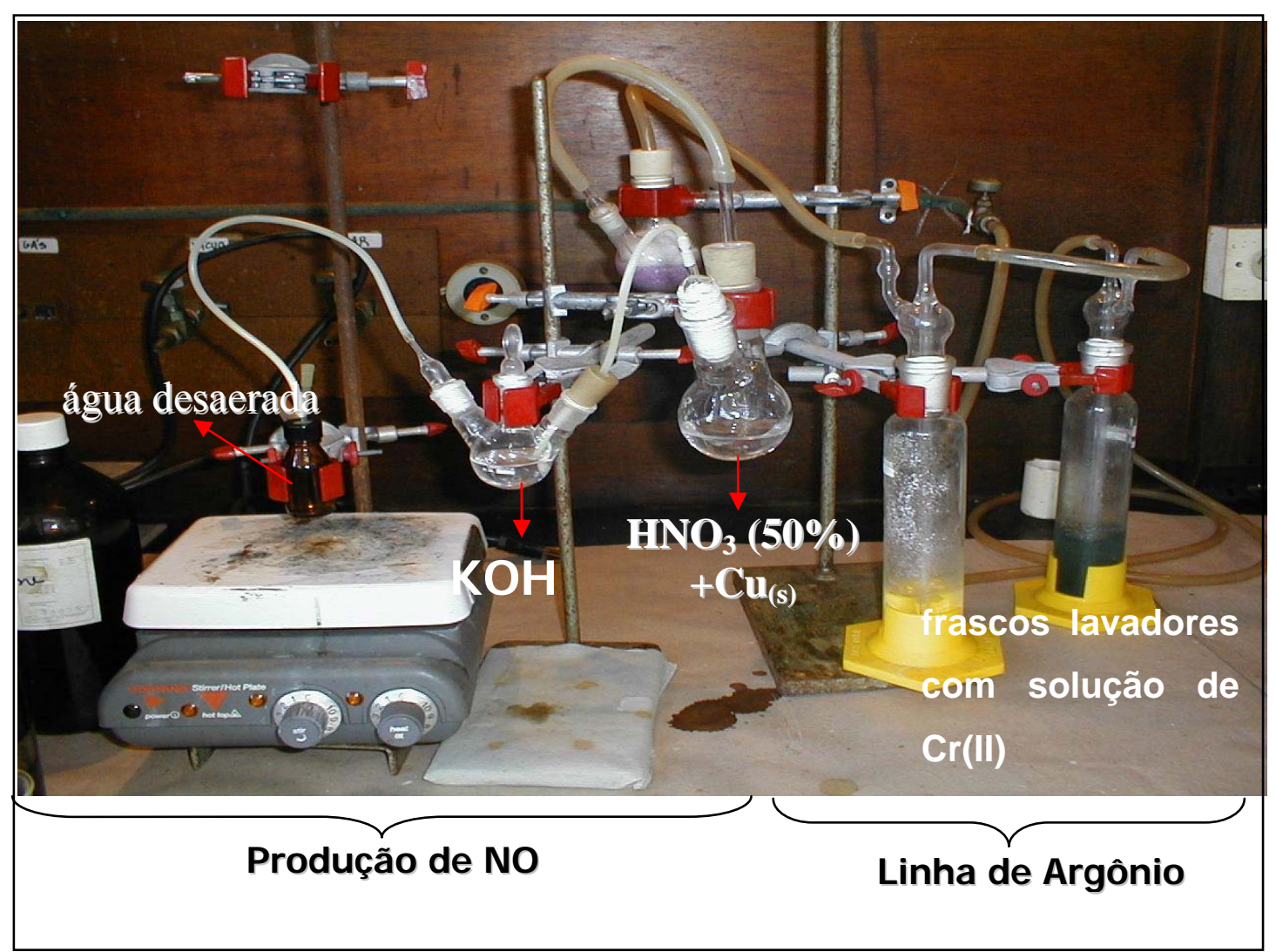

Figura 19: Aparato montado em capela para geração de óxido nítrico gasoso $\left(\mathrm{NO}^{0}\right)$.

Entre outras, o que, ressalta-se:

- A etapa de síntese do composto cis$\left[\mathrm{RuCl}(\mathrm{bpy})_{2}(\mathrm{NO})\right]\left(\mathrm{PF}_{6}\right)_{2}$ não foi reprodutível seguindo à risca o artigo mencionado, em uma tentativa inicial. Após estudos, foram testadas adaptações ao método descrito no artigo e conseguiu-se sintetizar o composto somente após a adição de ácido clorídrico $(\mathrm{HCl}) 2$ mol.L $\mathrm{L}^{-1}$. O artigo indicava o uso de $\mathrm{HCl}$ 0,5 mol. $\mathrm{L}^{-1}$. 
- A síntese do composto trans-[RuCl(bpy $\left.)_{2}(\mathrm{NO})\right]\left(\mathrm{PF}_{6}\right)_{2}$ não foi viável segundo o artigo. $\mathrm{O}$ artigo descreve que $\mathrm{o}$ precursor deve ser dissolvido em $50 \mathrm{~mL}$ de água, depois deveria ser filtrado para remover material insolúvel. Porém, sob as condições do artigo, a maioria da massa do precursor (70\%, aproximadamente) não se dissolvia. Para dar seqüência à etapa de síntese, ou seja, a irradiação, seria necessário trabalhar com solução. Após testes de solubilidade, conseguiu-se dissolver praticamente toda a massa do complexo, utilizando-se uma mistura 1:1 de água e etanol.

- A síntese do composto trans- $\left[\mathrm{RuCl}_{2}(\mathrm{bpy})_{2}\right]$ foi realizada conforme artigo, porém, ressalta-se que o processo é mais efetivo quando se dissolve lentamente o complexo $\left[\mathrm{Ru}(\mathrm{bpy})_{2}\left(\mathrm{CO}_{3}\right)\right]$ em ácido clorídrico $(\mathrm{HCl})$. Quando se adiciona o ácido sobre o sólido a reação não se processa com tanta eficiência, ou seja, o rendimento do processo é muito baixo. Ao se dissolver lentamente o sólido com o ácido, o rendimento aumenta consideravelmente.

\subsection{Espectroscopia na região do UV-visível}

Os espectros na região do UV-visível de complexos de rutênio, com ligantes insaturados coordenados, apresentam, geralmente, bandas na região do visível, atribuídas às transições de campo ligante e de transferência de carga, e bandas na região do ultravioleta, atribuídas às transições internas do ligante (LEVER, 1984). Essas transições podem ser 
observadas no diagrama ilustrado na Figura 20, que foi adaptado de RICHTER-ADDO \& LEGZDINS (1992)

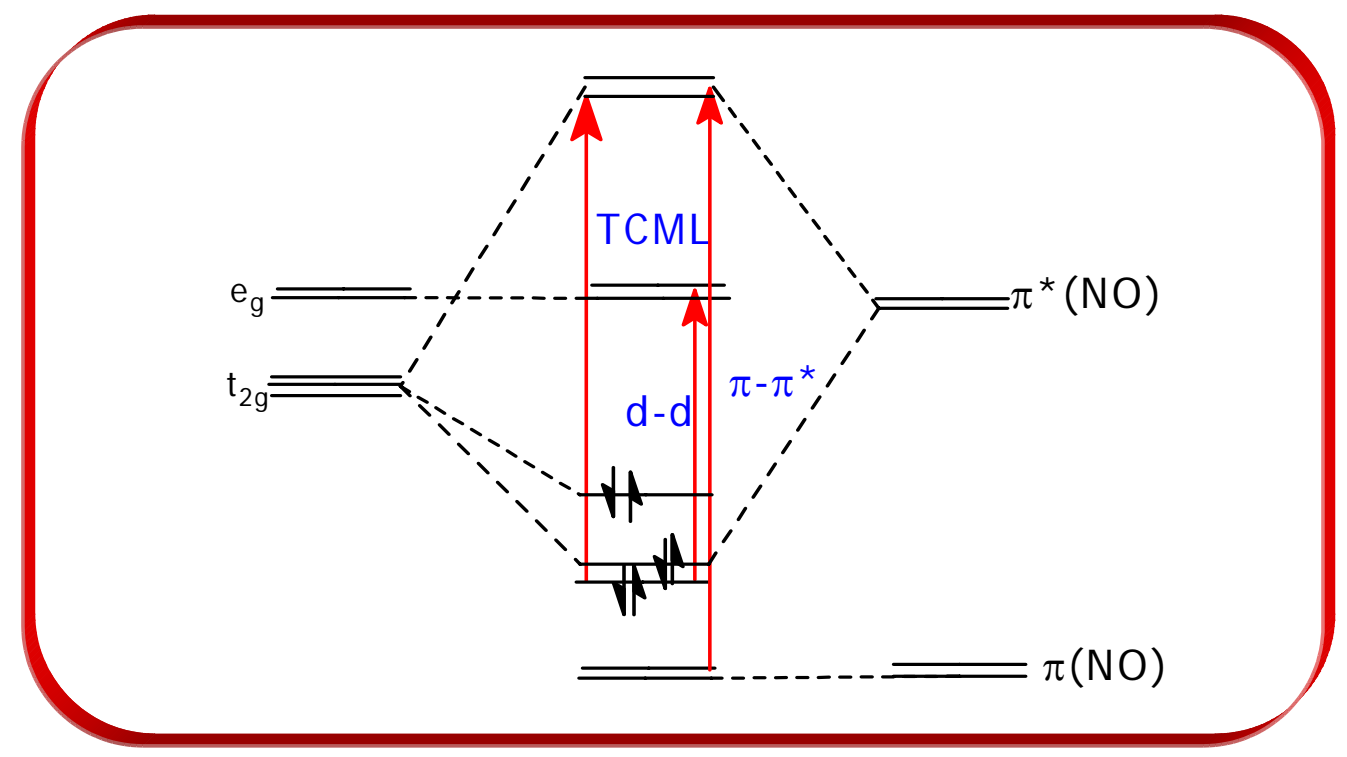

Figura 20: Diagrama simplificado de orbitais moleculares e transições eletrônicas para compostos do tipo cis-[RuL(bpy) $2(\mathrm{NO})]^{\mathrm{n}+}$.

- As transições de campo ligante são observadas entre níveis energéticos localizados no metal. As bandas são originadas pelo desdobramento das energias dos orbitais $d$ (transições $d \rightarrow d$ ), que num campo octaédrico podem ser designados por $t_{2 g}$ e $e_{g}$.

- As transições de transferência de carga ou elétron do metal para o ligante (TCML) caracterizam-se por uma ligação $\pi$ verificada nos compostos de rutênio com ligantes insaturados (FORD, et al., 1968; TFOUNI \& FORD, 1980). Essas bandas possuem coeficiente de absortividade molar $(\varepsilon)$ da ordem de $10^{4}$ L. $\mathrm{mol}^{-1} 1 . \mathrm{cm}^{-1}$ e normalmente localizam-se na região do visível. A ocorrência dessas bandas depende da existência de orbitais de simetria apropriadas no metal e no ligante, com energias pouco diferentes e grau de recobrimento diferente de zero. Uma vez que os elétrons de valência do íon metálico se encontram em orbitais de simetria $\pi$ e considerando que os orbitais desocupados de 
menor energia dos ligantes também possuam simetria $\pi$, a transição mais provável é, portanto, $\mathrm{d} \pi(\mathrm{M}) \rightarrow \mathrm{p} \pi^{*}(\mathrm{~L})$.

- As transições internas do ligante (IL) são semelhantes às transições observadas nos ligantes insaturados não coordenados. Por exemplo, os ligantes aromáticos n-heterocíclicos livres, ou não coordenados, geralmente apresentam, na região do ultravioleta próximo e médio, bandas de transição eletrônica atribuídas a $n \rightarrow \pi^{*}$ e $\pi \rightarrow \pi^{*}$. As transições envolvendo os elétrons livres (n) ocorrem em regiões de maior comprimento de onda e são relativamente fracas. As transições envolvendo os elétrons $\pi$ são bastante intensas, uma vez que são muito semelhantes às observadas para os hidrocarbonetos aromáticos correspondentes.

Nos espectros de UV-visível dos complexos cis/trans$\left[\mathrm{RuCl}(\mathrm{bpy})_{2}(\mathrm{NO})\right]^{2+}$, não foi possível visualizar as bandas de campo ligante. Provavelmente, essa limitação seja devida à baixa intensidade ou à alta energia de tais transições eletrônicas. Assim, a discussão a seguir é pertinente às bandas originadas por IL e TCML.

\subsubsection{Complexos $\left[\mathrm{RuCl}(\mathrm{bpy})_{2}(\mathrm{NO})\right]\left(\mathrm{PF}_{6}\right)_{2}$}

Para explicar as bandas do espectro na região do UV-visível do complexo cis-[RuCl(bpy $\left.)_{2}(\mathrm{NO})\right]\left(\mathrm{PF}_{6}\right)_{2}$, seu espectro foi comparado ao do complexo cis-[ $\left[\mathrm{RuCl}_{2}(\mathrm{bpy})_{2}\right]$, cujo comportamento foi estudado por Meyer e colaboradores (BRADDOCK \& MEYER, 1973; JOHNSON et al., 1978).

As bandas nas regiões de $380 \mathrm{~nm}$ e $550 \mathrm{~nm}$ foram atribuídas à TCML, e as bandas na região do ultravioleta foram atribuídas à IL.

A comparação dos espectros do complexo cis$\left[\mathrm{RuCl}(\mathrm{bpy})_{2}(\mathrm{NO})\right]\left(\mathrm{PF}_{6}\right)_{2}$ (Figura 21) e do complexo cis-[ $\left[\mathrm{RuCl}_{2}(\mathrm{bpy})_{2}\right]$ 
(Figura 22) mostra o desaparecimento das bandas na região do visível, provavelmente isso ocorra devido à estabilização dos orbitais $\mathrm{d}_{\pi}$ do metal face à interação com o ligante nitrosilo.

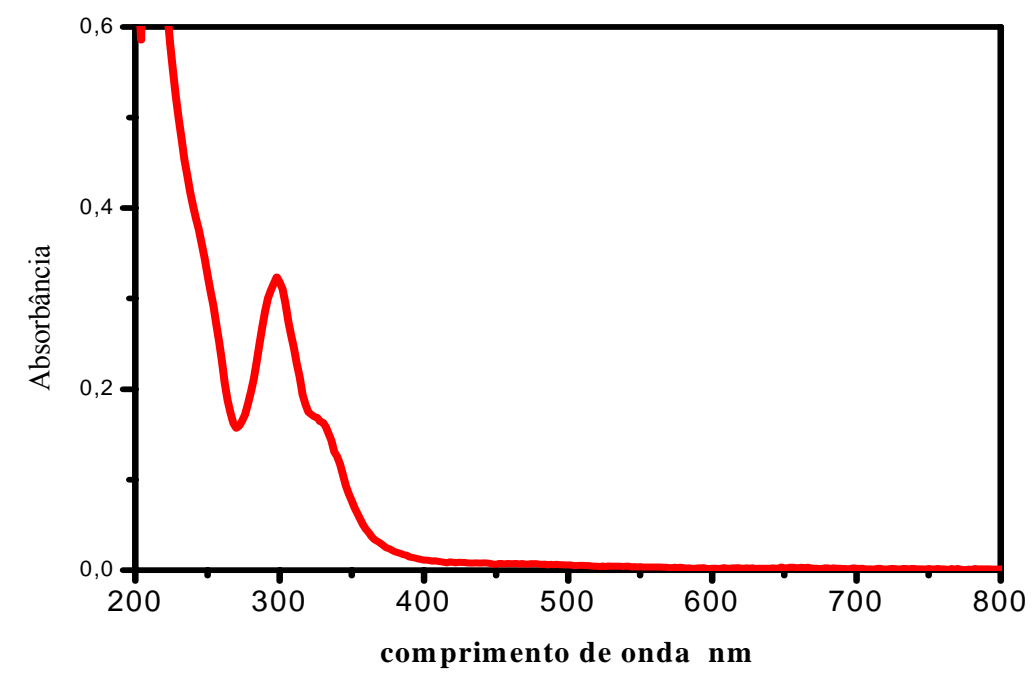

Figura 21: Espectro na região do UV-visível, em $\mathrm{HCl}$ 0,10 mol.L ${ }^{-1}$, do complexo cis- $\left[\mathrm{RuCl}(\mathrm{bpy})_{2}(\mathrm{NO})\right]\left(\mathrm{PF}_{6}\right)_{2}$. [complexo] $=6,30 \times 10^{-5}$ mol. $\mathrm{L}^{-1}$.

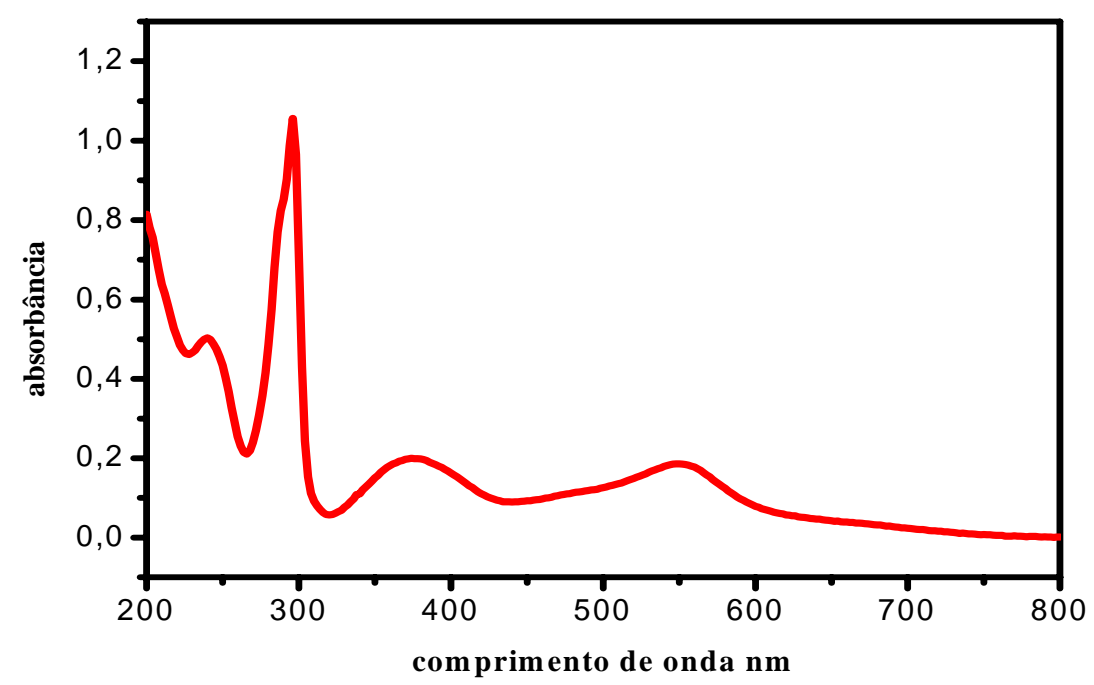

Figura 22:Espectro na região do UV-visível, em $\mathrm{HCl}$ 0,10 mol. $\mathrm{L}^{-1}$, do complexo cis-[ $\left.\mathrm{RuCl}_{2}(\mathrm{bpy})_{2}\right] .2 \quad \mathrm{H}_{2} \mathrm{O}$. [complexo] $=6,30 \times 10^{-5}$ mol. $L^{-1}$. 
$\mathrm{O}$ espectro do complexo cis-[RuCl(bpy $\left.)_{2}(\mathrm{NO})\right]\left(\mathrm{PF}_{6}\right)_{2}$ em meio aquoso apresenta uma banda em $298 \mathrm{~nm}$ e um ombro em $332 \mathrm{~nm}$. A banda em $298 \mathrm{~nm}$ foi atribuída à transição intraligante $\left(\pi \rightarrow \pi^{*}\right)$, que também é observada tanto no ligante livre como no espectro de seu precursor cis$\left[\mathrm{RuCl}_{2}(\text { bpy })_{2}\right]$ (Figura 22). O ombro na região de $332 \mathrm{~nm}$ foi atribuído à transferência de carga metal ligante (TCML), devido à transição $\mathrm{d}_{\pi}\left(\mathrm{Ru}^{\mathrm{II}}\right) \rightarrow \pi^{*}(\mathrm{NO})$ e $\mathrm{d}_{\pi}\left(\mathrm{Ru}^{\mathrm{II}}\right) \rightarrow \pi^{*}($ bpy $)$. Essa atribuição pôde ser feita baseando-se nos resultados de aquação do ligante NO no complexo cis$\left[\mathrm{RuCl}(\mathrm{bpy})_{2}(\mathrm{NO})\right]^{2+}$ originada durante sua fotólise e durante sua redução química, situações em que há a liberação do ligante $\mathrm{NO}$ e $\mathrm{o}$ desaparecimento do ombro em $332 \mathrm{~nm}$ (TOGNIOLO, 2001).

Semelhante análise espectroscópica foi feita com o complexo trans$\left[\mathrm{RuCl}(\mathrm{bpy})_{2}(\mathrm{NO})\right]\left(\mathrm{PF}_{6}\right)_{2} \quad($ Figura 23) e com seu precursor trans$\left[\mathrm{RuCl}_{2}(\text { bpy })_{2}\right]$ (Figura 24). As atribuições da natureza das bandas espectroscópicas para o complexo nitrosilo, por analogia ao composto cis$\left[\mathrm{RuCl}_{2}(\mathrm{bpy})_{2}\right]^{2+}$, foi tomado como sendo TCML para a banda em $334 \mathrm{~nm}$ e IL para a banda em $292 \mathrm{~nm}$.

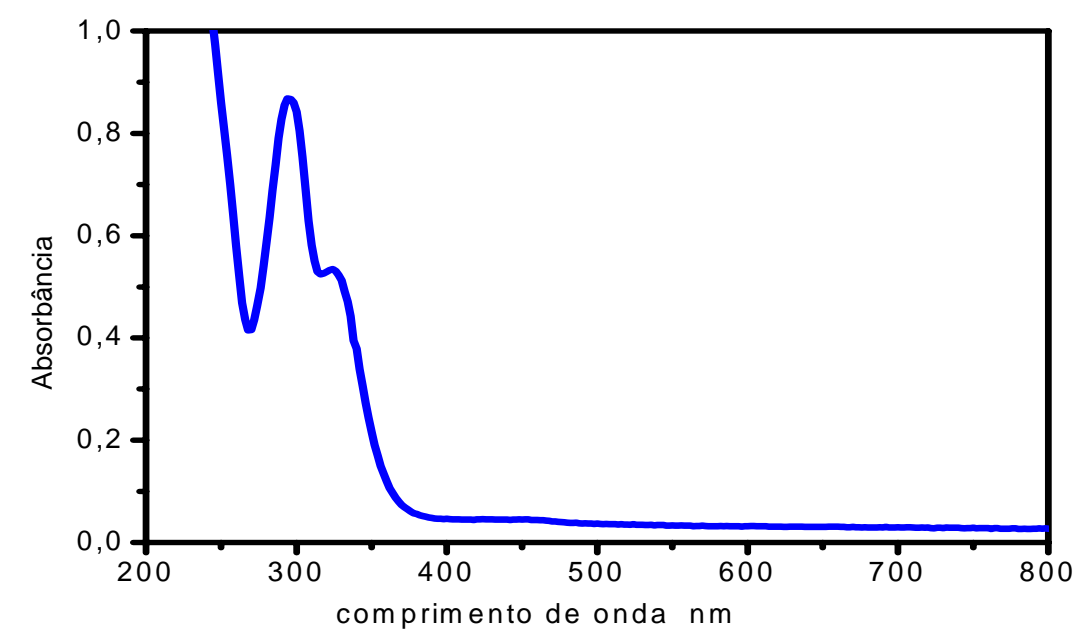

Figura 23: Espectro na região do UV-visível, em $\mathrm{HCl} \mathrm{0,10} \mathrm{mol.} \mathrm{L}^{-1}$, do complexo trans-[RuCl(bpy $\left.)_{2}(\mathrm{NO})\right]\left(\mathrm{PF}_{6}\right)_{2} \cdot[$ complexo $]=6,30 \times$ $10^{-5}$ mol. L ${ }^{-1}$ 


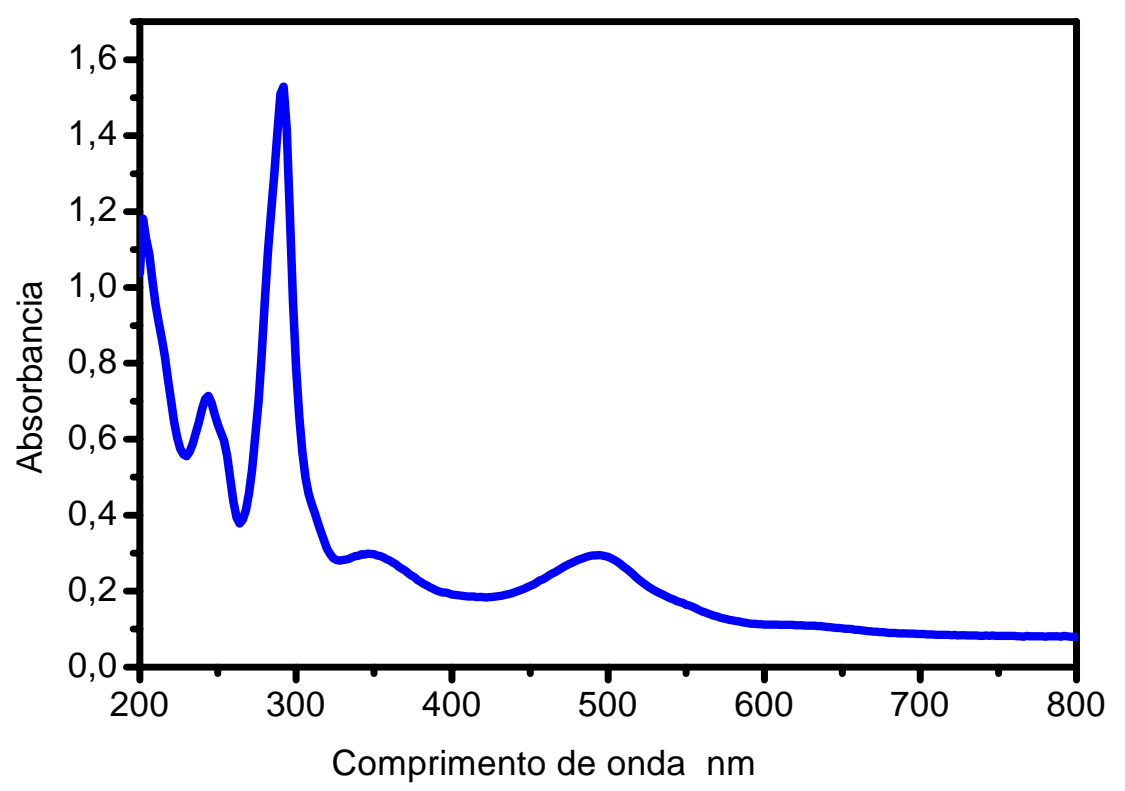

Figura 24: Espectro na região do UV-visível, em $\mathrm{HCl} 0,10$ mol. $\mathrm{L}^{-1}$, do complexo trans- $\left[\mathrm{RuCl}_{2}(\text { bpy })_{2}\right] \cdot 2 \mathrm{H}_{2} \mathrm{O}$. [complexo] $=6,30 \times 10^{-5}$ mol. $\mathrm{L}^{-1}$.

Os dados espectrofotométricos dos compostos nitrosilos estudados na região do UV-visível estão relatados na Tabela 4.

Tabela 4: Resultados de análise de espectros na região do UV-visível para os complexos de rutênio em solução de $\mathrm{HCl} 0,1$ mol. $\mathrm{L}^{-1} \mathrm{e}$ acetonitrila (ACN).

\begin{tabular}{c|l|l}
\hline Complexo & $\lambda(\mathrm{nm}),(\log \varepsilon)$ em ACN & $\lambda(\mathrm{nm}),(\log \varepsilon) \mathrm{em}_{2} \mathrm{O}$ \\
\hline $\mathbf{A}$ & $298(4,29), 332(3,97)(\mathrm{sh})^{\mathrm{a}}$ & $294(4,08), 334(3,67)(\mathrm{sh})^{\mathrm{a}}$ \\
\hline $\mathbf{B}$ & $296(4,37), 324(4,28)(\mathrm{sh})^{\mathrm{a}}$ & $294(3,88), 324(3,67)(\mathrm{sh})^{\mathrm{a}}$ \\
\hline $\mathbf{A}=$ cis-[RuCl$\left.(\mathrm{bpy})_{2}(\mathrm{NO})\right]\left(\mathrm{PF}_{6}\right)_{2}$ \\
$\mathbf{B}=$ trans-[RuCl(bpy $\left.)_{2}(\mathrm{NO})\right]\left(\mathrm{PF}_{6}\right)_{2}$ \\
$(\mathrm{sh})^{\mathrm{a}}=$ ombro
\end{tabular}




\subsection{Espectroscopia na região do Infravermelho}

No estudo de complexos nitrosilos, a espectroscopia na região do infravermelho é muito útil para verificar a coordenação de $\mathrm{NO}^{+}$ao íon metálico rutênio(II). Este ligante, quando coordenado ao rutênio, geralmente apresenta uma banda de intensa absorção na região de 1800 a $1970 \mathrm{~cm}^{-1}$ (FORD et al., 1998; BATISTA et al., 1997; SCHRÖDER \& STEPHENSON, 1987). A variação da freqüência de estiramento $v(\mathrm{NO})$ em compostos de coordenação depende do metal, do estado de oxidação do ligante nitrosilo e da estereoquímica do ligante NO.

Em relação à estereoquímica, alguns resultados empíricos de energia de estiramento sugerem distinção da ligação $\mathrm{N} \equiv \mathrm{O}$ como sendo linear ou "bent". Apesar de alguns trabalhos explorarem a variação da energia de estiramento do NO em função da estereoquímica, essa relação deve ser feita com cautela, haja vista que as freqüências de estiramento se sobrepõem em algumas regiões, conforme ilustrado na Figura 25 (RICHTER-ADDO \& LEGZDINS, 1992).

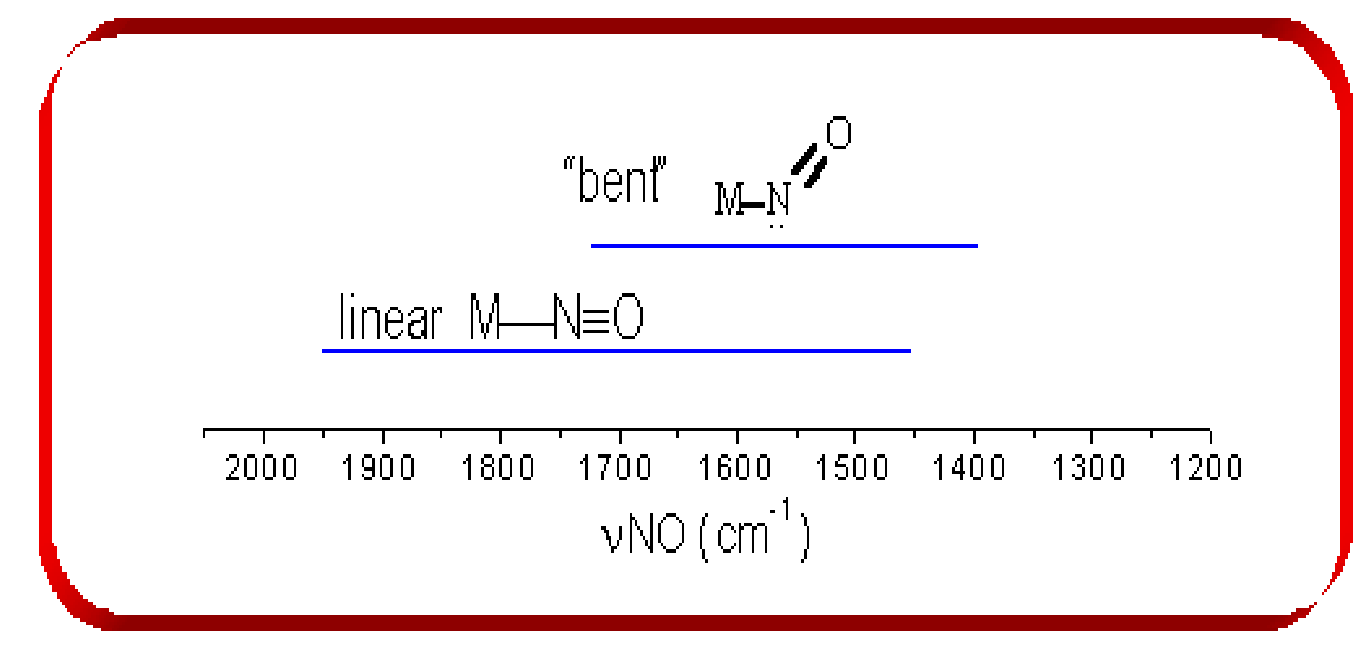

Figura 25: Intervalos típicos de freqüência de estiramento na região do infravermelho para complexos metálicos nitrosilos. 
Para as espécies estudadas neste trabalho, a banda de estiramento do NO em espectro na região do infravermelho surge na região de $1910 \mathrm{~cm}^{-1}$ nas amostras obtidas em pastilha de $\mathrm{KBr}$ ( Figuras 26 e 27).

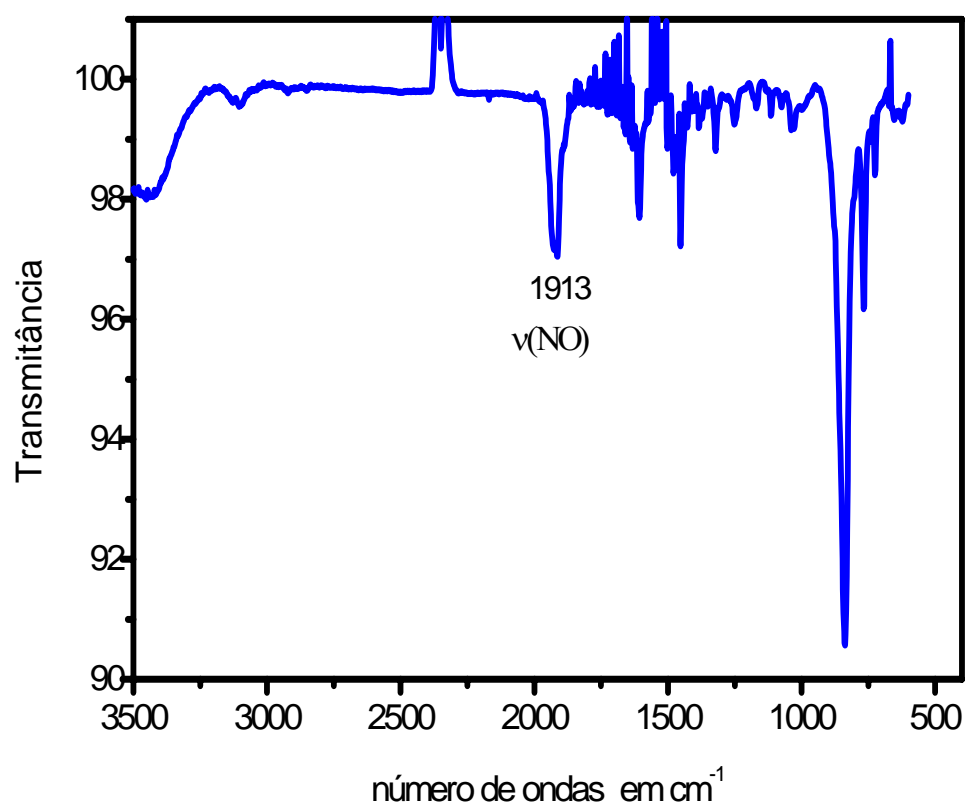

Figura 26: Espectro na região do infravermelho, em pastilha de $\mathrm{KBr}$, do complexo trans-[RuCl(bpy $\left.)_{2}(\mathrm{NO})\right]\left(\mathrm{PF}_{6}\right)_{2}$.

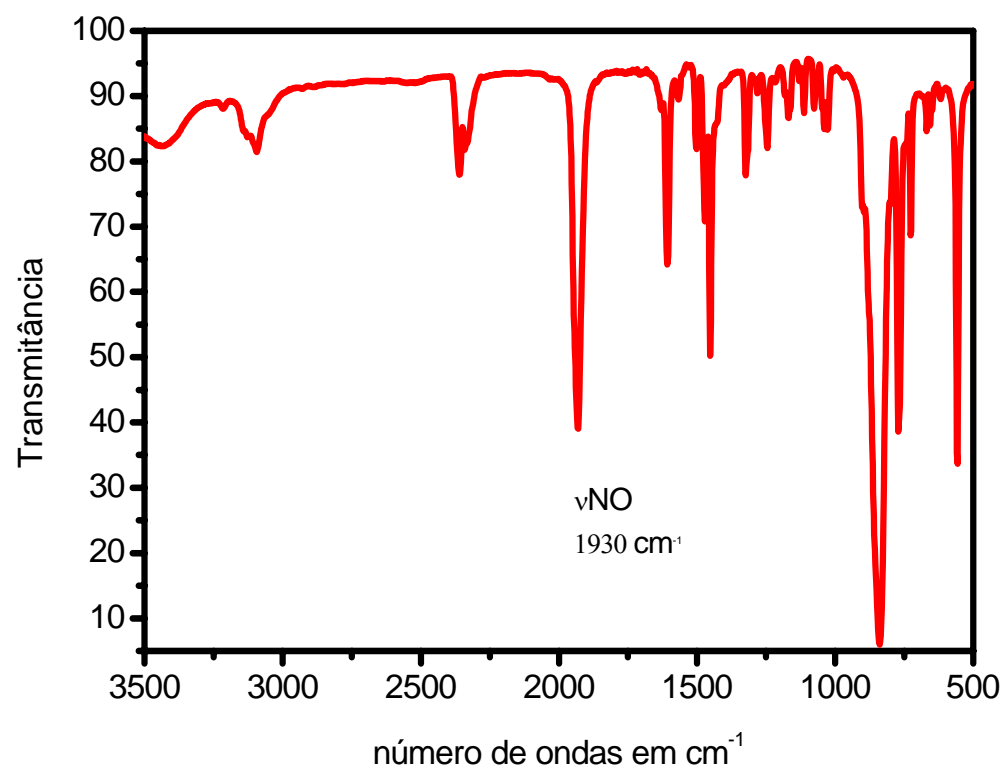

Figura 27: Espectro na região do infravermelho, em pastilha de $\mathrm{KBr}$, do complexo cis-[RuCl(bpy $\left.)_{2}(\mathrm{NO})\right]\left(\mathrm{PF}_{6}\right)_{2}$. 
A banda de estiramento do ligante nitrosil no complexo trans$\left[\mathrm{RuCl}(\mathrm{bpy})_{2}(\mathrm{NO})\right]\left(\mathrm{PF}_{6}\right)_{2}$ em menor energia do que aquela observada para cis-[RuCl(bpy $\left.)_{2}(\mathrm{NO})\right]\left(\mathrm{PF}_{6}\right)_{2}$ é consistente com o efeito sinergístico ocasionado pelo ligante cloreto em posição trans ao ligante nitrosil. Embora o íon metálico central seja Ru(II), a densidade eletrônica sobre este é muito influenciada pelos co-ligantes $\pi$-receptores bipiridina. Desta forma, pode-se inferir que a carga formal sob o íon metálico é maior que "2". Como o ligante cloreto é $\pi$-doador e levando-se em conta que os orbitais que interagem com o ligante $\mathrm{NO}^{+}$são os mesmos (Figura 28), a explicação do efeito sinergístico é coerente com o resultado de espectroscopia na região do infravermelho. Neste caso, o complexo cis$\left[\mathrm{RuCl}(\mathrm{bpy})_{2}(\mathrm{NO})\right]\left(\mathrm{PF}_{6}\right)_{2}$ sofreria um efeito sinergístico muito menor, o que justificaria uma energia de estiramento maior para o $\mathrm{NO}^{+}$em comparação ao complexo trans-[RuCl(bpy $\left.)_{2}(\mathrm{NO})\right]\left(\mathrm{PF}_{6}\right)_{2}$.

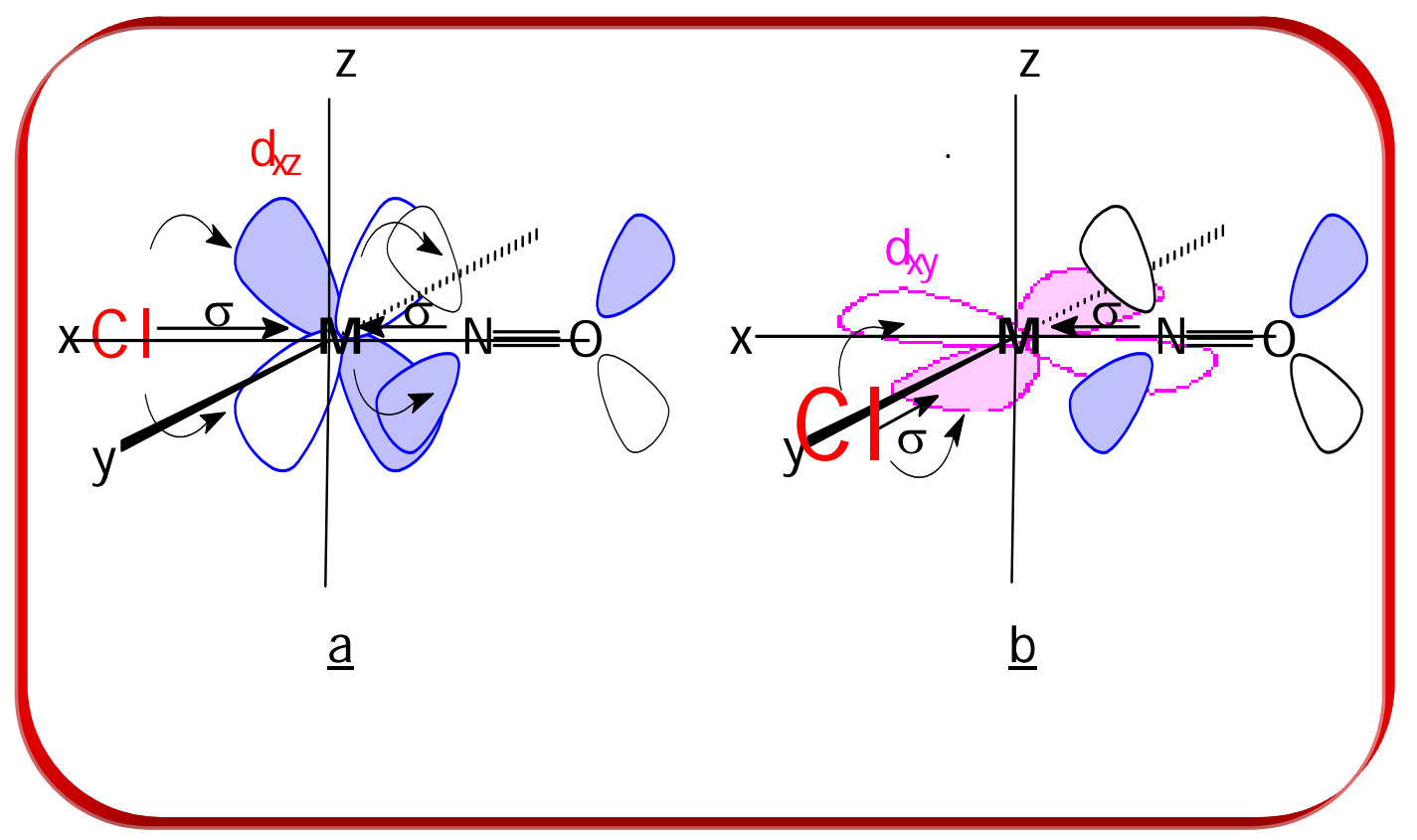

Figura 28: Influência da posição do ligante L na energia de estiramento do ligante nitrosil. a) posição trans e b) posição cis. 
Alguns autores mostraram que a influência do ligante na energia de estiramento do NO é maior quando eles estão em posição trans (NAGAO et al., 1989; TOGANO et al., 1992). Isso ocorre porque o ligante em posição trans influencia diretamente os orbitais "d" do metal, que fazem a retro-doação com o NO, enquanto que o ligante em posição cis interage com o outro orbital "d" do metal, diferente daquele diretamente responsável pela retro-doação para o NO (Figura 28).

De fato, a freqüência de estiramento na região do infravermelho, para complexos cuja simetria é trans, cresce quase linearmente em função da somatória do parâmetro de LEVER ( $\left.\mathrm{E}_{\mathrm{L}}\right)$ (LEVER, 1990), como mostram os gráficos da Figura 29. Esses gráficos foram construídos com base no estudo feito por BORGES et al. (1998) para a série trans-[Ru( $\left.\left.\mathrm{NH}_{3}\right)_{4} \mathrm{~L}(\mathrm{NO})\right]^{3+}$ e no trabalho de TOGANO et al. (1992) para a série trans-[RuL(py) $\left.{ }_{4}(\mathrm{NO})\right]^{\mathrm{n}+}$.

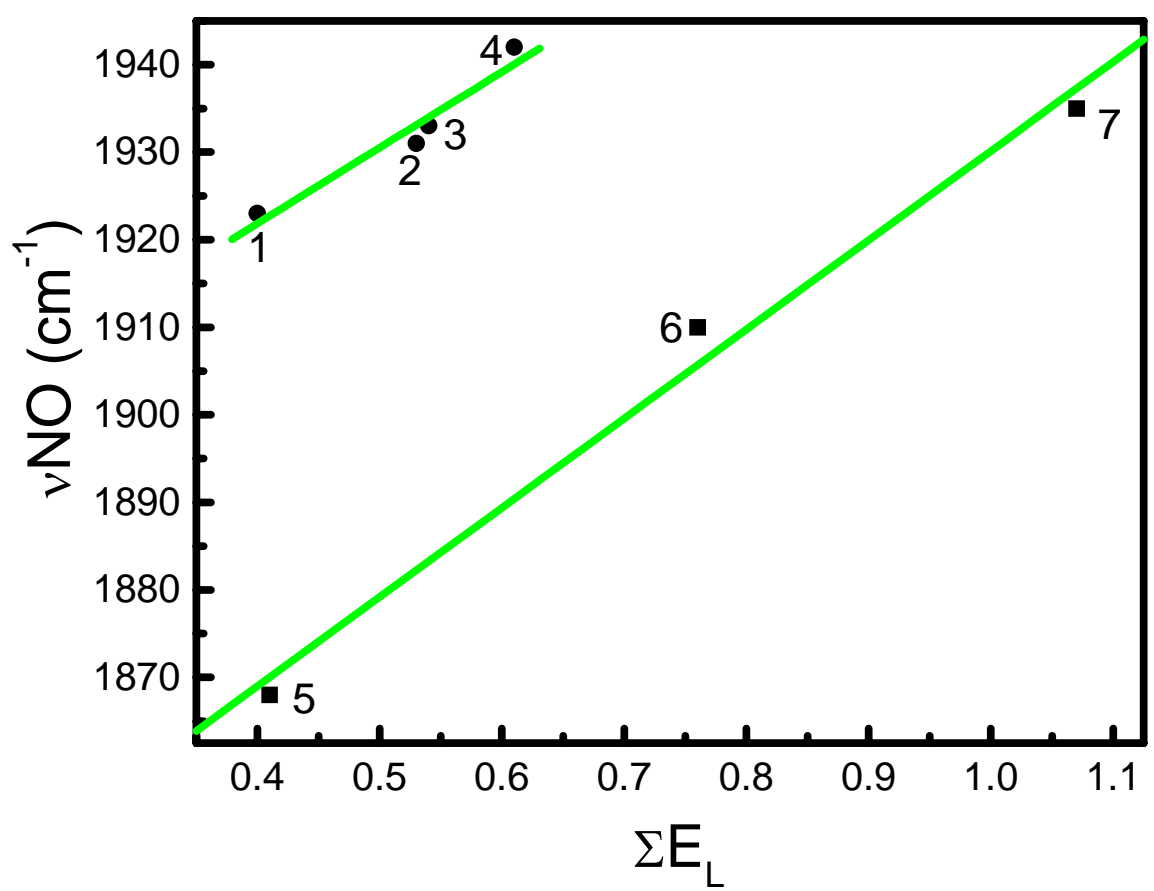

Figura 29: Variação de $v \mathrm{NO}$ em função de $\Sigma \mathrm{E}_{\mathrm{L}}$ para complexos de rutênio de simetria trans. 1) $\mathrm{L}=\mathrm{imN}$, 2) $\mathrm{L}=\mathrm{py}$, 3) $\mathrm{L}=$ isc e 4) $\mathrm{L}=\mathrm{pz}$ para a série trans- $\left[\mathrm{Ru}\left(\mathrm{NH}_{3}\right)_{4} \mathrm{~L}(\mathrm{NO})\right]^{3+}$. 5) $\left.\mathrm{L}=\mathrm{OH}^{-}, 6\right) \mathrm{L}=\mathrm{Cl}^{-} \mathrm{e}$ 7) $\mathrm{L}=\mathrm{NH}_{3}$ para a série trans- $\left[\mathrm{RuL}(\mathrm{py})_{4}(\mathrm{NO})\right]^{\mathrm{n}+}$. 
O parâmetro de LEVER (1990) relaciona o efeito que cada ligante exerce na densidade eletrônica do íon metálico. Para os complexos cuja simetria é cis não ocorrem a mesma variação de energia de estiramento em relação à somatória desse parâmetro. Pode-se ter como exemplo os complexos da série cis-[RuL(bpy) $2(\mathrm{NO})]^{\mathrm{n}+}$, estudados por CALLAHAN \& MEYER (1977), cujos valores de freqüência de estiramento estão relatados na Tabela 5. Comparando-se os valores extremos (quando $\mathrm{L}=\mathrm{Cl}^{-}$e py), obtém-se somente uma diferença da ordem de $13 \mathrm{~cm}^{-1}$, enquanto que a diferença de $\Sigma \mathrm{E}_{\mathrm{L}}$ é da ordem de 0,49 .

Tabela 5: Energia vibracional do $\mathrm{NO}^{+}$em complexos do tipo cis$\left[\mathrm{RuL}(\mathrm{bpy})_{2}(\mathrm{NO})\right]^{\mathrm{n}+}(\mathrm{CALLAHAN} \&$ MEYER, 1977).

\begin{tabular}{c|c|c}
\hline $\mathrm{L}$ & $\begin{array}{c}v \mathrm{NO}\left(\mathrm{cm}^{-1}\right) \\
\text { Em acetonitrila }\end{array}$ & $\Sigma \mathrm{E}_{\mathrm{L}}$ \\
\hline $\mathrm{Cl}^{-}$ & 1940 & 0,78 \\
$\mathrm{NO}_{2}^{-}$ & 1948 & 1,07 \\
$\mathrm{NH}_{3}$ & 1950 & 1,11 \\
$\mathrm{Py}$ & 1953 & 1,27 \\
\hline
\end{tabular}

Assim, os resultados observados mostram claramente que o posicionamento do ligante $\mathrm{L}$ em relação ao grupo nitrosil influencia no valor de sua energia de estiramento. Em complexos do tipo trans$\left[\mathrm{Ru}\left(\mathrm{N}_{4}\right)(\mathrm{NO})\right]^{\mathrm{nt}}$ em que $\mathrm{N}$ é $\mathrm{NH}_{3}$ ou py, a $v(\mathrm{NO})$ geralmente aumenta com o aumento do caráter eletrofílico do NO (Figura 29), porém, o mesmo não se observa para os complexos de geometria cis do tipo $\left[\mathrm{RuL}(\mathrm{bpy})_{2}(\mathrm{NO})\right]^{\mathrm{n}+}$, em que L é ligante derivado piridínico.

Toda essa discussão pode ser tomada como subsídio para a explicação relacionada com a variação de vNO nos complexos cis/trans$\left[\mathrm{RuCl}(\text { bpy })_{2}(\mathrm{NO})\right]\left(\mathrm{PF}_{6}\right)_{2}$ relatado anteriormente, ou seja: a variação 
espectral depende fundamentalmente dos orbitais envolvidos com os coligantes $\mathrm{Cl}^{-}$e $\mathrm{NO}^{+}$.

\subsection{Comportamento voltamétrico em meio não aquoso}

O comportamento voltamétrico para os complexos sintetizados no presente trabalho foi estudado em solução de acetonitrila contendo hexafluorofosfato de tetrabutilamônio (TBAH) como eletrólito de suporte, utilizando-se eletrodo de platina como eletrodo de trabalho. Com base na literatura (DEB et al., 1988; NAGAO et al., 1989) espera-se, a princípio, que os complexos apresentem um comportamento eletroquímico, na janela de potencial do solvente, centrado no ligante nitrosilo conforme representado no Esquema 7.

$$
\begin{aligned}
& {\left[\mathrm{L}(\mathrm{bpy})_{2} \mathrm{Ru}^{\mathrm{II}}-\mathrm{NO}\right] \stackrel{+}{\stackrel{+\mathrm{e}}{\rightleftharpoons}}\left[\mathrm{L}(\mathrm{bpy})_{2} \mathrm{Ru}^{\mathrm{II}}-\mathrm{NO}^{0}\right]} \\
& {\left[\mathrm{L}(\mathrm{bpy})_{2} \mathrm{Ru}^{\mathrm{II}}-\mathrm{NO}^{0}\right] \stackrel{+\mathrm{e}}{\stackrel{-\mathrm{e}}{\rightleftharpoons}}\left[\mathrm{L}(\mathrm{bpy})_{2} \mathrm{Ru}^{\mathrm{II}}-\mathrm{NO}^{-}\right]}
\end{aligned}
$$

Esquema 7: Processos eletroquímicos centrados no ligante nitrosil para complexos do tipo $\left[\mathrm{RuL}(\mathrm{bpy})_{2}(\mathrm{NO})\right]^{\mathrm{n}+}$.

Na região de potencial entre 1,00 a $-1,20 \mathrm{~V}$ vs. $\mathrm{Fc}^{+/ 0}$ observa-se dois picos catódicos (picos 1c e 2c). O pico 1c ocorre em potencial na região de $0,13 \mathrm{~V}$ vs. $\mathrm{Fc}^{+/ 0}$ e apresenta um pico anódico na varredura reversa de potencial (1a). A corrente do primeiro pico catódico aumenta linearmente com o aumento de $\mathrm{v}^{1 / 2}$, indicando que a corrente de pico é controlada por difusão. 
A razão entre os valores de corrente de pico catódico e anódico $\left(\mathrm{I}_{\mathrm{pa}} / \mathrm{I}_{\mathrm{pc}}\right)$ é próxima à unidade em praticamente todo o intervalo de velocidade de varredura investigado.

Esses resultados são indicativos de que a primeira etapa de redução do complexo ocorre através da transferência reversível de 1 elétron. A segunda etapa de redução do complexo em acetonitrila ocorre em potencial mais negativo (na região de $-0,70 \mathrm{~V}$ vs. $\mathrm{Fc}^{+/ 0}$ ) e não apresenta nenhum pico na varredura reversa de potencial, sugerindo comportamento de processo de transferência de carga irreversível ou reação rápida subseqüente à transferência eletrônica, que consome o produto eletrogerado.

A intensidade de corrente de pico catódico para ambos os picos são semelhantes, indicando que provavelmente a segunda etapa de redução envolve também transferência de 1 elétron.

Foram realizados voltamogramas cíclicos para os complexos cis e trans-[RuCl(bpy $\left.)_{2}(\mathrm{NO})\right]\left(\mathrm{PF}_{6}\right)_{2}$, os quais se comportaram de modo semelhante. Nas Figuras 30 e 31 estão representados os voltamogramas cíclicos, respectivamente, para os compostos cis-[RuCl(bpy $\left.)_{2}(\mathrm{NO})\right]\left(\mathrm{PF}_{6}\right)_{2} \mathrm{e}$ trans-[RuCl(bpy $\left.)_{2}(\mathrm{NO})\right]\left(\mathrm{PF}_{6}\right) 2$. Os mesmos foram iniciados em $+0,81 \mathrm{~V}$ vs $\mathrm{Fc}^{+/ 0}$, conduzidos para potencial negativo, revertidos em $-1,12 \mathrm{~V} \mathrm{vs} \mathrm{Fc}^{+/ 0} \mathrm{e}$ conduzido novamente para potencial positivo até atingirem $+0,81 \mathrm{~V}$ vs $\mathrm{Fc}^{+/ 0}$. 


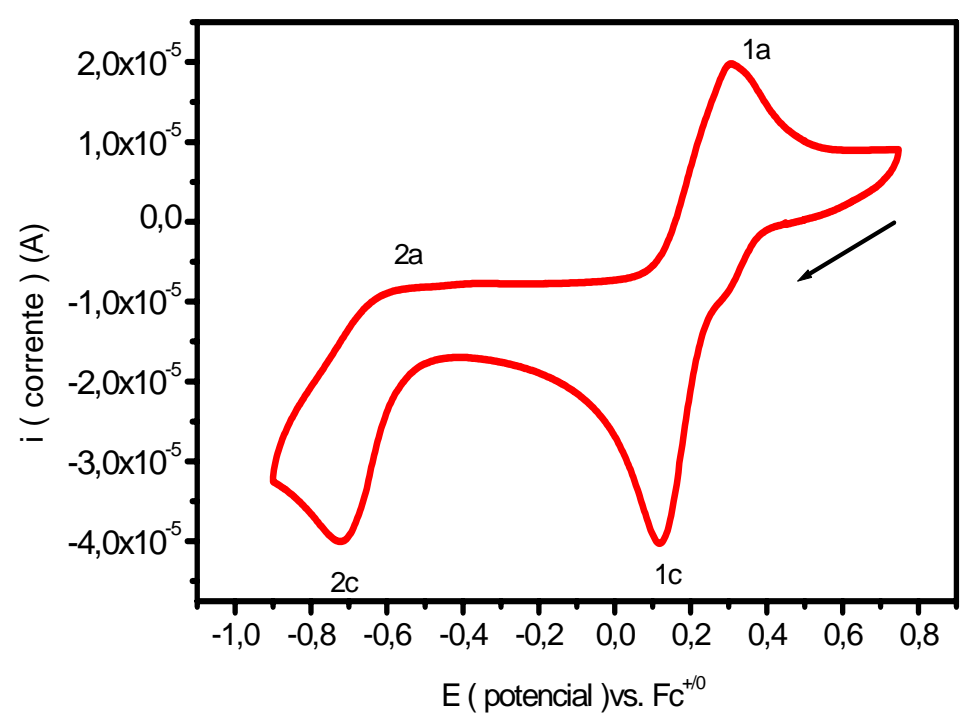

Figura 30: Voltamograma cíclico do complexo cis-[RuCl(bpy $\left.)_{2}(\mathrm{NO})\right]\left(\mathrm{PF}_{6}\right)_{2}$ em acetonitrila. Eletrólito de suporte: TBAH 0,10 mol. $\mathrm{L}^{-1}$. Potencial de reversão: $-1,12 \mathrm{~V}$ vs $\mathrm{Fc}^{+/ 0}$. [complexo] $=6,50 \mathrm{x}$ $10^{-5} \mathrm{~mol} . \mathrm{L}^{-1} . ; \mathrm{v}=100 \mathrm{mV} / \mathrm{s} . \mathrm{T}=25^{\circ} \mathrm{C}$

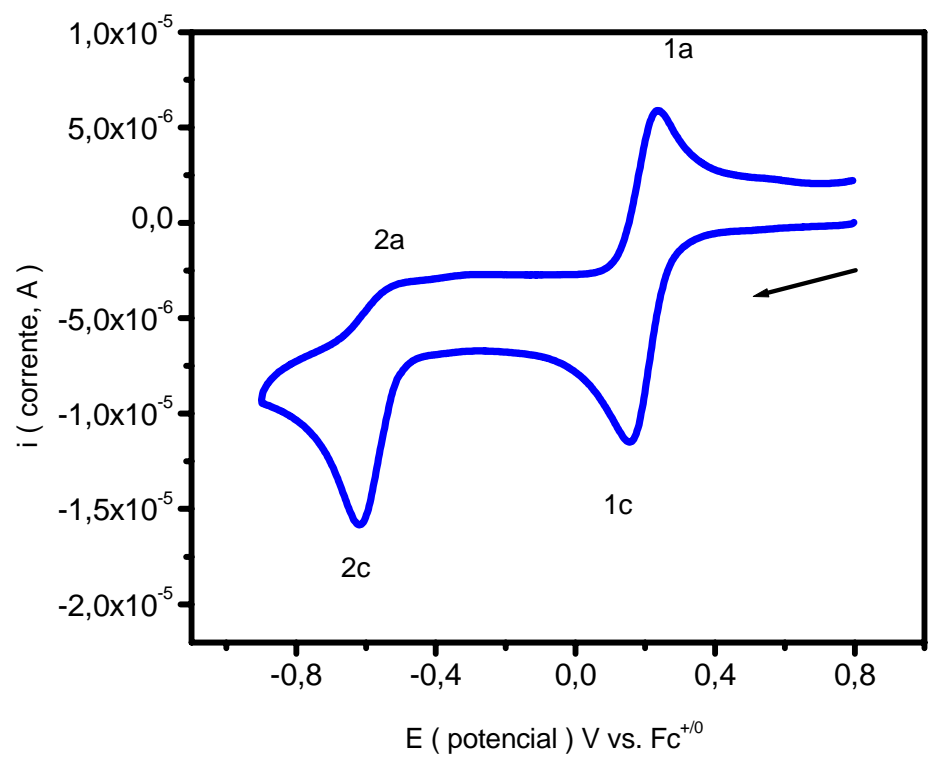

Figura 31: Voltamograma cíclico do complexo, em acetonitrila, trans $\left[\mathrm{RuCl}(\mathrm{bpy})_{2}(\mathrm{NO})\right]\left(\mathrm{PF}_{6}\right)_{2}$. Eletrólito de suporte: TBAH 0,1mol.L1. Potencial de reversão: $-1,12 \mathrm{~V}$ vs $\mathrm{Fc}^{+/ 0}$. [complexo] $=6,50 \mathrm{x}$ $10^{-5} \mathrm{~mol} \cdot \mathrm{L}^{-1} \cdot \mathrm{v}=100 \mathrm{mV} / \mathrm{s} . \mathrm{T}=25^{\circ} \mathrm{C}$. 
$\mathrm{O}$ voltamograma cíclico do complexo cis-[RuCl(bpy $\left.)_{2}(\mathrm{NO})\right]\left(\mathrm{PF}_{6}\right)_{2}$ (Figura 30) exibe uma onda catódica (1c), juntamente com uma onda anódica (1a) na varredura reversa, em torno de $+0,13 \mathrm{~V}$ vs $\mathrm{Fc}^{+/ 0}$. Esse processo ocorre conforme o esperado e por analogia a outras espécies (DEB et al., 1988; NAGAO et al., 1989) pode ser atribuído à oxi-redução do grupo nitrosil. Por analogia, atribui-se o mesmo processo eletroquímico para o complexo trans-[RuCl(bpy $\left.)_{2}(\mathrm{NO})\right]\left(\mathrm{PF}_{6}\right)_{2}$ (Figura 31); ou seja: o potencial com $\mathrm{E}_{1 / 2}$ em $0,195 \mathrm{~V}_{\text {vs }} \mathrm{Fc}^{+/ 0}$ se deve à redução do ligante $\mathrm{NO}^{+}$ para $\mathrm{NO}^{0}$, conforme Equação 3:

$\left[\mathrm{RuL}(\mathrm{bpy})_{2}\left(\mathrm{NO}^{+}\right)\right]^{\mathrm{n}^{+} \stackrel{+\mathrm{e}^{-}}{\rightleftharpoons}[\mathrm{e}}\left[\mathrm{RuL}(\mathrm{bpy})_{2}\left(\mathrm{NO}^{0}\right)\right]^{(\mathrm{n}-1)^{+}}$

Equação 3: Equação da reação de oxi-redução do grupo nitrosil, referente ao processo eletroquímico 1a/1c, em acetonitrila.

Para estudar a reversibilidade desse processo eletroquímico, foram feitos vários voltamogramas cíclicos em diferentes velocidades (Figuras 32 e 34), os quais foram iniciados em $+0,81 \mathrm{~V} \mathrm{vs} \mathrm{Fc}^{+/ 0}$, conduzidos para potenciais negativos, revertidos em $-0,30 \mathrm{~V}$ vs $\mathrm{Fc}^{+/ 0}$ e conduzidos para potenciais positivos até atingir $+0,81 \mathrm{~V}_{\mathrm{vs} \mathrm{Fc}}{ }^{+/ 0}$, novamente.

De acordo com os critérios de NICHOLSON \& SHAIN (1965), esse processo eletroquímico pode ser denominado reversível, para velocidades de varredura maiores que $50 \mathrm{mV} / \mathrm{s}$. A razão de corrente de pico $I_{p a} / I_{p c}$ é muito próxima à unidade, quando o potencial é revertido em, no mínimo, $0,035 \mathrm{~V}$ após a onda catódica.

Além disso, $I_{p c}$ aumenta linearmente com o aumento da raiz quadrada da velocidade de varredura ( $\mathrm{v}^{1 / 2}$ ) (Figuras 33 e 35), e o valor da 
diferença de potencial $\left(\Delta \mathrm{E}_{\mathrm{p}}\right)$ é independente da velocidade de varredura (Tabelas 6 e 7).

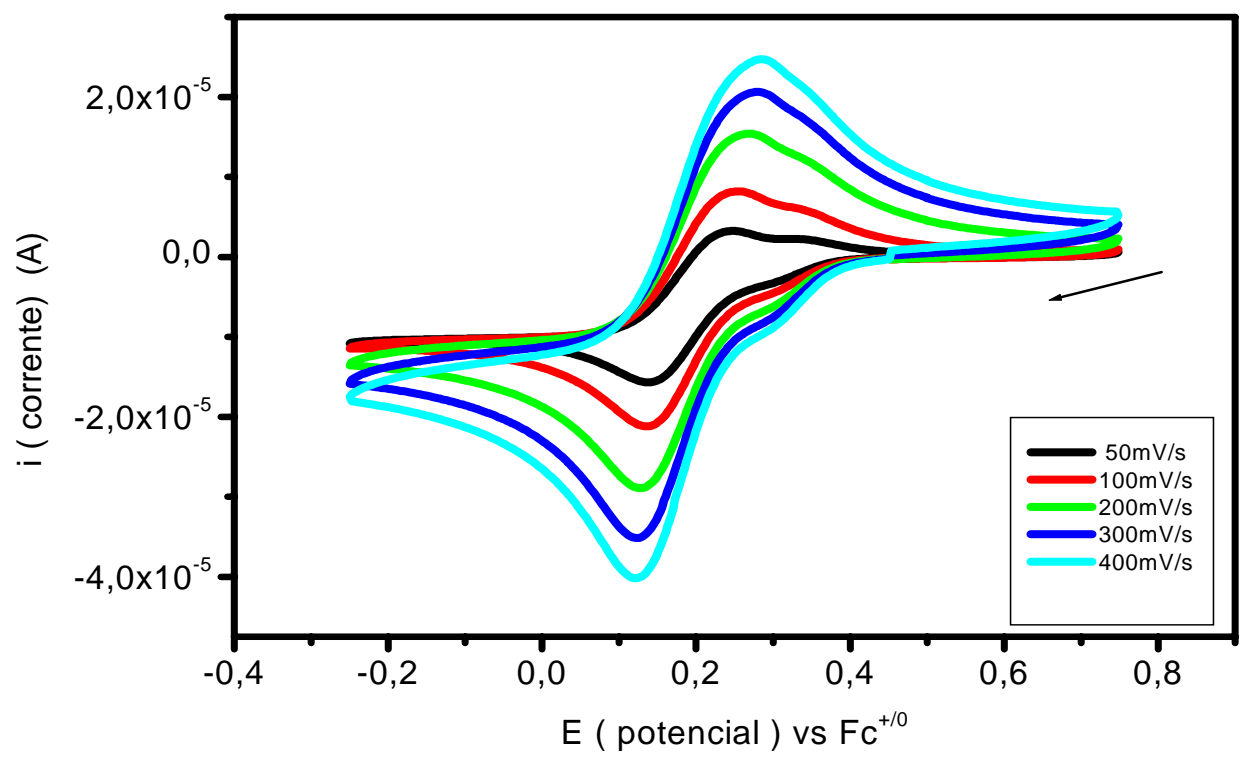

Figura 32: Voltamogramas cíclicos do complexo cis

$\left[\mathrm{RuCl}(\mathrm{bpy})_{2}(\mathrm{NO})\right]\left(\mathrm{PF}_{6}\right)_{2}$ em acetonitrila Eletrólito suporte: TBAH 0,10 mol. $\mathrm{L}^{-1}$ [complexo] $=1,00 \times 10^{-4} \mathrm{~mol} . \mathrm{L}^{-1}$. Velocidades de varredura $(\mathrm{mV} / \mathrm{s}): 50,100,200,300$ e $400 . \mathrm{T}=25^{\circ} \mathrm{C}$.

Tabela 6: Parâmetros eletroquímicos, em acetonitrila, para o complexo cis$\left[\mathrm{RuCl}(\mathrm{bpy})_{2}(\mathrm{NO})\right]\left(\mathrm{PF}_{6}\right)_{2} . \mathrm{T}=25^{\circ} \mathrm{C} . \mathrm{E}(\mathrm{V}$ vs Ag/AgCl$)$.

\begin{tabular}{c|c|c|c|c|c}
\hline $\mathrm{v}(\mathrm{mV} / \mathrm{s})$ & $\begin{array}{c}\text { Ipc } \\
(\mathrm{A}) \times 10^{+6}\end{array}$ & $\begin{array}{c}\text { Ipa } \\
(\mathrm{A}) \times 10^{+6}\end{array}$ & $\begin{array}{c}\text { Isp } \\
(\mathrm{A}) \times 10^{+6}\end{array}$ & $\Delta \mathrm{Ep}$ & $\mathrm{Ipa} / \mathrm{Ipc}$ \\
\hline 20 & 4,34 & 1,41 & 3,24 & 71,1 & 0,77 \\
\hline 50 & 6,50 & 3,23 & 3,55 & 70,2 & 0,84 \\
\hline 100 & 8,69 & 5,28 & 4,09 & 75,1 & 0,92 \\
\hline 200 & 12,5 & 8,83 & 5,51 & 77,2 & 1,00 \\
\hline 300 & 15,4 & 11,3 & 6,73 & 79,4 & 1,02 \\
\hline 400 & 17,9 & 13,2 & 7,89 & 79,4 & 1,03 \\
\hline
\end{tabular}




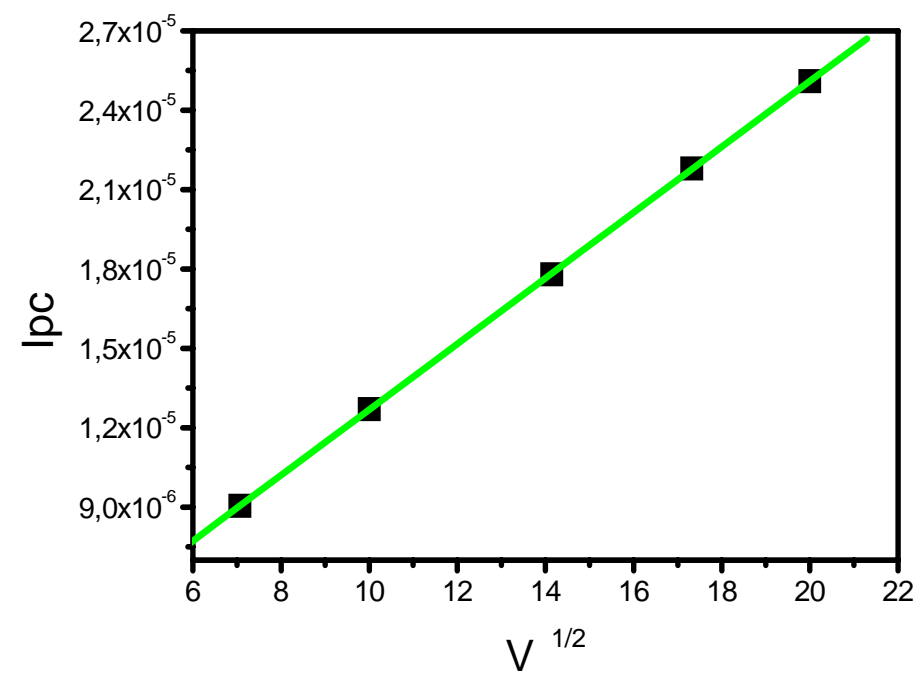

Figura 33: Variação de $\mathrm{I}_{\mathrm{pc}}$ em função de $\mathrm{v}^{1 / 2}$, em acetonitrila, para o complexo cis- $\left[\mathrm{RuCl}(\mathrm{bpy})_{2}(\mathrm{NO})\right]\left(\mathrm{PF}_{6}\right)_{2} \cdot \mathrm{T}=25^{\circ} \mathrm{C}$.

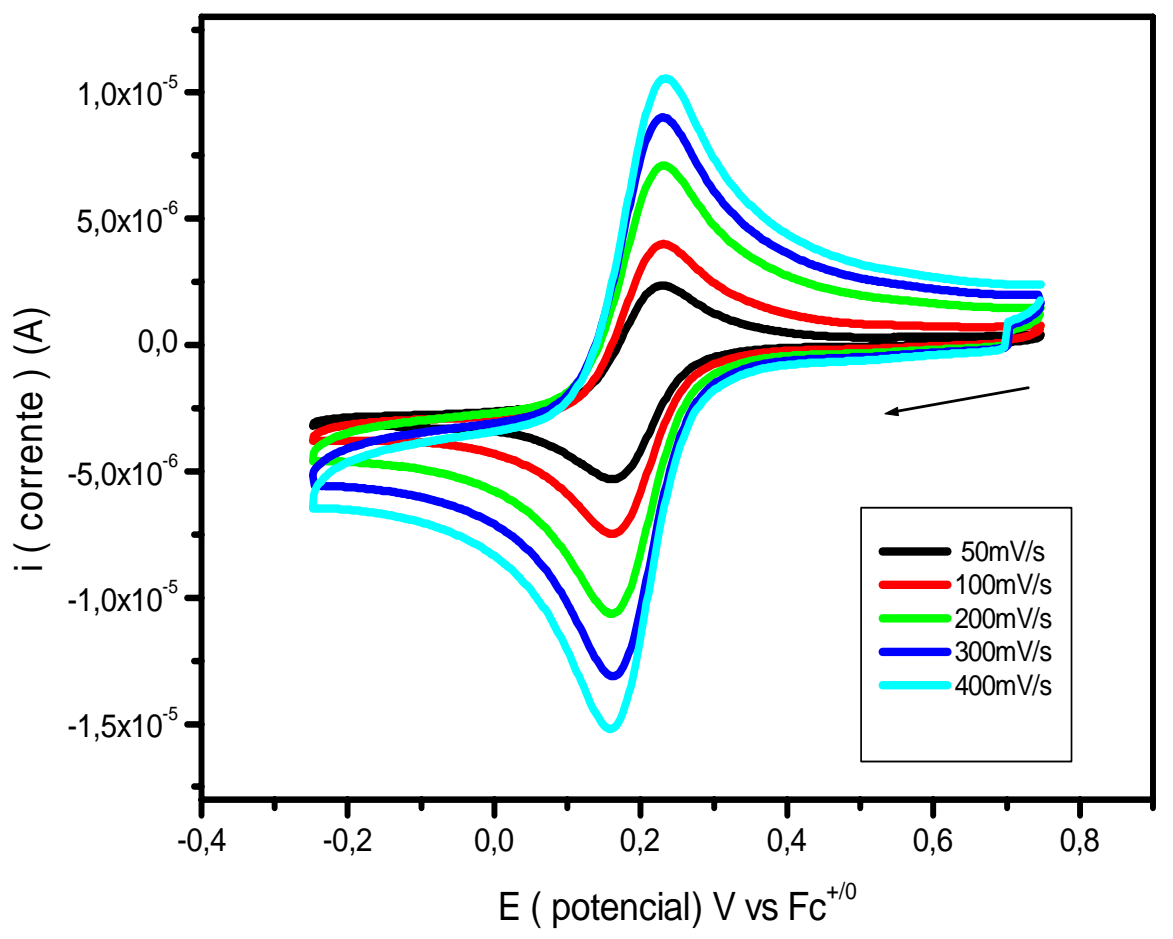

Figura 34: Voltamogramas cíclicos do complexo trans-

$\left[\mathrm{RuCl}(\mathrm{bpy})_{2}(\mathrm{NO})\right]\left(\mathrm{PF}_{6}\right)_{2}$ em acetonitrila. Eletrólito de suporte: TBAH $0,10 \mathrm{~mol} \cdot \mathrm{L}^{-1}$. [complexo] $=1,0 \times 10^{-4} \mathrm{~mol} \cdot \mathrm{L}^{-1}$.Velocidades de varredura $(\mathrm{mV} / \mathrm{s}): 50,100,200,300$ e $400 . \mathrm{T}=25^{\circ} \mathrm{C}$. 
Tabela 7: Parâmetros eletroquímicos, em acetonitrila, para o complexo trans- $\left[\mathrm{RuCl}(\mathrm{bpy})_{2}(\mathrm{NO})\right]\left(\mathrm{PF}_{6}\right)_{2} . \mathrm{T}=25^{\circ} \mathrm{C} . \mathrm{E}(\mathrm{V}$ vs $\mathrm{Ag} / \mathrm{AgCl})$.

\begin{tabular}{c|c|c|c|c|c}
\hline $\mathrm{v}(\mathrm{mV} / \mathrm{s})$ & $\begin{array}{c}\mathrm{Ipc} \\
(\mathrm{A}) \times 10^{+6}\end{array}$ & $\begin{array}{c}\text { Ipa } \\
(\mathrm{A}) \times 10^{+6}\end{array}$ & $\begin{array}{c}\text { Isp } \\
(\mathrm{A}) \times 10^{+6}\end{array}$ & $\Delta \mathrm{Ep}$ & Ipa/Ipc \\
\hline 50 & 5,31 & 2,34 & 3,18 & 67,1 & 0,818 \\
\hline 100 & 7,46 & 4,00 & 3,79 & 69,5 & 0,868 \\
\hline 200 & 10,6 & 7,10 & 4,58 & 69,6 & 0,962 \\
\hline 300 & 13,1 & 9,01 & 5,56 & 74,1 & 0,978 \\
\hline 400 & 15,1 & 10,5 & 6,46 & 73,8 & 0,987 \\
\hline
\end{tabular}

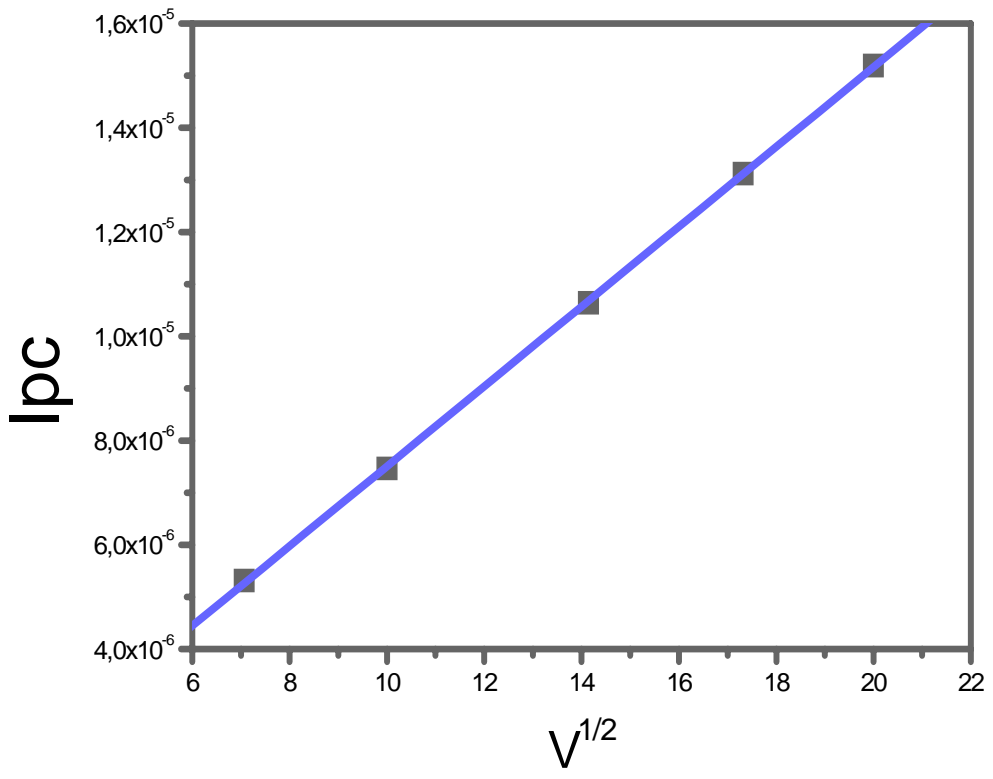

Figura 35: Variação de $\mathrm{I}_{\mathrm{pc}}$ em função de $\mathrm{v}^{1 / 2}$, em acetonitrila, para o complexo trans- $\left[\mathrm{RuCl}(\mathrm{bpy})_{2}(\mathrm{NO})\right]\left(\mathrm{PF}_{6}\right)_{2} \cdot \mathrm{T}=25^{\circ} \mathrm{C}$.

$\mathrm{O}$ segundo processo eletroquímico (2c/2a) ocorre em potencial próximo de $-0,80 \mathrm{~V}$ vs $\mathrm{Fc}^{+/ 0}$ para o complexo cis e por volta de $-0,70 \mathrm{~V}$ vs $\mathrm{Fc}^{+/ 0}$ para o complexo trans que também foram analisados em várias 
velocidades de varredura (Figuras 36 e 37). O processo fora atribuído como devido à redução do $\mathrm{NO}^{0}$ para $\mathrm{NO}^{-}$.

Os ciclovoltamogramas foram iniciados em $+0,81 \mathrm{~V}$ vs $\mathrm{Fc}^{+/ 0}$, conduzidos para potencial negativo, revertidos em $-1,20 \mathrm{~V} \mathrm{vs} \mathrm{Fc}^{+/ 0} \mathrm{e}$ conduzidos novamente para potencial positivo até atingir $+0,81 \mathrm{~V}_{\mathrm{Vs} \mathrm{Fc}^{+/ 0}}$.

Todos os complexos aqui estudados possuem comportamento voltamétrico semelhante.

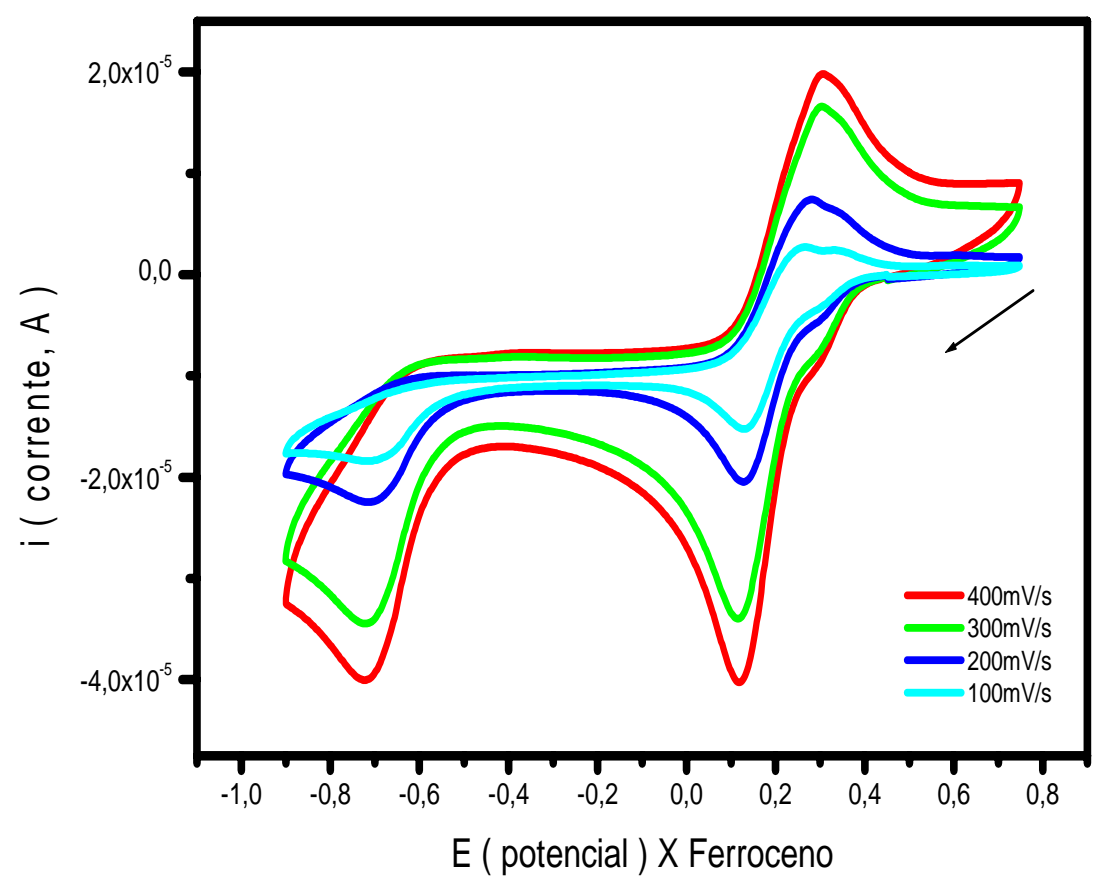

Figura 36: Voltamogramas cíclicos do complexo cis-

$\left[\mathrm{RuCl}(\mathrm{bpy})_{2}(\mathrm{NO})\right]\left(\mathrm{PF}_{6}\right)_{2}$ em acetonitrila. Eletrólito de suporte: TBAH 0,10 mol. $\mathrm{L}^{-1}$. [Complexo] $=7,20 \times 10^{-4} \mathrm{~mol} \cdot \mathrm{L}^{-1}$. Velocidades de varredura (mV/s): 50, 100, 300 e 400. $\mathrm{T}=25^{\circ} \mathrm{C}$. 


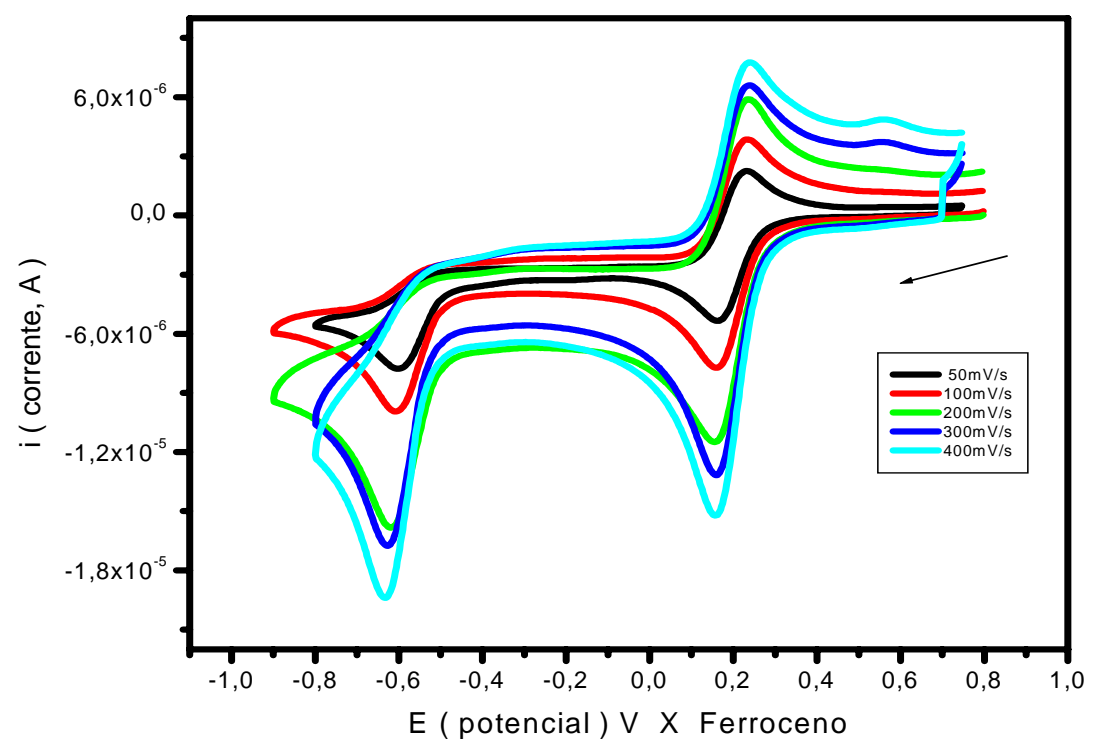

Figura 37: Voltamogramas cíclicos do complexo trans-

$\left[\mathrm{RuCl}(\mathrm{bpy})_{2}(\mathrm{NO})\right]\left(\mathrm{PF}_{6}\right)_{2}$ em acetonitrila. Eletrólito de suporte: TBAH 0,10 mol. $\mathrm{L}^{-1}$. [Complexo] $=7,20 \mathrm{x} \quad 10^{-4} \mathrm{~mol} \cdot \mathrm{L}^{-1}$. Velocidades de varredura (mV/s): 50, 100, 200, 300 e 400. $\mathrm{T}=25{ }^{\circ} \mathrm{C}$

Observa-se uma correlação linear entre $\mathrm{E}_{1 / 2}\left(\mathrm{NO}^{+/ 0}\right)$ e a somatória do parâmetro de LEVER (LEVER, 1990) para os ligantes em complexos do tipo cis- $\left[\mathrm{Ru}(\mathrm{L})(\mathrm{bpy})_{2}(\mathrm{NO})\right]^{\mathrm{n}+}$ para diversos compostos. Isto mostra que a contribuição global de todos os ligantes nos complexos cis$\left[\mathrm{Ru}(\mathrm{L})(\mathrm{bpy})_{2}(\mathrm{NO})\right]^{\mathrm{n}+}$, sendo $\mathrm{L}$ um ligante qualquer, afeta a densidade eletrônica do metal, que por sua vez influencia a densidade eletrônica do ligante nitrosil. No processo eletroquímico, os orbitais envolvidos são os orbitais vazios antiligantes de menor nível energético (LUMO) do grupamento nitrosil.

Do processo eletroquímico $2 \mathrm{a} / 2 \mathrm{c}$ pode-se inferir que ocorre uma reação química acoplada, pois a relação de $\mathrm{I}_{\mathrm{pc}} / \mathrm{v}^{1 / 2} \operatorname{com~} \mathrm{v}^{1 / 2}$ é decrescente tanto para a espécie cis como para a trans. Este parâmetro é muito útil para 
determinar se a irreversibilidade do processo eletródico é devida a uma transferência eletrônica lenta ou a alguma reação química acoplada.

De acordo com NICHOLSON \& SHAIN (1965), um gráfico de $\mathrm{I}_{\mathrm{pc}} / \mathrm{v}^{1 / 2} \mathrm{Vs}^{1 / 2}$ é constante durante toda a faixa de velocidade de varredura aplicada, para processos eletroquímicos reversíveis e irreversíveis.

Caso a irreversibilidade seja provocada por complicações químicas acopladas ao processo de transferência eletrônica, observa-se uma diminuição de $\mathrm{I}_{\mathrm{pc}} / \mathrm{v}^{1 / 2}$ com o aumento de $\mathrm{v}^{1 / 2}$.

De acordo com os dados de $\mathrm{Ipc} / \mathrm{v}^{1 / 2} \mathrm{vs} \mathrm{v}^{1 / 2}$ em relação aos picos 2a/2c para os complexos cis/trans-[RuCl(bpy $\left.)_{2}(\mathrm{NO})\right]\left(\mathrm{PF}_{6}\right)_{2}$, pode-se inferir que há reação química acoplada ao processo de redução total do óxido nítrico (Figuras 38 e 39).

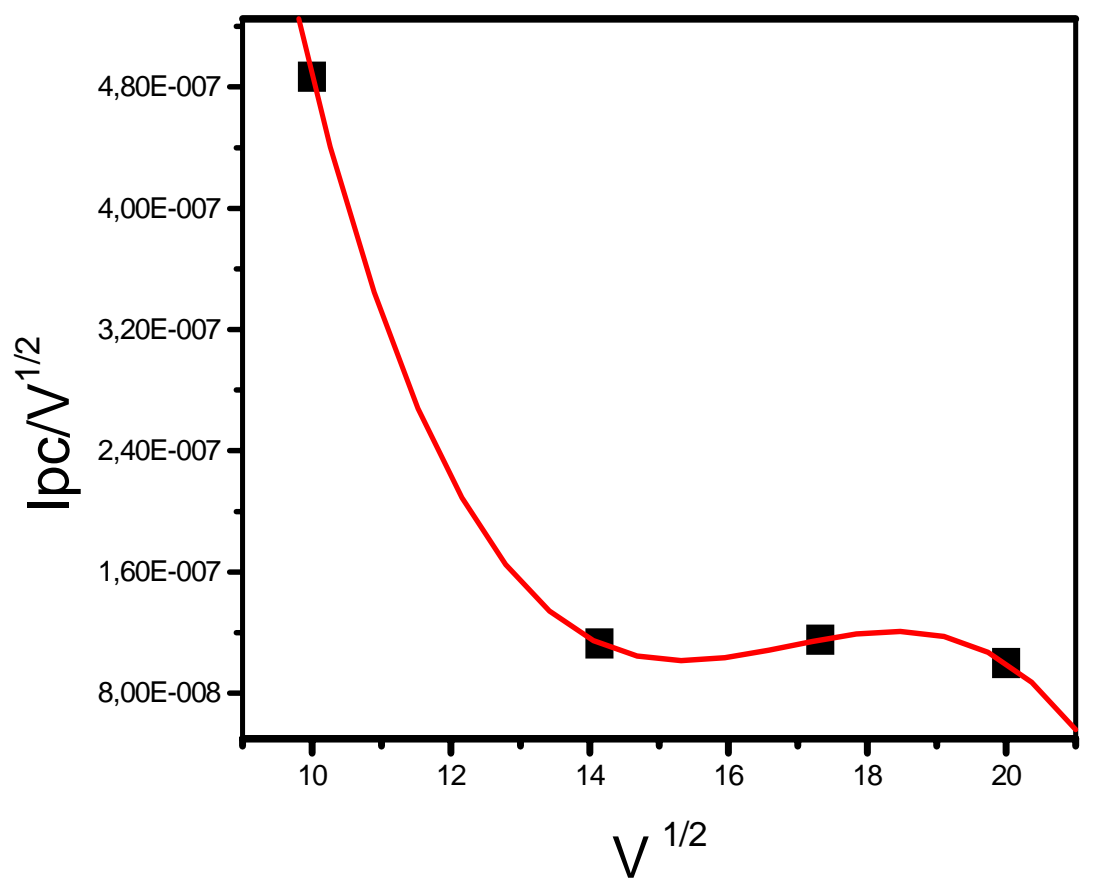

Figura 38: Relação entre Ipc/V $\mathrm{V}^{1 / 2}$ vs $\mathrm{V}^{1 / 2}$ para o complexo cis$\left[\mathrm{RuCl}(\mathrm{bpy})_{2}(\mathrm{NO})\right]\left(\mathrm{PF}_{6}\right)_{2}$, em acetonitrila. 


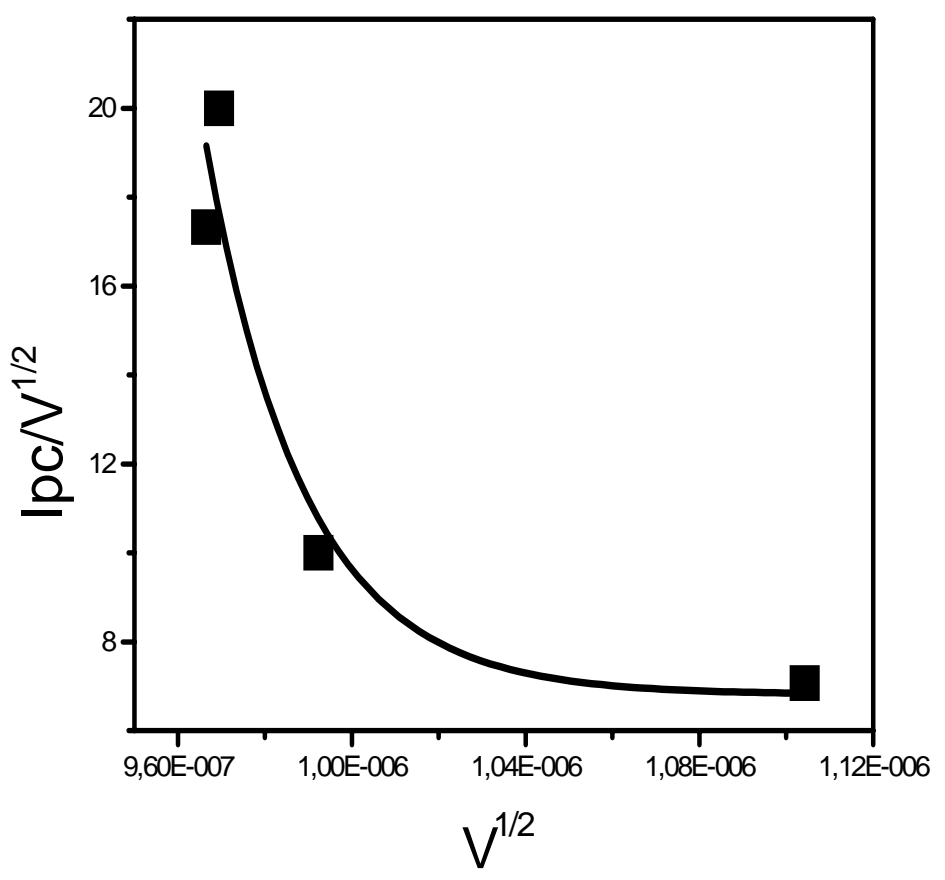

Figura 39: Relação entre Ipc/ $\mathrm{V}^{1 / 2}$ vs $\mathrm{V}^{1 / 2}$ para o complexo trans-[RuCl(bpy $\left.)_{2}(\mathrm{NO})\right]\left(\mathrm{PF}_{6}\right)_{2}$, em acetonitrila.

\subsection{Estudo da permeação passiva}

\subsubsection{Permeação passiva dos complexos a partir do tampão fosfato}

Após o experimento de permeação passiva dos complexos a partir do tampão fosfato, foram registrados espectros UV-visível das amostras obtidas do estrato córneo, da epiderme viável e da solução receptora. As Figuras 40 e 41 são relativas ao espectro UV-visível do complexo cis$\left[\mathrm{RuCl}(\mathrm{bpy})_{2}(\mathrm{NO})\right]\left(\mathrm{PF}_{6}\right)_{2}$ extraído do estrato córneo e da epiderme viável e as Figuras 42 e 43 são relativas ao espectro do complexo trans$\left[\mathrm{RuCl}(\mathrm{bpy})_{2}(\mathrm{NO})\right]\left(\mathrm{PF}_{6}\right)_{2}$, extraído do estrato córneo e da epiderme viável. Os espectros são relacionados a diferentes experimentos (triplicata) sob mesmas condições. 


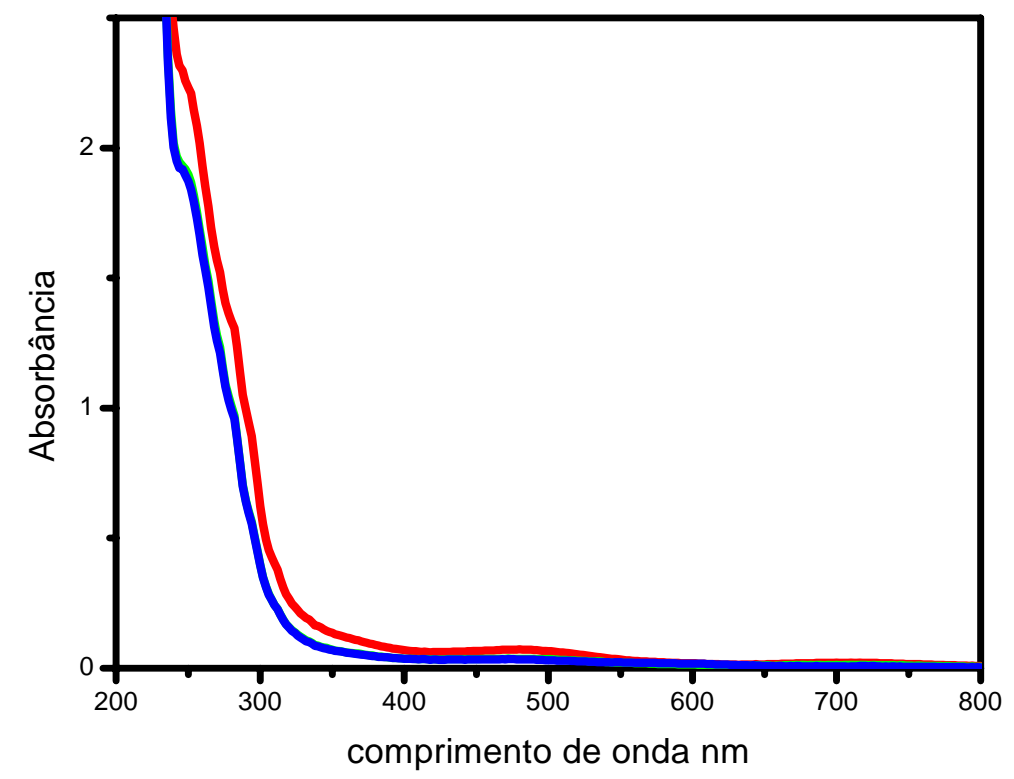

Figura 40: Espectro UV-visível no estrato córneo do complexo cis $\left[\mathrm{RuCl}(\mathrm{bpy})_{2}(\mathrm{NO})\right]\left(\mathrm{PF}_{6}\right)_{2}$, em acetonitrila.

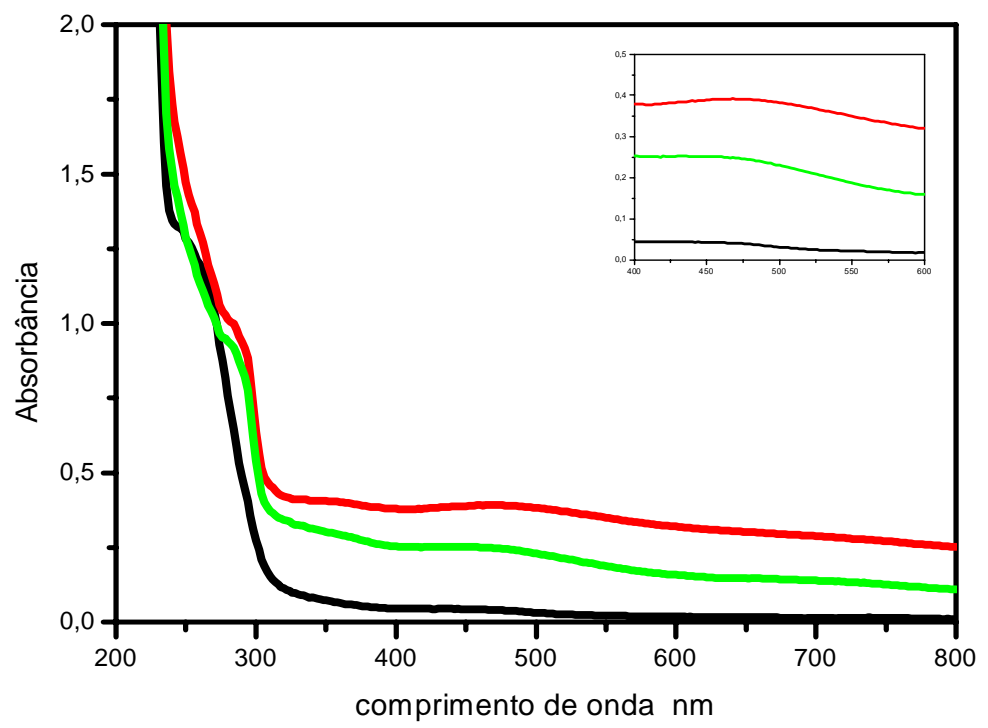

Figura 41: Espectro UV-visível na epiderme viável do complexo cis$\left[\mathrm{RuCl}(\mathrm{bpy})_{2}(\mathrm{NO})\right]\left(\mathrm{PF}_{6}\right)_{2}$, em acetonitrila Em detalhe: espectro na região de 400 - $600 \mathrm{~nm}$. 


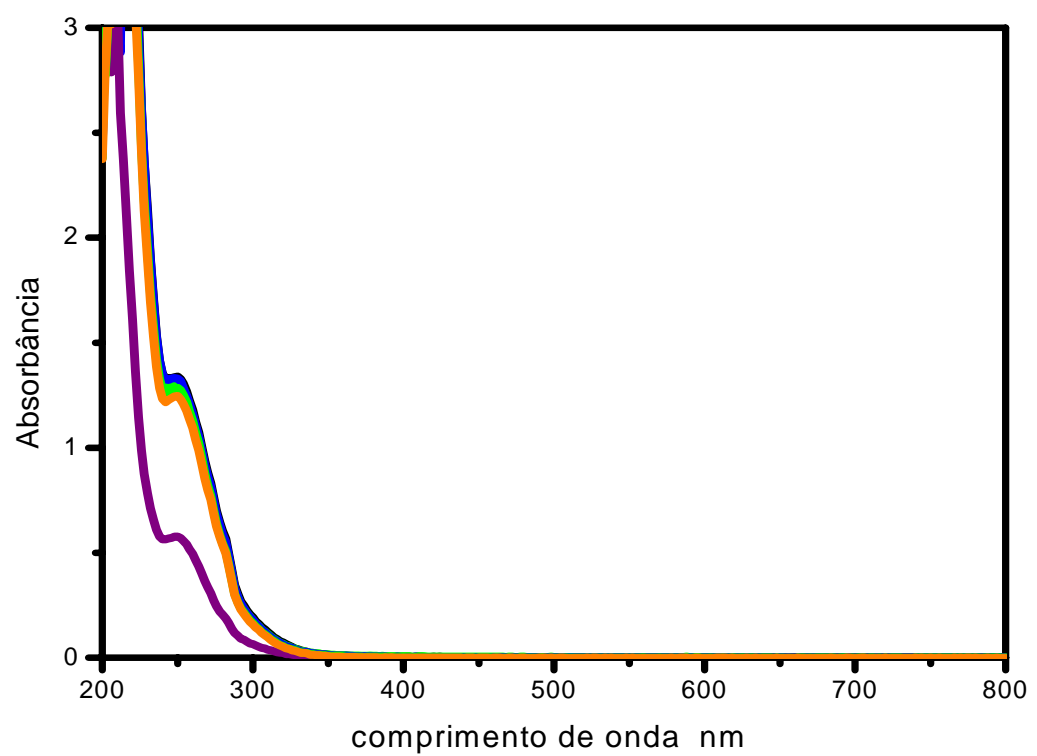

Figura 42: Espectro UV-visível no estrato córneo do complexo trans$\left[\mathrm{RuCl}(\mathrm{bpy})_{2}(\mathrm{NO})\right]\left(\mathrm{PF}_{6}\right)_{2}$, em acetonitrila

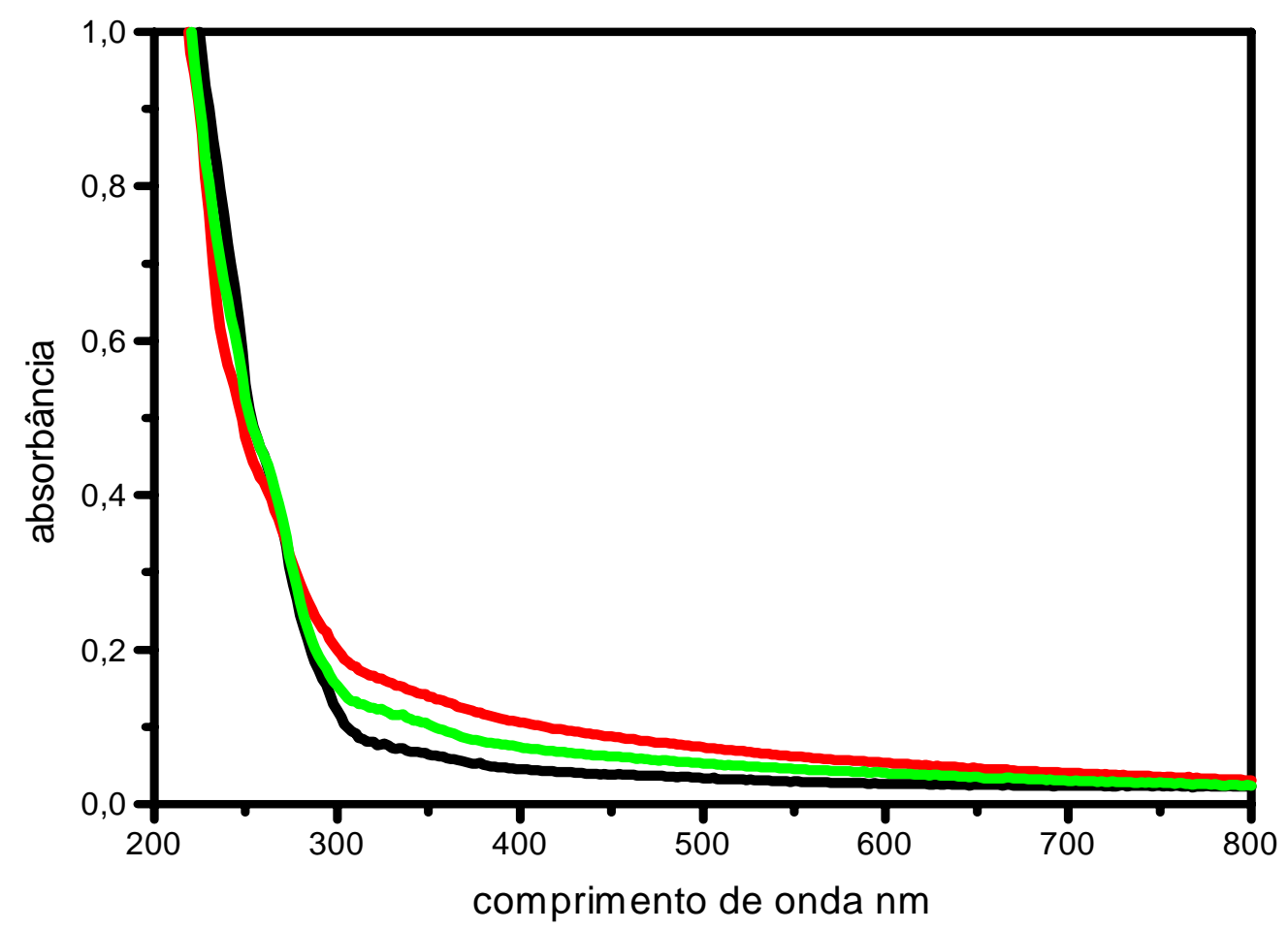

Figura 43: Espectro UV-visível na epiderme viável do complexo trans-[RuCl(bpy $\left.)_{2}(\mathrm{NO})\right]\left(\mathrm{PF}_{6}\right)_{2}$ 


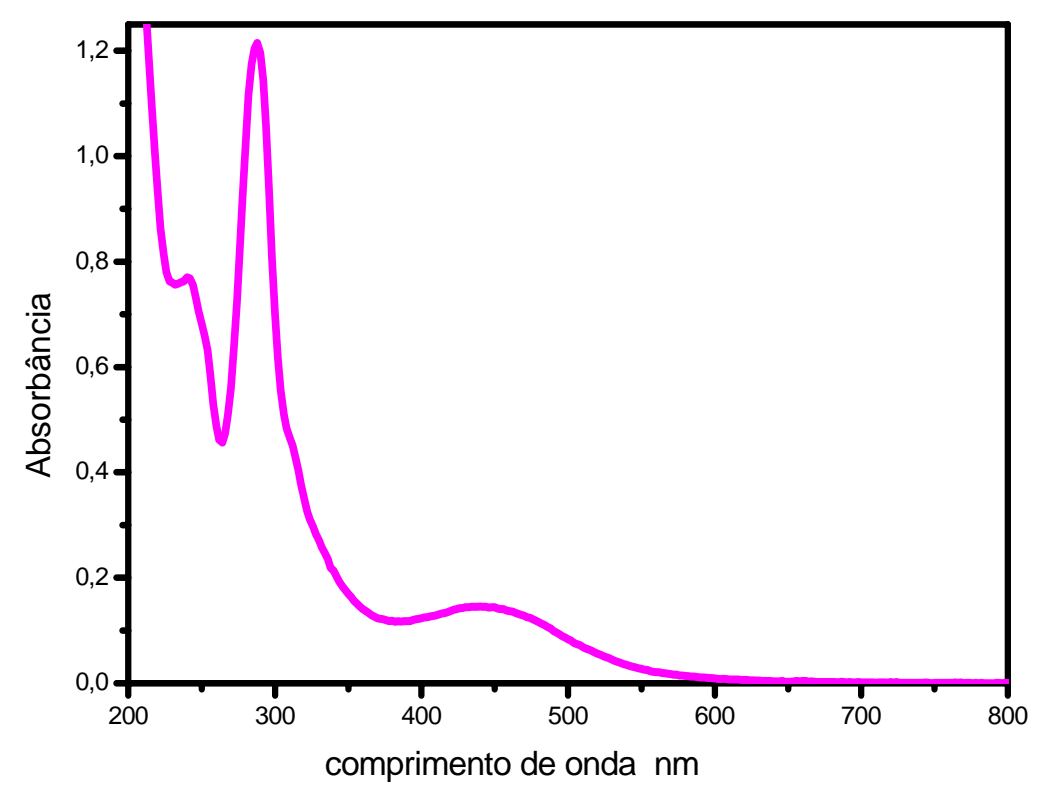

Figura 44: Espectro UV-visível do complexo cis- $\left[\mathrm{RuCl}(\mathrm{bpy})_{2}\left(\mathrm{H}_{2} \mathrm{O}\right)\right]^{+} \mathrm{em}$ solução tampão fosfato $\mathrm{pH}=5.0$ após redução do complexo cis-[RuCl(bpy $\left.)_{2}(\mathrm{NO})\right]\left(\mathrm{PF}_{6}\right)_{2}$ com amálgama de zinco.

A interpretação dos espectros UV-visível das amostras coletadas dos complexos nos sugere que os compostos encontram-se presentes no estrato córneo sem sofrerem qualquer tipo de alteração química. Aparentemente não houve mudança espectroscópica para o composto nessa região da pele, o que nos sugere que não houve alteração das características químicas do complexo nitrosilo. Embora seja um composto de alto peso molecular, a evidência dessa espécie no estrato córneo, sem alteração de suas propriedades químicas, é um avanço no uso de compostos de rutênio como fármaco. A importância de tal constatação refere-se a uma possível utilização do composto como uma pró-droga. Assim, seria possível induzir a liberação de óxido nítrico quer por processo fotoquímico, quer por processo químico, em diferentes regiões da pele.

A análise dos espectros dos complexos da epiderme viável mostra uma variação de absorbância e formação de uma nova banda na região de 
$470 \mathrm{~nm}$ (Figura 41). Tal banda em $470 \mathrm{~nm}$ não é observada no espectro dos complexos quando dissolvidos em tampão e sem serem submetidos ao teste de permeação passiva. Suspeitou-se, então, que os complexos haviam sido reduzidos na epiderme viável, devido à existência de redutores naturais presentes na epiderme. Esta nova banda poderia ser resultado da redução dos complexos de rutênio, com a conseqüente liberação do $\mathrm{NO}$, e a substituição deste por um grupo aquo, havendo, portanto, a formação do complexo $\left[\mathrm{RuCl}(\text { bpy })_{2}\left(\mathrm{H}_{2} \mathrm{O}\right)\right]\left(\mathrm{PF}_{6}\right)_{2}$ (TOGNIOLO, 2001 ).

Para verificar se houve formação da espécie aquo foi realizada a redução do complexo cis-[RuCl(bpy $\left.)_{2}(\mathrm{NO})\right]\left(\mathrm{PF}_{6}\right)_{2}$ e trans-[RuCl (bpy) $\left.{ }_{2}(\mathrm{NO})\right]\left(\mathrm{PF}_{6}\right)_{2}$ com amálgama de zinco, sob atmosfera de argônio, por 5 minutos seguido do registro do espectro UV-visível da solução (Figura 44).

Observou-se que o complexo contendo o grupamento nitrosil, após redução, apresentava o mesmo deslocamento de banda para a faixa de 470 nm, o que caracteriza a formação da espécie aquoclorobis(2,2'-bipiridina) rutênio(II) (TOGNIOLO, 2001). A conclusão imediata é que a pele possui substâncias redutoras e suficientes para ocasionar a liberação de óxido nítrico na epiderme viável.

Aliado às características anticancerígenas do óxido nítrico e levandose em conta que complexos de rutênio geralmente são atóxicos, a descoberta aqui relatada pode nos levar a uma série de testes que poderiam culminar com a disponibilização de um portentoso reagente capaz de ser utilizado como agente anticancerígeno, tanto como pró-droga (estrato córneo), como fármaco, na epiderme viável.

As análises dos espectros UV-visível das frações, coletadas após passagem do tampão pela pele, nos sugeriram que não ocorre a passagem dos complexos pela pele, pois, os espectros não evidenciam a presença dos complexos nessa fração. Os espectros mostram a existência de bandas 
diversas nesta fração, provavelmente devido à possível passagem de substâncias presentes na própria pele, uma vez que a mesma não recebe qualquer tipo de tratamento prévio, no sentido de retirar qualquer um de seus componentes naturais.

\subsubsection{Permeação passiva dos complexos a partir de emulsões}

Foram realizados experimentos com os complexos mencionados utilizando-se emulsões como sistema de liberação. Foram preparadas duas emulsões diferentes para se avaliar a liberação dos complexos. As emulsões estudadas serão aqui denominadas Croda Base ${ }^{\circledR}$ e Paramul ${ }^{\circledR}$. A estabilidade das emulsões sem os complexos fora anteriormente estudada por outros componentes do grupo. Paralelamente estudou-se a estabilidade dos complexos incorporados nessas formulações. Verificou-se que os mesmos são estáveis nas emulsões estudadas, pelo menos durante o tempo de experimento de permeação cutânea (12 horas).

\subsubsection{Emulsão Croda Base ${ }^{\circledR}$}

Após os experimentos constatou-se que os complexos praticamente não penetraram a pele ou então a sensibilidade do método qualitativo (UVvisível) não foi suficiente para a detecção dos mesmos.

\subsubsection{Emulsão Paramul ${ }^{\circledR}$}

Após os experimentos, constatou-se que os complexos permearam o estrato córneo até atingirem a epiderme viável, porém, não foram observados na solução receptora. Tal fato pode ser decorrente da não permeação completa (ou seja: não atravessaram completamente a epiderme 
viável), ou a sensibilidade do método qualitativo (UV-visível), usado para detecção dos mesmos na solução receptora, não foi sensível o suficiente.

Observa-se a presença dos complexos no estrato córneo, sem sofrer qualquer tipo de alteração química (Figuras 45 e 46).

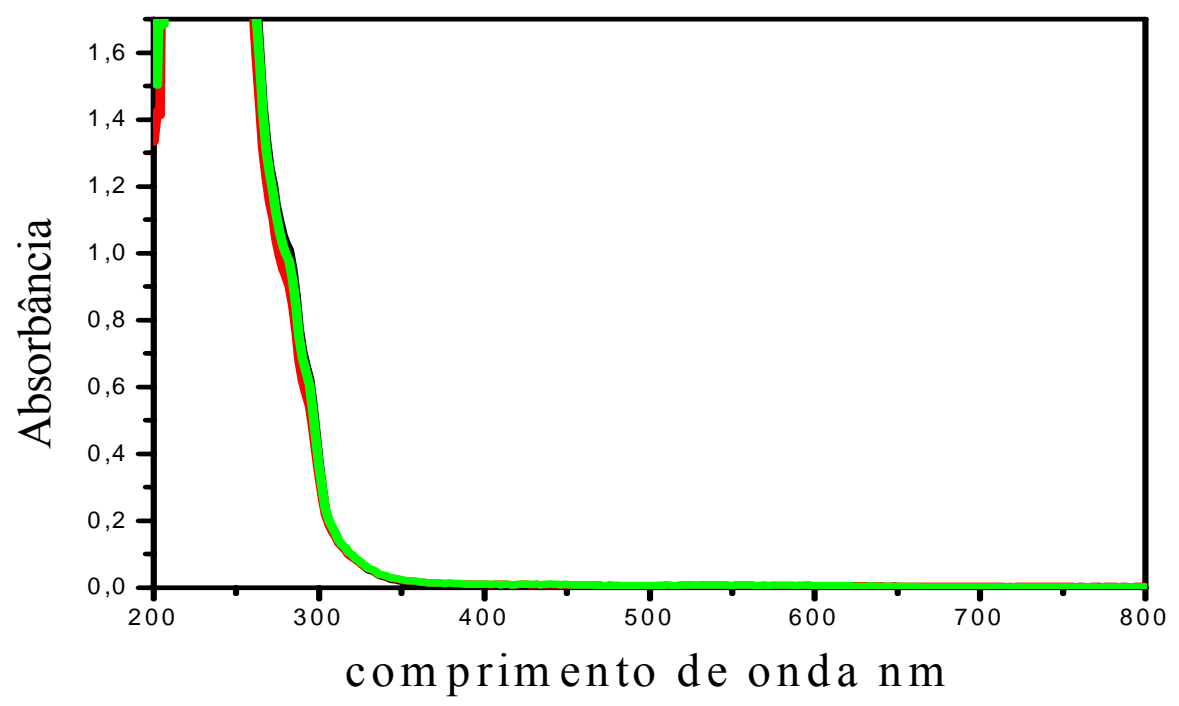

Figura 45: Espectro UV-visível do complexo cis-[RuCl(bpy $)_{2}(\mathrm{NO}]\left(\mathrm{PF}_{6}\right)_{2}$ no estrato córneo.

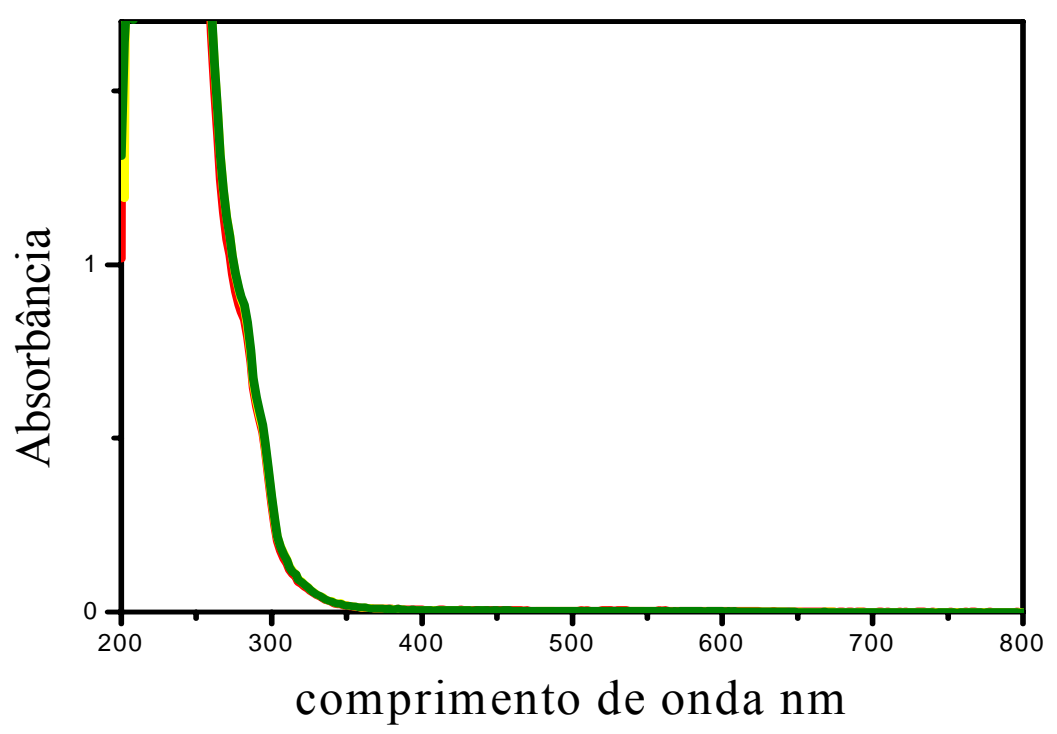

Figura 46: Espectro UV-visível do complexo trans$\left[\mathrm{RuCl}(\mathrm{bpy})_{2}(\mathrm{NO})\right]\left(\mathrm{PF}_{6}\right)_{2}$ no estrato córneo. 
Observa-se a presença dos complexos na epiderme viável, com a formação de uma banda na região de $480 \mathrm{~nm}$, nos remetendo à formação do complexo aquo, devido à possível redução química do complexo em meio biológico (Figuras 47 e 48). Nessas figuras, temos em detalhe a região da banda do aquo-complexo.

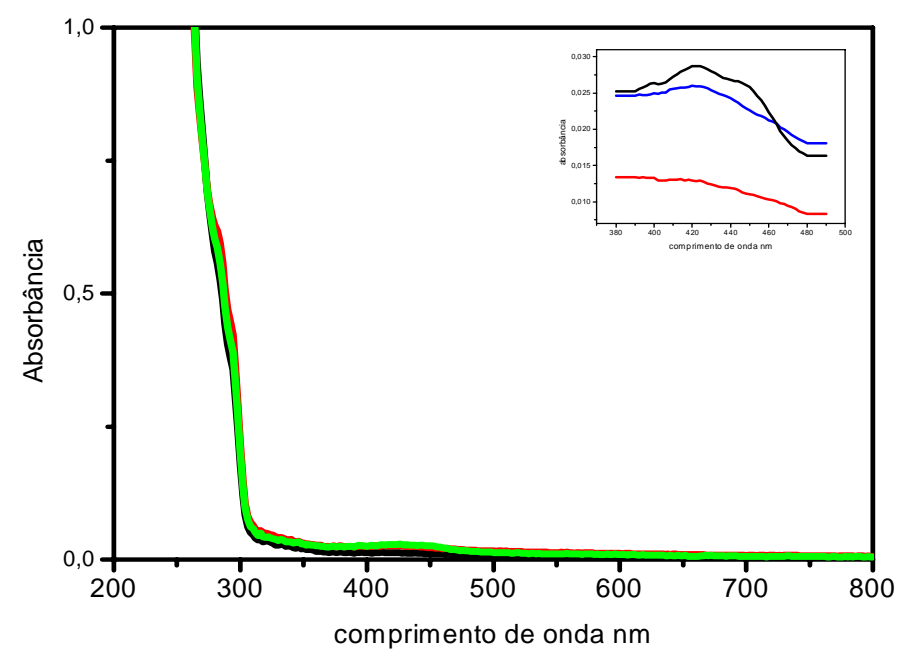

Figura 47: Espectro UV-visível do complexo cis-[ $\left.\mathrm{RuCl}(\mathrm{bpy})_{2}(\mathrm{NO})\right]\left(\mathrm{PF}_{6}\right)_{2}$ na epiderme viável. Em detalhe, região de $480 \mathrm{~nm}$.

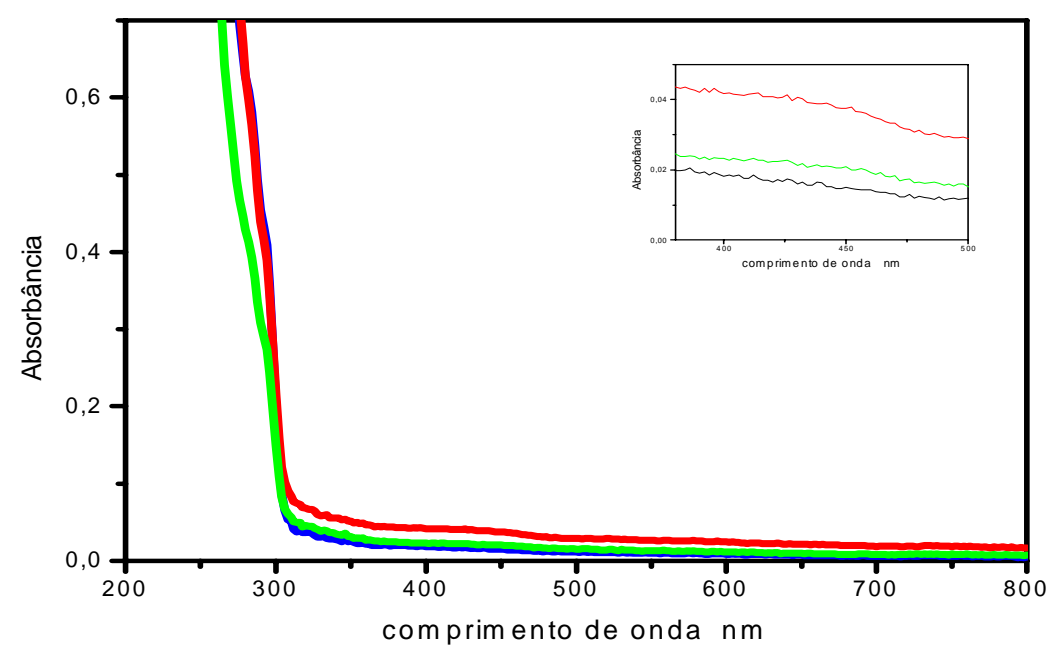

Figura 48: Espectro UV-visível do complexo trans-

$\left[\mathrm{RuCl}(\mathrm{bpy})_{2}(\mathrm{NO})\right]\left(\mathrm{PF}_{6}\right)_{2}$ na epiderme viável. Em detalhe, região de $480 \mathrm{~nm}$. 


\subsubsection{Estudo de liberação utilizando-se membrana sintética}

Os experimentos foram realizados utilizando-se a mesma célula de difusão dos experimentos de permeação, porém, utilizando-se uma membrana sintética hidrofílica de acetato de celulose, ao invés de pele, para separar o compartimento doador do compartimento receptor.

Pesou-se $1 \mathrm{~g}$ de emulsão paramul contendo o complexo incorporado por técnica de espatulação, com concentração $10^{-3}$ mol.L $\mathrm{L}^{-1}$, e esta foi colocada no compartimento doador.

A solução receptora contendo tampão fosfato $0,01 \mathrm{~mol} \cdot \mathrm{L}^{-1}, \mathrm{pH}=5,0$ foi mantida a $37,0{ }^{\circ} \mathrm{C}$ por 12 horas com agitação a $300 \mathrm{rpm}$, como nos estudos de permeação. Amostras da solução receptora foram coletadas nos tempos de 1 até $12 \mathrm{~h}$ e analisadas por espectrometria UV-visível.

Os experimentos foram feitos em triplicata e os resultados obtidos estão relacionados nas Figuras 49 e 50.

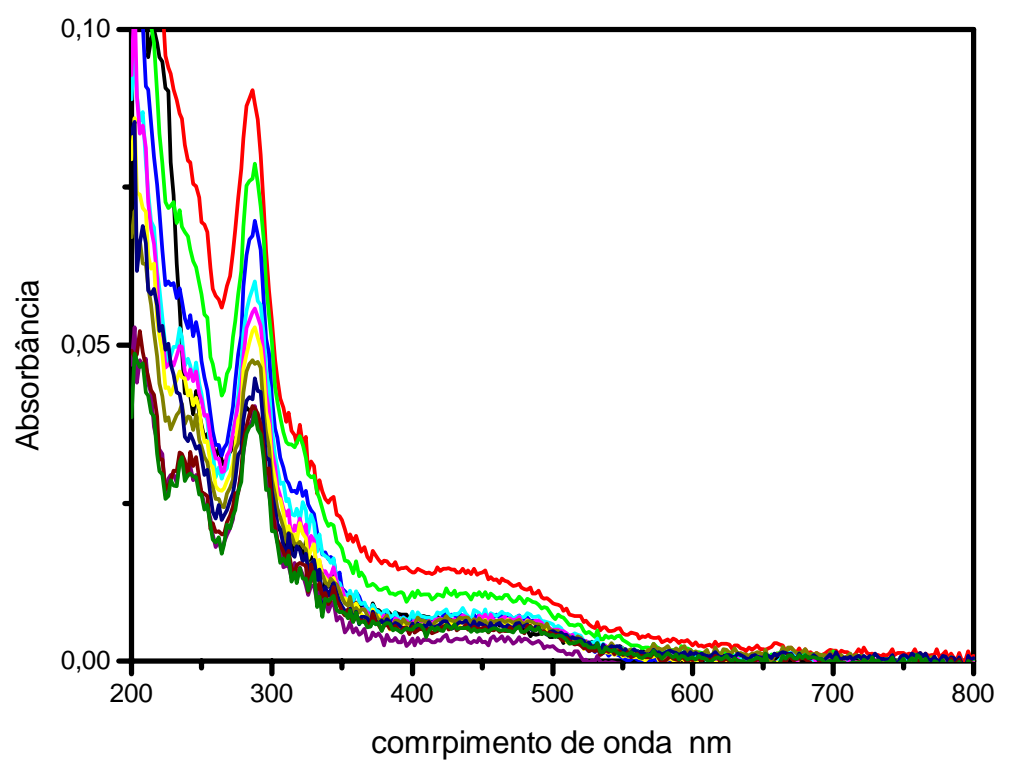

Figura 49: Espectro UV-visível do complexo cis-[RuCl(bpy $\left.)_{2}(\mathrm{NO})\right]\left(\mathrm{PF}_{6}\right)_{2}$ 
após permeação passiva em membrana após período de 12 horas.

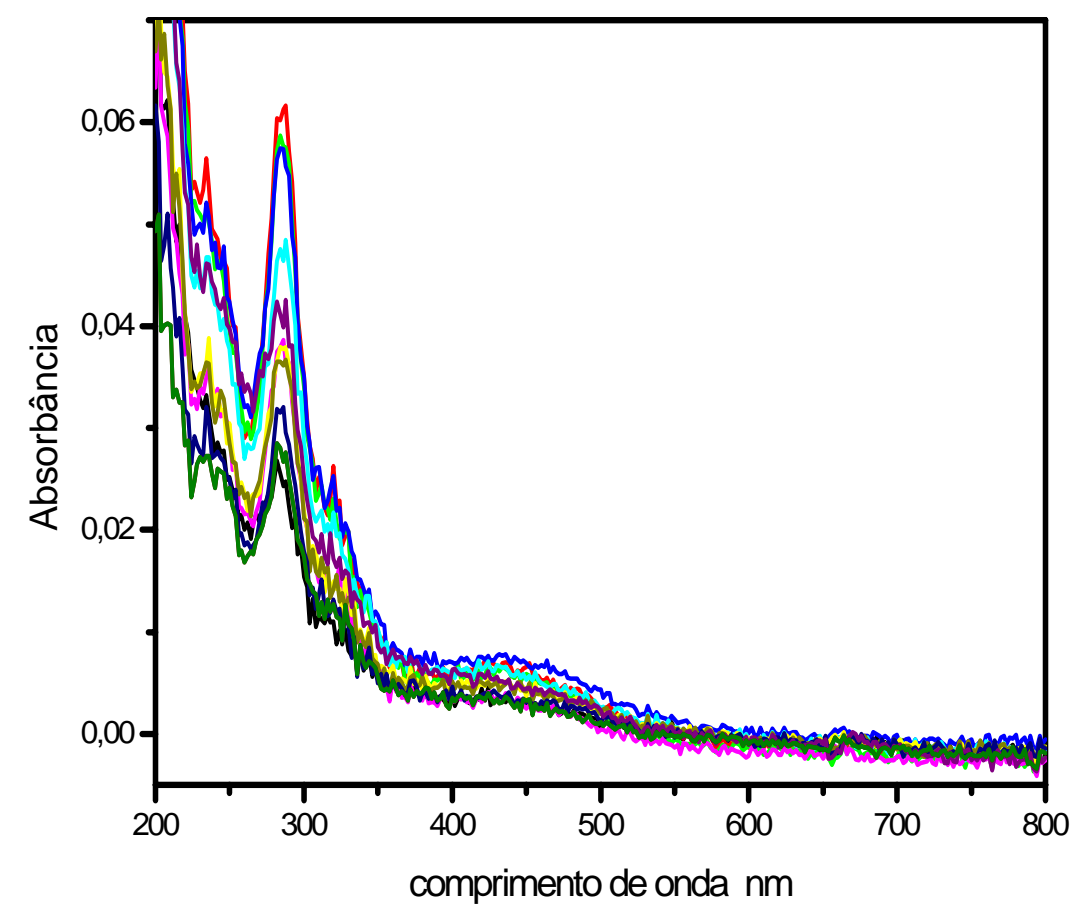

Figura 50: Espectro UV-visível do complexo trans-[RuCl(bpy $\left.)_{2}(\mathrm{NO})\right]\left(\mathrm{PF}_{6}\right)_{2}$ após permeação passiva em membrana após período de 12 horas.

Os resultados obtidos comprovam que ocorrem a liberação e permeação dos fármacos através da membrana utilizada. Tal fato vem a corroborar a idéia de que o fármaco é liberado a partir da emulsão empregada no experimento. Assim, nos experimentos de penetração passiva com a pele de porco pode-se afirmar que o fármaco é liberado da emulsão, ficando disponível para poder penetrar na pele de porco. Portanto, pode-se concluir que o sistema utilizado (emulsão) pode ser empregado como um sistema liberador de fármacos e pode ser utilizado como veículo para os fármacos em questão. 


\subsubsection{Determinação da concentração liberada ou permeada através}

\section{da membrana}

Na Tabela 8 têm-se os parâmetros analíticos obtidos do estudo de liberação, utilizando-se membrana de acetato de celulose, feitos a partir da emulsão com complexo em saturação. Os valores foram corrigidos, devido à diluição a cada coleta, conforme descrito abaixo.

Tabela 8: Concentração $\left(m o l . L^{-1} \cdot \mathrm{cm}^{2}{ }^{-1}\right)$ de fármaco liberado a partir de emulsão paramul em membrana de acetato de celulose.

\begin{tabular}{|c|c|c|c|c|}
\hline \multirow[t]{3}{*}{$\begin{array}{c}\text { Tempo } \\
\text { (h) }\end{array}$} & \multicolumn{4}{|c|}{ Concentração acumulada de complexo em $\mathrm{mol} / \mathrm{cm}^{2}$} \\
\hline & \multicolumn{2}{|c|}{ Complexo cis } & \multicolumn{2}{|c|}{ Complexo trans } \\
\hline & \begin{tabular}{|c|}
$\begin{array}{c}\text { Concentração } \\
\mu \mathrm{mol}\end{array}$ \\
\end{tabular} & $\begin{array}{c}\text { Desvio } \\
\text { padrão }(+/-)\end{array}$ & $\begin{array}{c}\text { Concentração } \\
\mu \mathrm{mol}\end{array}$ & $\begin{array}{c}\text { Desvio } \\
\text { padrão (+/-) }\end{array}$ \\
\hline 1 & 15,57 & 3,35 & 5,57 & 0,80 \\
\hline 2 & 106,93 & 48,39 & 54,13 & 9,58 \\
\hline 3 & 226,33 & 66,61 & 160,00 & 5,20 \\
\hline 4 & 342,67 & 72,34 & 277,33 & 13,28 \\
\hline 5 & 449,33 & 73,70 & 386,33 & 34,06 \\
\hline 6 & 542,33 & 77,86 & 472,00 & 43,30 \\
\hline 7 & 624,33 & 82,13 & 545,00 & 48,50 \\
\hline 8 & 700,00 & 84,61 & 606,67 & 50,81 \\
\hline 9 & 769,00 & 89,60 & 654,00 & 46,77 \\
\hline 10 & 887,33 & 34,85 & 690,33 & 35,80 \\
\hline 11 & 1055,67 & 188,80 & 713,33 & 11,55 \\
\hline 12 & 1115,00 & 181,45 & 736,33 & 16,17 \\
\hline
\end{tabular}

Os perfis de liberação dos complexos foram plotados em relação à média de liberação obtida, pois tais experimentos foram realizados em triplicata. 
A Figura 51 mostra o perfil de liberação de ambos os complexos a partir da emulsão paramul, referentes às amostras obtidas da permeação.

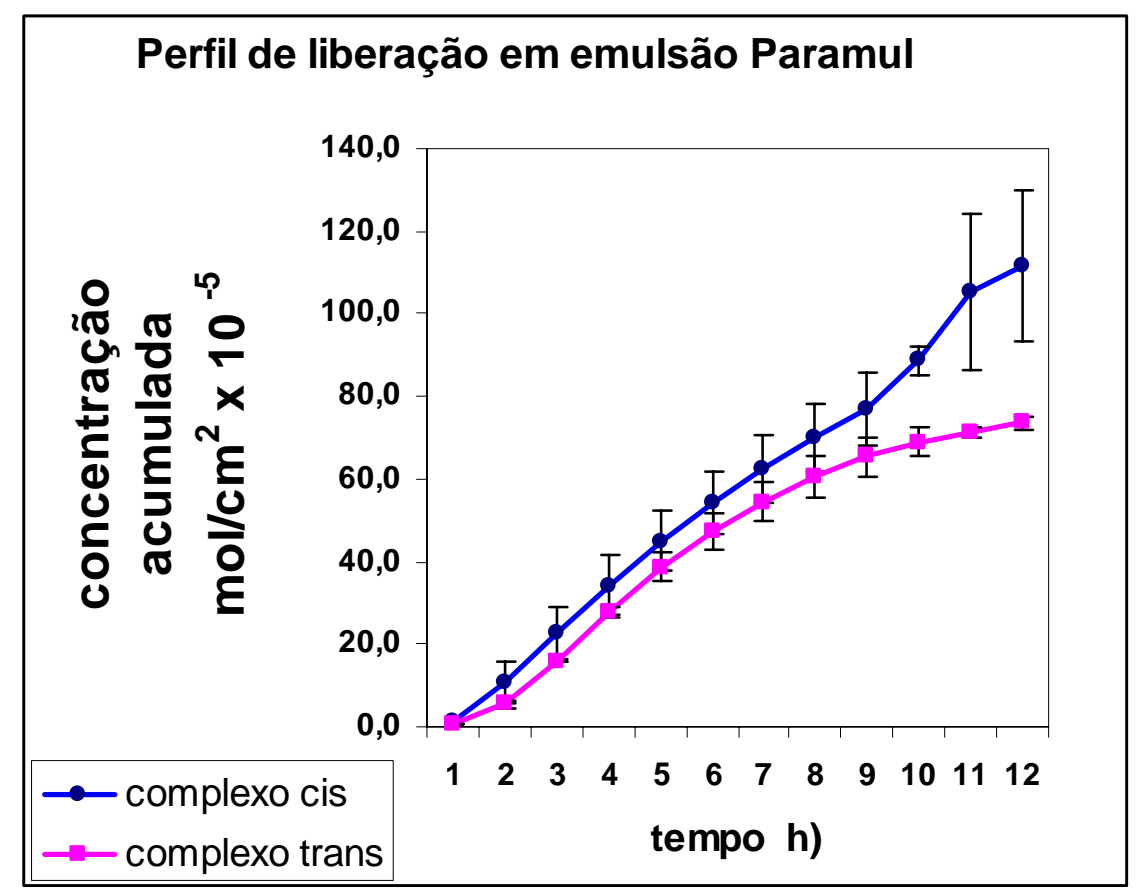

Figura 51: Perfil de liberação dos complexos em membrana de acetato de celulose complexo cis-[RuCl(bpy $\left.)_{2}(\mathrm{NO})\right]\left(\mathrm{PF}_{6}\right)_{2}$ (Azul) e trans$\left[\mathrm{RuCl}(\mathrm{bpy})_{2}(\mathrm{NO})\right]\left(\mathrm{PF}_{6}\right)_{2}$ (rosa)

Para se determinar a quantidade de complexo que foi liberado da formulação, ou permeado através da membrana de acetato de celulose, é necessário fazer uma correção na quantidade de fármaco analisada, pois a solução receptora é diluída após cada coleta. É necessário dividir a concentração obtida a partir do espectro UV-visível pelo coeficiente de extinção molar dos complexos em meio aquoso, obtendo-se a concentração da solução receptora. $\mathrm{O}$ valor obtido deve ser multiplicado por 6 (volume do compartimento da solução receptora) e dividido por y (área da membrana, que no caso corresponde a $1,13 \mathrm{~cm}^{2}$ ). Para tanto, foram feitos cálculos de diluição de acordo com o esquematizado abaixo, para os tempos 1, 2 e $3 \mathrm{~h}$ (os cálculos para os demais tempos foram calculados de modo análogo): 


$$
\begin{aligned}
& \mathrm{m}_{1}=\mathrm{C}_{0} \cdot \mathrm{V}_{\text {receptor }} \\
& \mathrm{m}_{2}=\mathrm{C}_{1} \cdot \mathrm{V}_{\text {receptor }}+\mathrm{C}_{0} \cdot \mathrm{V}_{\text {coleta }} \\
& \mathrm{m}_{3}=\mathrm{C}_{2} \cdot \mathrm{V}_{\text {receptor }}+\mathrm{C}_{1} \cdot \mathrm{V}_{\text {coleta }}+\mathrm{C}_{0} \cdot \mathrm{V}_{\text {coleta }}
\end{aligned}
$$

onde:

$\mathrm{m}_{1}, \mathrm{~m}_{2}$ e $\mathrm{m}_{3}$ representam a quantidade total de complexo, em $\mathrm{mol} / \mathrm{mL}$, liberada ou permeada nos tempos 1,2 e $3 \mathrm{~h}$, respectivamente.

$\mathrm{C}_{0}, \mathrm{C}_{1}$ e $\mathrm{C}_{2}$ são as concentrações de complexo, em $\mathrm{mol} / \mathrm{cm}^{2}$ quantificada por espectro eletrônico na região UV-visível nos tempos 1,2 e $3 \mathrm{~h}$, respectivamente.

$\mathrm{V}_{\text {receptor }}=6 \mathrm{~mL}$.

$\mathrm{V}_{\text {coleta }}=3 \mathrm{~mL}$.

Os experimentos foram realizados em triplicata para ambos os complexos, obtendo-se os resultados apresentados pelas Figuras 52 e 54 para o complexo cis-[RuCl(bpy $\left.)_{2}(\mathrm{NO})\right]\left(\mathrm{PF}_{6}\right)_{2}$ e Figuras 53 e 55 para o complexo trans-[RuCl(bpy $\left.)_{2}(\mathrm{NO})\right]\left(\mathrm{PF}_{6}\right)_{2}$.

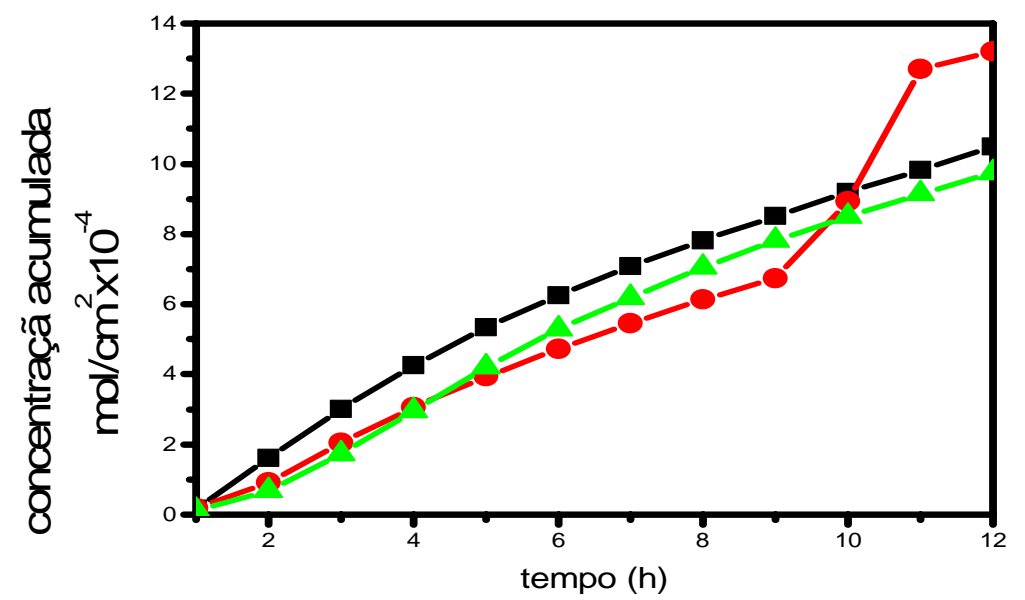

Figura 52: Perfil de liberação das amostras, em membrana de acetato de celulose, em triplicata. Complexo cis-[RuCl(bpy $\left.)_{2}(\mathrm{NO})\right]\left(\mathrm{PF}_{6}\right)_{2}$. 


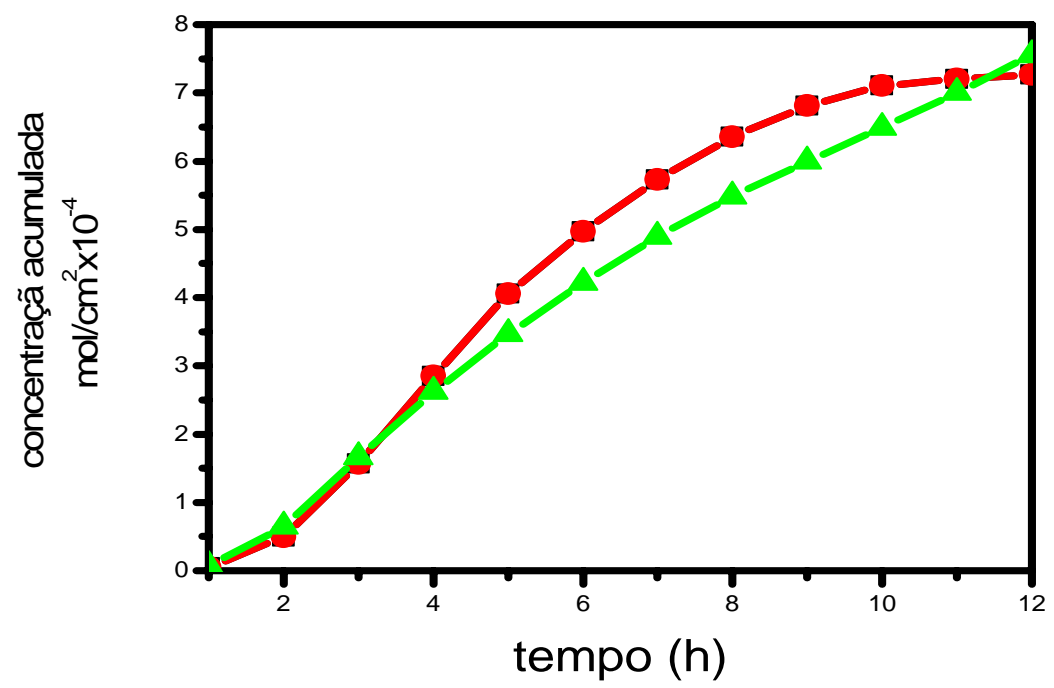

Figura 53: Perfil de liberação das amostras em membrana de acetato de celulose, em triplicata.

Complexo trans- $\left[\mathrm{RuCl}(\mathrm{bpy})_{2}(\mathrm{NO})\right]\left(\mathrm{PF}_{6}\right)_{2}$

O perfil de liberação dos complexos foi analisado por meio de métodos gráficos, relacionando-se a quantidade liberada do fármaco $\left(\mathrm{mol} / \mathrm{cm}^{2}\right)$ em função do tempo (h).

Os dados acima foram analisados segundo três modelos cinéticos para liberação de fármacos: cinética de ordem zero (concentração/tempo), cinética de pseudo-primeira ordem (concentração/ $\sqrt{\text { tempo }}$ ) e primeira ordem (logaritmo da concentração/tempo) (GUY e HADGRAFT, 1990). A melhor correlação linear obtida foi quando a concentração de complexo acumulada e liberada em 12 horas de experimento foi relacionada com raiz quadrada do tempo $\left(\mathrm{t}^{1 / 2}\right)$. Assim, a liberação do complexo através da membrana de acetato de celulose segue a cinética de pseudo-primeira ordem, segundo modelo de HIGUCHI (1999) e ilustrados para os complexos cis e trans-[RuCl(bpy $\left.)_{2}(\mathrm{NO})\right]\left(\mathrm{PF}_{6}\right)_{2}$ pelas Figuras 54 e 55. 


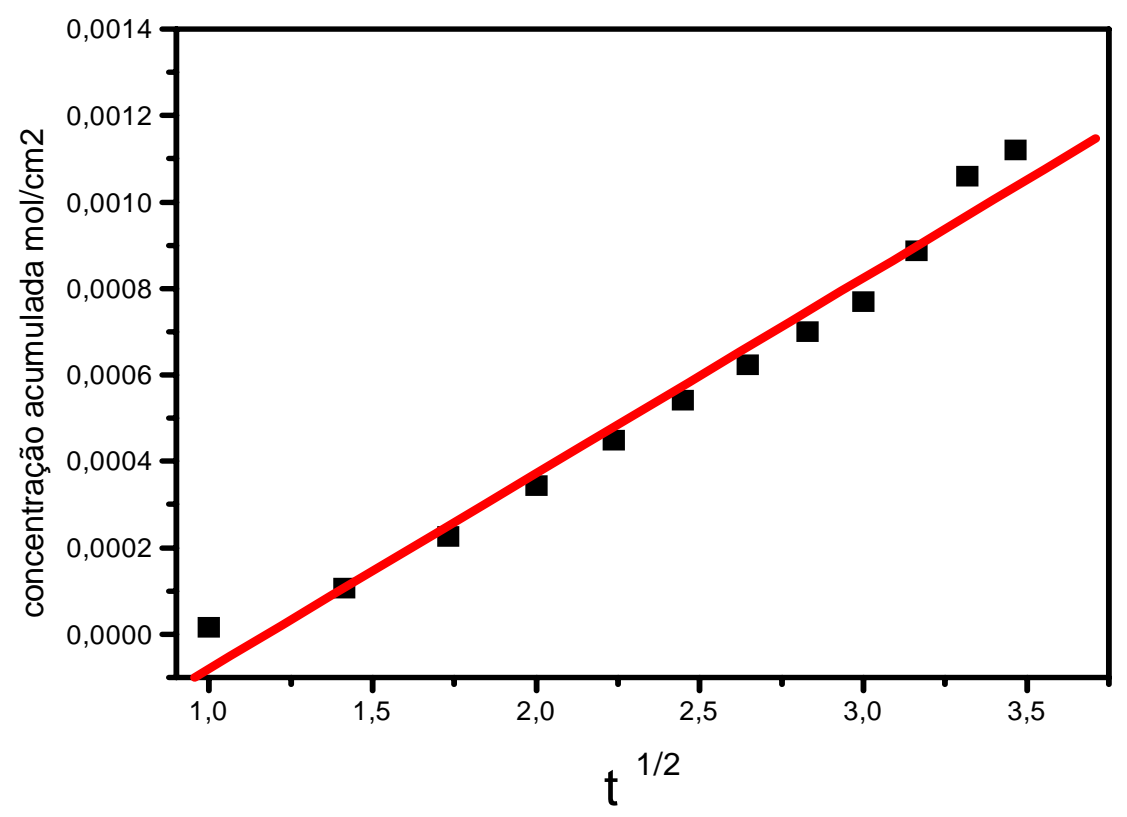

Figura 54: Perfil de liberação do complexo em membrana de acetato de celulose. Complexo cis-[RuCl(bpy $\left.)_{2}(\mathrm{NO})\right]\left(\mathrm{PF}_{6}\right)_{2}$

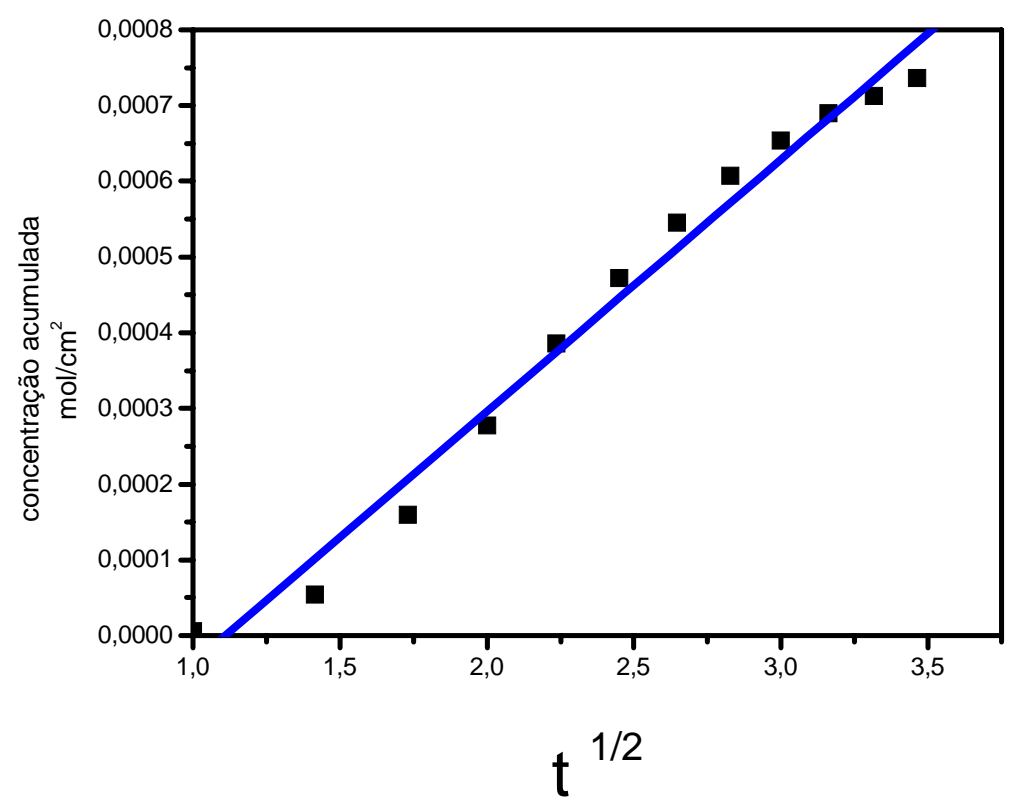

Figura 55: Perfil de liberação do complexo em membrana de acetato de celulose. Complexo trans-[RuCl(bpy $\left.)_{2}(\mathrm{NO})\right]\left(\mathrm{PF}_{6}\right)_{2}$. 
Os dados de liberação obtidos foram utilizados para calcular o fluxo de fármaco (velocidade de liberação através da membrana), que é representado pela inclinação da porção linear da curva de liberação.

Na Tabela 9 estão relacionados os parâmetros cinéticos das curvas de liberação dos complexos em função do tempo.

Tabela 9: Parâmetros cinéticos das curvas de liberação dos complexos $\left(\mathrm{mol} / \mathrm{cm}^{2}\right)$ em função do tempo.

\begin{tabular}{llc}
\hline Complexo & $\begin{array}{l}\text { Fluxo J } \\
\left(\mathrm{mol} / \mathrm{cm}^{2} \cdot h^{-1 / 2}\right)\end{array}$ & $\begin{array}{l}\text { Coef. correlação } \\
\text { linear (r) }\end{array}$ \\
\hline cis & 0,000453 & 0,9873 \\
trans & 0,000333 & 0,9913 \\
\hline
\end{tabular}

Onde : $\mathrm{J}^{\#}$ : velocidade de liberação através da membrana, representada pela inclinação da porção linear da curva de liberação (valores relativos às Figuras 54 e 55).

Como pode ser observado na Tabela 9 o complexo trans apresenta um fluxo menor do que o complexo cis, ou seja: difunde-se mais lentamente através da emulsão antes de ser liberado. Esta liberação mais lenta pode estar relacionada com a menor solubilidade em água deste complexo, indicando que o mesmo deve estar interagindo mais intensamente com a fase interna oleosa da emulsão, retardando sua liberação da fórmulação em relação ao complexo cis. A emulsão pode estar funcionando, então, como um reservatório para o complexo trans. 


\subsection{Estudo de liberação de NO por potencial controlado}

O perfil de liberação de NO a partir de potencial controlado, no caso em questão $0,00 \mathrm{~V}$ vs $\mathrm{Ag} / \mathrm{AgCl}$ ( valor de potencial onde teríamos somente a redução da espécie $\mathrm{NO}^{+} / \mathrm{NO}^{0}$ ) foi realizado em função do tempo. $\mathrm{O}$ processo teve o acompanhamento da liberação de óxido nítrico gasoso $\left(\mathrm{NO}^{0}\right)$ in situ e foi realizado pelo acoplamento do eletrodo medidor de NO na cela voltamétrica.

A monitorização in situ de NO durante a redução do complexo é uma técnica importante para mostrar que ocorre a redução do complexo e conseqüente liberação de NO. Previamente à aplicação de potencial, deixase o sistema estabilizar. O sinal gravado pelo sensor de NO aumenta a partir do momento em que se aplica o potencial. As duas espécies estudadas foram capazes de liberar óxido nítrico gasoso $\left(\mathrm{NO}^{0}\right)$ quando submetidas à eletrólise a potencial controlado. Nas Figuras 56 e 57 estão representados os perfis de corrente em função do tempo decorrido após aplicação do potencial.

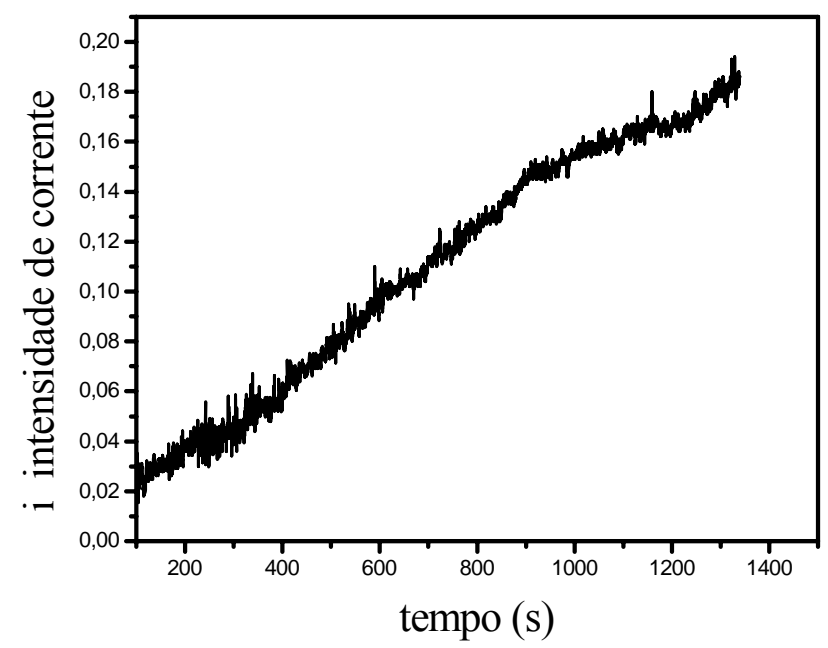

Figura 56: Cronoamperograma do NO liberado pela redução do complexo cis-[RuCl(bpy $\left.)_{2}(\mathrm{NO})\right]\left(\mathrm{PF}_{6}\right)_{2}$, em solução tampão fosfato, $\mathrm{pH}=$ $5,0 \mathrm{com}$ potencial aplicado de $0,00 \mathrm{~V}$ vs $\mathrm{Ag} / \mathrm{AgCl}$. 


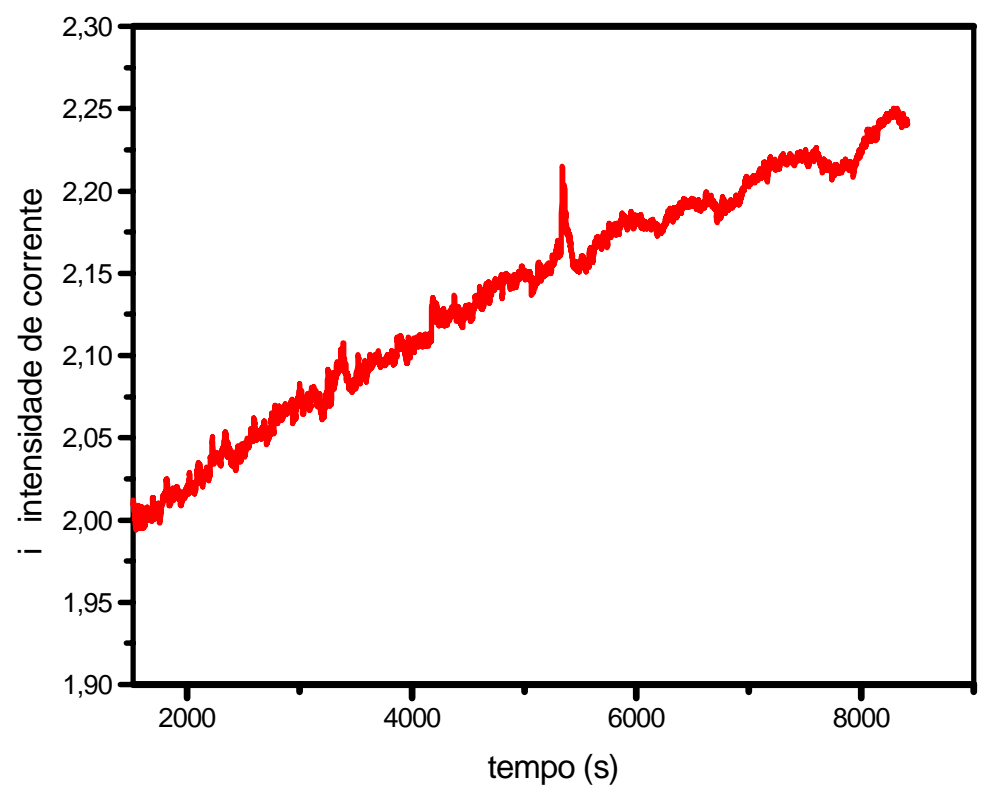

Figura 57: Cronoamperograma do NO liberado pela redução do complexo trans-[RuCl(bpy $\left.)_{2}(\mathrm{NO})\right]\left(\mathrm{PF}_{6}\right)_{2}$, em solução tampão fosfato, $\mathrm{pH}=5,0$ com potencial aplicado de $0,00 \mathrm{~V}$ vs $\mathrm{Ag} / \mathrm{AgCl}$.

A redução do ligante nitrosil $\left(\mathrm{NO}^{+}\right)$a partir do complexo, com conseqüente liberação de NO, gera uma resposta em função da corrente elétrica, conforme a espécie vai sendo reduzida. A concentração de NO é então detectada pelo eletrodo específico de NO, que se encontra acoplado à cela eletroquímica. Pode-se verificar a partir dos gráficos das Figuras 56 e 57 que, mantendo-se o potencial controlado, ocorre a redução do complexo, acarretando assim a liberação do NO a partir de ambos os complexos.

\subsection{Estudo cinético de labilização do NO}

Foram realizados vários estudos cinéticos visando determinar a constante cinética de labilização do NO a partir da redução dos complexos. 
A redução dos complexos foi realizada por diferentes metodologias: a redução química, com utilização de solução de ácido ascórbico; redução química utilizando-se amálgama de zinco e, também, com amálgama de cádmio; e redução potenciométrica, sob potencial controlado, em galvanostato/potenciostato.

\subsubsection{Redução química com solução redutora de ácido ascórbico}

Verificou-se que ocorria a redução do complexo imediatamente após a adição de solução redutora. Tal verificação é macroscópica, devido a mudança de coloração do sistema, passando de uma cor amarelo-pálida para uma coloração róseo-avermelhada, que é a cor verificada após a redução dos complexos estudados.

Como alternativa para se tentar adicionar a solução redutora diretamente dentro da cubeta de leitura do espectro UV-visível, monitorando instantaneamente a redução, usou-se a técnica "stopped flow". Nesta técnica a mistura das soluções ocorre simultaneamente dentro da cubeta.

Novamente, constatou-se que a mistura das soluções já haviam mudado de cor, sugerindo que já havia ocorrido a redução do complexo no momento em que as soluções entram em contato. Como os resultados obtidos destes experimentos foram muito dissonantes, julgou-se que essa técnica não seria apropriada para a determinação da constante cinética.

Outros agentes redutores foram ainda utilizados na tentativa de obter a constante de velocidade de saída de NO. Porém, todos os resultados mostraram-se infrutíferos. Embora tivéssemos constatado a liberação do óxido nítrico em todos os sistemas estudados, não nos foi possível, mesmo 
usando a técnica de "stopped flow", encontrar o valor da constante de velocidade.

\section{CONSIDERAÇÕES FINAIS}

Os complexos do tipo cis-[RuCl(bpy $\left.)_{2}(\mathrm{NO})\right]\left(\mathrm{PF}_{6}\right)_{2}$ e trans$\left[\mathrm{RuCl}(\mathrm{bpy})_{2}(\mathrm{NO})\right]\left(\mathrm{PF}_{6}\right)_{2}$ apresentam comportamento semelhante e com pouca variação de valores em todas as técnicas de caracterização utilizadas.

A rota de síntese desenvolvida para os complexos cis$\left[\mathrm{RuCl}(\mathrm{bpy})_{2}(\mathrm{NO})\right]\left(\mathrm{PF}_{6}\right)_{2}$ e trans-[RuCl$\left.(\mathrm{bpy})_{2}(\mathrm{NO})\right]\left(\mathrm{PF}_{6}\right)_{2}$, apesar de ser trabalhosa, pois envolve 2 etapas, mostrou ser reprodutível e de bom rendimento, ao contrário daquele relatado na literatura.

Em relação à aplicação como fármacos, pode-se afirmar que ambos os complexos estudados nesse trabalho são estáveis na forma $\mathrm{Ru}-\mathrm{NO}^{+}$no estado sólido.

Em função dessas características buscou-se neste trabalho a utilização dos mesmos, visando o aproveitamento dessas espécies em terapia fotodinâmica, através de estudo de possível administração tópica dos complexos.

Acreditamos que a técnica de permeação passiva possibilita a utilização desses complexos como fármacos, pois, para que o óxido nítrico liberado, após redução dos complexos possa atuar terapeuticamente, o mesmo precisa ao menos atingir a epiderme. A razão desta afirmação devese ao fato de que sendo o óxido nítrico gasoso, e tendo uma meia vida de aproximadamente 3 segundos, e sua liberação ocorrendo na forma gasosa, acima do estrato córneo, o mesmo se perderia para o ambiente, não exercendo qualquer ação sobre o tecido epitelial. 
Os experimentos de permeação passiva foram repetidos utilizando-se emulsão como sistema de liberação. Os resultados mostraram-se satisfatórios. Uma menor penetração do complexo a partir da emulsão foi observada, haja vista que aparentemente os espectros UV-visível mostraram-se pouco intensos, em comparação ao mesmo processo em tampão. Tal fato se deve à cinética de liberação dos complexos a partir da emulsão. Quando os complexos foram veiculados em tampão fosfato os mesmos já poderiam permear a pele, ou pelo menos estariam disponíveis para o processo de permeação. Porém, ao se incorporar os complexos em emulsão, os mesmos estão interagindo com esta e sua disponibilidade para o processo de permeação, que deve obedecer a uma cinética de liberação a partir da mesma. Somente depois de liberado da emulsão, estariam disponíveis para o processo de permeação.

O fato de se ter um processo cinético de liberação do fármaco a partir da emulsão é um ponto de extrema relevância, pois, ao obedecer a uma cinética de liberação, pode-se ter uma liberação controlada de fármaco. Tal peculiaridade é de grande interesse quando se deseja um controle de dosagem do fármaco, disponível para o processo de permeação.

Em relação à estereoquímica deve-se acrescentar que ambos os complexos penetram a pele e a influência do ligante, em relação ao grupamento nitrosil, parece não ser sentida, haja visto que basicamente as mesmas propriedades e características foram observadas para as espécies cis/trans-[RuCl(bpy $\left.)_{2}(\mathrm{NO})\right]\left(\mathrm{PF}_{6}\right)_{2}$ nos meios estudados. 


\section{REFERÊNCIAS BIBLIOGRÁFICAS}

ABRAMS, M. J.; MURRER, B. A. Metal compounds in therapy and diagnosis. Science. V. 261, p. 725-30, 1993

ABRAHAM, B.W. The factors that influence skin penetration of solutes.

J.Pharm. Pharmacol., v.47, p.8-16, 1994.

AGUILELLA, V.; BAELAYA, M.; LEVADNY, V. Passive transport of small ions through human stratum corneum. J. Control. Release, v.44, p.11-18, 1997.

ALLEN, L.V.; Manipulando cremes e loções. International Journal Pharmacology Compounding v. 3(2) p. 11-115, 1999.

AINSCOUGH, E. W.; BRODIE, A. M. Nitric oxide - some old and new perspectives. Journal of Chemical Education. v. 72, p. 686-692, 1995.

ALENCASTRE, J.B. Micropartículas de carboximetilcelulose/quitosana para liberação de vitamina E na pele. Caracterização, avaliação da estabilidade e estudos de permeação e retenção cutânea in vitro. Dissertação de mestrado. Faculdade de Ciências Farmacêuticas de Ribeirão Preto, Universidade de São Paulo, 2001

ALLARDYCE, C. S.; DYSON, P. J. Ruthenium in medicine: current clinical uses and future prospects. Platinum Metals Reviews., v. 45, p. 62-9, 2001. 
ANSEL, H.C.; POPOVICH, N.G.; ALLEN, L.V. Farmacotécnica - Formas

Farmacêuticas, Sistemas de Liberação de Fármacos. $6^{\text {a }}$ ed. São Paulo, Editorial Premier, 1999, p.397-400.

ASSEFA, Z.; STANBURY, D. M. Oxidation of coordinated ammonia to nitrosyl in the reaction of aqueous chlorine with cis- $\left[\mathrm{Ru}(\mathrm{bpy})_{2}\left(\mathrm{NH}_{3}\right)_{2}\right]^{2+}$. Journal of the American Chemical Society, v. 119, p. 521-30, 1997.

AU, Y. K.; WONG, W. T. Ruthenium 1994. Coordination Chemical Reviews. v. 162, p. 417-75, 1997.

BAGATIN, I.A.; SANTOS, R.H.D.; FRANCO, D.W.; MAGALHAES, A.; FERREIRA, A.G. Spectroscopic and electrochemical properties of a new nitrosyl-complex of $\quad \mathrm{Ru}(\mathrm{II}):$ trans$\left[\mathrm{Ru}(\mathrm{NO})\left\{\left(\mathrm{CH}_{3} \mathrm{CH}_{2}\right)(2) \mathrm{PCH}_{2} \mathrm{CH}_{2} \mathrm{P}\left(\mathrm{CH}_{2} \mathrm{CH}_{3}\right)(2)\right\}(2) \mathrm{Cl}\right]\left(\mathrm{PF}_{6}\right)(2)$ inorganica Chimica Acta. v. 333, p. 109-115, 2002.

BAKHTIAR, R.; OCHIAI, E. I. Pharmacological applications of inorganic complexes, General Pharmacology v. 32, p. 525-40, 1999.

BATISTA, A. A.; PEREIRA, C.; QUEIROZ, S.L.; DEOLIVEIRA, L.A.A.; SANTOS, R.H.D.; GAMBARDELLA, M.T.D. Nitrosyl ruthenium complexes with general formula $\left[\mathrm{RuCl}_{3}(\mathrm{NO})(\mathrm{P}-\mathrm{P})\right]$ (P-P $=$ $\left\{\mathrm{PPh}_{2}\left(\mathrm{CH}_{2}\right)_{\mathrm{n}} \mathrm{PPh}_{2}\right\}, \mathrm{n}=1-3$ and $\left.\left\{\mathrm{PPh}_{2}-\mathrm{CH}=\mathrm{CH}-\mathrm{PPh}_{2}\right\}\right)$. X-ray structure of $\left[\mathrm{RuCl}_{3}(\mathrm{NO})\left\{\mathrm{PPh}_{2}\left(\mathrm{CH}_{2}\right)_{3} \mathrm{PPh}_{2}\right\}\right.$. Polyhedron. v. 16, p. 927-31, 1997. 
BATISTA, A. A; QUEIROZ, S.L.; HEALY, P.C.; BUCKLEY, R.W.; BOYD, S.E.; BERNERS-PRICE, S.J.; CASTELLANO, E.E.; ELLENA, J. A novel coordination mode for a pyridylphosphine ligand. X-ray structures of $\left[\mathrm{RuCl}_{2}(\mathrm{NO}) \mathrm{L}\right]$ (I) and $\left[\mathrm{RuCl}_{2}(\mathrm{NO}) \mathrm{L}\right]$ center dot DMSO $\left(\mathrm{L}=\left[(2-p y)(2) \mathrm{PC}_{2} \mathrm{H}_{4} \mathrm{POO}(2-\mathrm{py})(2)\right](-)\right)$. Canadian Journal of ChemistryRevue Canadienne de Chimie v. 79,p. 1030-1035, 2001.

BECKMAN, J. S. The physiological and pathological chemistry of nitric oxide. In: LANCASTER JUNIOR, J. (ed.) Nitric oxide. Principles and Actions.. Califórnia, American Press, 1996. Cap.1, p. 1-81.

BERNERS-PRICE, S. J.; SADLER, P. J. Coordination chemistry of metalodrugs: insights into biological speciation from NMR spectroscopy. Coordination Chemical Reviews. v. 151, p. 1-40, 1996.

BERTI, J. J. \& LIPSKY, L. J. , Transcutaneous drug delivery: A practical review. Mayo Clin. Proc. 70: 581-586, 1995

BORGES, S. D. S.; DAVANZO, C.U.; CASTELLANO, E.E.; ZSCHPECTOR, J.; SILVA, S.C.; FRANCO, D.W.. Ruthenium nitrosyl complexes with n-heterocyclic ligands. Inorganic Chemistry., v. 37, p. 2670-7, 1998.

BOTTOMLEY, F. Nitrosyl complexes of ruthenium. Coordination Chemical Reviews. v. 26, p. 7-32, 1978. 
BRADDOCK, J. N.; MEYER, T. J. Kinetics of the oxidation of bis $(\pi-$ cyclopentadienylcarbonyliron) by $\mathrm{Ru}(\mathrm{bpy})_{2} \mathrm{Cl}_{2}{ }^{+}$and by $[(\pi-$ $\left.\left.\mathrm{C}_{5} \mathrm{H}_{5}\right) \mathrm{Fe}(\mathrm{CO})\right]_{4}^{+}$. Inorganic Chemistry, v. 12, p. 723-7, 1973.

BUTLER, A. R. The biological roles of nitric oxide. Chemistry \& Industry, v.26, p. 828-30, 1995.

CALLAHAN, R. W.; MEYER, T. J. Reversible electron transfer in ruthenium nitrosyl complexes. Inorganic Chemistry. v. 16, p. 574-81, 1977.

CARLOS, R.M.; FERRO, A.A.; SILVA, H.A.S.; GOMES, M.G.; BORGES, S.S.S.; FORD, P.C.; TFOUNI, E.; FRANCO, D.W. Photochemical reactions of trans-[Ru(NH3)(4)L(NO)](3+) complexes. Inorganica Chimica Acta v.357 (5), p. 1381-1388, 2004

CHEN, Y.; SHEPHERD, R. E. $\left[\mathrm{Ru}_{2}{ }^{\mathrm{II}}(\mathrm{ttha})\left(\mathrm{H}_{2} \mathrm{O}\right)\right]^{2-}$ is a rapid NO Scavenger (ttha $^{6-}=$ triethylenetetraminehexaacetate). Journal of Inorganic Biochemisty, v. 68, p. 183-190, 1997.

CHEN, Y.; LIN, F. T. SHEPHERD, R. E. N-15 NMR and electrochemical studies of $\left[\mathrm{Ru}-\mathrm{II}(\text { hedta) }]^{(-)}\right.$complexes of $\mathrm{NO}, \mathrm{NO}^{+}, \mathrm{NO}^{2-}$, and $\mathrm{NO}^{-}$. Inorganic Chemistry, v. 38, p. 973-83, 1999.

CHENEY, R. P.; ARMOR, J. N. Reactivity of coodinated nitrosyls. 6. Preparation, and reduction nitrosylpentaaquoruthenium (3+) and reduction of various ruthenium ammine nitrosyls. Inorganic. Chemistry, v. 16, p. 3338-3344, 1977. 
CHI,C.M. et al. Cis-ruthenium complexes of 1, 4, 8, 11tetraazaciclotetradecane (cyclam): crystal and molecular structure of cis[Ru(cyclam) $\mathrm{Cl}_{2}$ ]. Inorganic Chemistry, v. 24, p. 1359-1366, 1985.

CHIEN, W.Y. Novel drug delivery systems, $2^{\text {nd }}$ Ed, v.50. Cap 7, 1992.

CULOTTA, E.; KOSHLAND JUNIOR, D. E. NO news is good news. Science, v. 258, p. 1862-1865, 1992.

DE BARROS, B.F.; TOLEDO, J.C.; FRANCO, D.W.; TFOUNI, E.; KRIEGER, M.H. A new inorganic vasodilator, trans[Ru(NO)(NH3)(4)(POEt)(3)](PF6)(3): hypotensive effect of endotheliumdependent and -independent vasodilators in different hypertensive animals models. Nitric Oxide-Biology and Chemistry, v.7 (1), p. 50-56, 2002.

DEB, A. K.; PAUL, P. C.; GOSWAMI, S. Synthesis, characterization, and reactivity of new mononitrosyl complexes of ruthenium containing 2(arylazo)pyridines: examples of strongly eletrophilic nitrosyls. J. Chem. Soc. Dalton Trans. v. 8, p. 2051-4, 1988.

DURHAM, B.; WALSH, J.L.; CARTER, C.L.; MEYER, T.J. Synthetic applications of photosubstitution reactions of poly(pyridyl) complexes of ruthenium(II). Inorganic. Chemistry, v. 19, p. 860-865, 1980. 
DWYER, F. P; GOODWIN, H. A.; GYARFAS, E. C. Mono and bis(2, 2'bipyridine) and (1, 10-phenantroline) chelates of ruthenium and osmium. 1. Monochelates of bivalent, tervalent, and quadrivalent ruthenium. Aust. J. Chem. v. 16, p. 42, 1963.

ELSON, C. M.; ITZKOVITCH, I. J.; PAGE, J. A. Electrochemistry of ruthenium ammine complexes. Can. J. Chem. v. 53, p. 2922-9, 1975.

FELDMAN, P.L.; GRIFFITH, O.W.; STUEHR, D.J. The surprising life of nitric oxide. Chemical \& Engineering News, v. 20, p. 26-38, 1993.

FERREIRA, K.Q.; SANTOS, F.G.; DA ROCHA, Z.N.; GUARATINI, T.; DA SILVA, R.S.; TFOUNI, E. Conformational isomers of cischloro(nitrosyl)(1,4,7,10-tetraazacyclododecene)ruthenium(II), cis[(RuCl)-Cl-II(imcyclen)(NO+)](2+). Oxidation of the coordinated 1,4,7,10-tetraazacyclododecane (cyclen) ligand. Inorganic Chemistry Communications, v. 7 (2), p. 204-208, 2004.

FERRO , A. A. Síntese, caracterização e reatividade química e fotoquímica de aminas de rutênio (trans-[Ru(NO(NH$\left.)_{4} \mathrm{~L}\right]\left(\mathrm{BF}_{4}\right)_{3}(\mathrm{~L}=$ pz, 4-acpy, imN ou L-hist) e trans-[RuCl(NO)(cyclam)]( $\left.\mathrm{PF}_{6}\right)_{2}$ (cyclam = 1, 4, 8, 11-tetraazaciclotetradecano). Ribeirão Preto, 2000. Tese (Doutorado)-Departamento de Química - Faculdade de Filosofia, Ciências e Letras de Ribeirão Preto, Universidade de São Paulo. 
FORD, P. C.; et al. Synthesis and properties of pentaamminepyridine ruthenium(II) and related pentaamineruthenium complexes of aromatic nitrogen heterocycles. Journal of the American Chemical Society, v. 90, p. 1187-94, 1968.

FORD, P.C.; BOURASSA, J.; MIRANDA, K.; LEE, B.; LORKOVIC, I.; BOGGS, S.; KUDO, S.; LAVERMAN, L. Photochemistry of metal nitrosyl complexes. Delivery of nitric oxide to biological targets. Coordination Chemical Reviews, v. 171, p. 185-202, 1998.

FRICKER, S.P.; SLADE, E.; POWELL, N.A.; VAUGHAN, O.J.; HENDERSON, G.R.; MURRER, B.A.; MEGSON, I.L.; BISLAND, S.K.; FLITNEY, F.W. Ruthenium complexes as nitric oxide scavengers: a potential therapeutic approach to nitric oxide-mediated diseases. British Journal of Pharmacology, v. 122, p. 1441-1449, 1997.

GLIKFELD, P.; CULLANDER, C.; HINZ, R.S.; GUY, R.H. A new system for in vitro studies of iontophoresis. Pharm. Res., v.5, n.7, p.443-446, 1988.

GLOOR, M. ; HAUTH, A.; GEHRING, W.. O/W emulsions compromise the stratum corneum barrier and improve drug penetration. Pharmazie v.58(10) p.709-15, 2003.

GODWIN, J. B.; MEYER, T. J. The preparation of ruthenium nitrosyl complexes containing 2, 2'-bipyridine and 1, 10-phenanthroline. Inorganic Chemistry, v. 10, p. 471-4, 1971a. 
GODWIN, J. B.; MEYER, T. J. Nitrosyl-nitrite interconversion in ruthenium complexes. Inorganic Chemistry., v. 24, p. 2150-2153, 1971b.

GORELSKY, S. I.; et al. Electronic spectra of trans- $\left[\mathrm{Ru}\left(\mathrm{NH}_{3}\right)_{4}(\mathrm{~L})(\mathrm{NO})\right]^{3+/ 2+}$ complexes. Inorganic Chimica Acta. v. 300-302., p. 698-708, 2000.

GUENGERICH,C. P.; SCHUG, K. Reaction of nitrosylpentaamminruthenium (II) with ethylamine, methylamine, and hexaammineruthenium(III) ion to produce dinitrogen complexes. Inorganic Chemistry, v. 17, p.1378-1379, 1978.

GUO, Z.J.; SADLER, P. J. Medicinal inorganic chemistry. Advances in Inorganic Chemistry, v. 49, p. 183-306, 2000.

GUY, R.H.; HADGRAFT, J; On the determination of drug release rates from topical dosage forms. International Journal of Pharmaceutics, v.60 (2), R1-R3, 1990.

HADGRAFT, J; WHITEFIELD, M; ROSHER P.H. Skin penetration of topical formulations of ibuprofen 5\%: an in vitro comparative study.Skin Pharmacol Appl Skin Physiol. v16(3) p137-42 2003

HEINEMANN,C.;ELSNER,P. Efficacy measurement of topical antihistamines: a review. Skin Pharmacol Appl Skin Physiol. v16(1) p4-11.2003 
HIGUCHI, W.I.; LI, S.K.; GAHNEM, A.H.; ZHU, H.; SONG, Y. Mechanistic aspects of iontophoresis in human epidermal membrane. J. Control. Rel., v. 62, p. 13-23, 1999.

IGNARRO L. Nitric Oxide: Biology and Phatobiology, San Diego, California, USA, 1. Ed., Academic Press, 2000.

JAECKLE E.; SCHAEFER, U.F.; LOTH, H. Comparison of effects of different ointment bases on the penetration of ketoprofen through heatseparated human epidermis and artificial lipid barriers.Journal PharmaceuticalScience.v.92(7)p.1396-406.

JOHNSON, E. C. et al. Synthesis and properties of the chloro-bridged dimer $\left[(\mathrm{bpy})_{2} \mathrm{RuCl}_{2}\right]^{2+}$ and its $3+$ mixed-valence ion. Inorganic Chemistry,v. 17, p. 2211-5, 1978.

JUNQUEIRA \& CARNEIRO. Pele e anexos. In:_. Histologia Básica 9.ed. Rio de Janeiro: Guanabara Koogan,.p.303-14, 1999

JURIS, A.; BALZANI, V. Ru(II) polypyridine complexes: photophysics, photochemistry, electrochemistry, and chemiluminescense. Coordination Chemical Reviews, v. 84, p. 85-277, 1988.

KAMMERAU, B.; ZESCH, A.; SCHAEFER, H. Absolute concentrations of dithranol and triacetyl-dithranol in the skin layers after local treatment: in vivo investigations with four different types of pharmaceutical vehicles. $\mathbf{J}$ 
$\begin{array}{lllllll}\text { Invest } & \text { Dermatol. } & \text { v. } & 64 & \text { (3) } & \text { p.145-9, } & 1975\end{array}$

KHAN, M.; SEKHON, B.; JATANA, M.; GIRI, S.; GILG, A. G.;

SEKHON, C.; SINGH, I.; SINGH, A. K. Administration of Nacetylcysteine after focal cerebral ischemia protects brain and reduces inflammation in a rat model of experimental stroke. Journal Of Neuroscience Research v.76 (4): p. 519-527, 2004

KOPPENOL, W.H. Nitric oxide measurements using electrochemical methods.. In: PACKER, L. (ed.) Nitric Oxide. Part A: sources and detection of NO; NO synthase. Methods in Enzimology, Califórnia, Academic Press, v. 268, 1996. Cap. 2, p. 7-12.

KRIEGER, M.H.; SUMITANI, M.; MARCONDES, F.G.; FERRO, A.A.; CLARKE, M.J.; FRANCO, D.W.; TFOUNI, E. NO-cyclam: Mechanism of the vasodilator effect. Hypertension, v. 37 (3), p. 1020-1020, 2001.

KRIEGER, M.H.; BARROS, B.F.; TOLEDO, J.C.; FRANCO, D.W.; TFOUNI,E.Vasodilatoreffect of trans-[Ru(NH3)4P(OEt)(3)(NO)](PF6)(3) in different hypertensive rats. Journal of Hypertension, v.20, R169 Suppl. 4, 2002.

KITSON, N.; THEWALT, J.L. Hypothesis: the epidermal permeability barrier is a porous medium. Acta Derm. Venereol., Supp 208, p.12-15, 2000.

LANG, D.R.; DAVIS, J.A.; LOPES, L.G.F.; FERRO, A.A.; VASCONCELLOS, L.C.G.; FRANCO, D.W.; TFOUNI, E.; 
WIERASZKO, A.; CLARKE, M.J. A controlled NO-releasing compound: synthesis, molecular structure, spectroscopy, electrochemistry, and chemical reactivity of R,R,S,S-trans-[RuCl(NO)(cyclam)](2+)(1,4,8,11tetraazacyclotetradecane). Inorganic Chemistry, v. 39, p. 2294-2300, 2000

LEVER, A. B. P. Inorganic electronic spectroscopy. 2.ed. Nova Iorque, Elsevier, 1984.

LEVER, A. B. P. Electrochemical parametrization of metal complex redox potentials, using the ruthenium(III)/ruthenium(II) couple to generate a ligand electrochemical series. Inorg. Chem., v. 29, p. 1271-85, 1990.

LOPEZ, R.F.V.; BENTLEY, M.V.L.B.; DELGADO-DOMO, M.B.; GUY, R.H. Optimization of aminolevulinic acid delivery by iontophoresis. $\boldsymbol{J}$. Control. Release, v.88, n.1, p.65-70, 2003.

MARCONDES, F. G. et al. In vivo action of new NO donor/scavenger ruthenium cyclam complexes: a promising tool for the control of vascular tonus.Submetido à publicação em Life Sciences. 2001.

MARCONDES, F.G; FERRO, A.A.; SOUZA-TORSONI, A; SUMITANI, M; CLARKE, M.J.; FRANCO, D.W.; TFOUNI, E.; KRIEGER, M.H. In vivo action of new NO donor/scavenger ruthenium cyclam complexes: a promising tool for the control of vascular tonus. Life Sciences, v.70 (23), p. 2735-2752, 2002. 
MARTINEZ, M. S. Fotoquímica e determinação das energias dos estados excitados responsáveis pelas reações fotoquímicas de algumas aminas de rutênio via supressão/sensibilização. São Carlos, 1997. Tese (Doutorado) - Instituto de Química de São Carlos, Universidade de São Paulo.

McGARVEY, B.R.; FERRO, A.A.; TFOUNI, E.; BEZERRA, C.W.B.; BAGATIN, I.; FRANCO, D.W. Detection of the EPR spectra of NO center dot in ruthenium(II) complexes. Inorganic Chemistry, v. 39, p. 3577-81, 2000.

MONCADA, S.; PALMER, R.M.J.; HIGGS, E.A. Nitric oxide: physiology, pathophysiology and pharmacology. Pharmacology Reviews, v. 43, p. 109-120, 1991.

MOSER, K.; KRIWET, K.; NAIK, A.; KALIA, Y.N.; GUY, R.H. Passive skin permeation enhancement and its quantification in vitro. Eur. $\boldsymbol{J}$. Pharm. Biopharm., v.52, p.103-112, 2001.

MURPHY, W. R. Jr.; TAKEUCHI, K. J.; MEYER, T. J. Interconversion of nitrite and ammonia: progress toward a model for nitrite reductase. Journal of the American Chemical Society, v. 104, p. 5817-5819, 1982.

MURPHY, W.R.; TAKEUCHI, K.; BARLEY, M.H.; MEYER, T.J. Mechanism of reduction of bound nitrite to ammonia. Inorganic Chemistry, v. 25, p. 1041-53, 1986. 
NAGAO, H.; NISHIMURA, H.; FUNATO, H.; ICHIKAWA, Y.; HOWELL, F.S.; MUKAIDA, M.; KAKIHANA, H. Synthesis, properties, and molecular-structure of trans-chloronitrosylbis(2,2'bipyridine)ruthenium(2+): trans and cis isomer characteristics compared. Inorganic Chemistry, v. 28, p. 3955-3959, 1989.

NICHOLSON, R.S.; SHAIN, I. Theory of stationary electrode polarography for a chemical reaction coupled between two charge transfers. Analytical Chemistry, v. 37, p. 178-90, 1965.

OLIVEIRA, F.S.; TGNIOLO, V.; PUPO, T.T.; TEDESCO, A.C.; SILVA, R.S. Nitrosyl ruthenium complex as nitric oxide delivery agent: synthesis, characterization and photochemical properties. Inorganic Chemistry Communication, v.7, p.160-164, 2004.

OOYAMA, D.; MIURA, Y.; KANAZAWA, Y.; HOWELL, F.S.; NAGAO, N.; MUKAIDA, M.; NAGAO, H.; TANAKA, K.; Synthesis, characterization, structure and redox behavior of cis$\left[\mathrm{Ru}(\mathrm{NO}) \mathrm{X}(\mathrm{bpy})(\mathrm{py})_{2}\right]^{\mathrm{z}} \quad(\mathrm{X}=$ monodentate $) \quad$ type complexes of nitrosylruthenium (II) and their related complexes. Inorganica Chimica Acta, v. 237, p. 47-55, 1995.

PEREIRA, G.R. Estudo da monoleína como promotor de absorção cutânea para a progesterona: proposição de um sistema de liberação transdérmica. Tese de Mestrado. Faculdade de Ciências Farmacêuticas de Ribeirão Preto, Universidade de São Paulo, 1999. 
PIROT,F.;KALIA,Y.N.;STINCHCOMB,A.L.;KEATING,G.;BUNGE,A.;GU

Y, R.H. Characterization of the permeability barrier of human skin in vivo. Proc Natl Acad Sci U S A. v 94(4)p.1562-7, 1997

RANADE, V V , Drug delivery systems. 6. Transdermal drug delivery. J. Clin. Pharmacol. 31: 401-418, 1991

RICHTER-ADDO, G. B.; LEGZDINS, P. Metal nitrosyls. Nova Iorque, Oxford University Press, Inc., 1992.

SADLER, P. J. Inorganic chemistry and drug design. Adv. Inor. Chem. v. 36, p. 1-48, 1991.

SAUAIA, M.G.;DA SILVA, R.S. The reactivity of nitrosyl ruthenium complexes containing polypyridyl ligands Transition Metal Chemistry, v.28(3), p.254-259, 2003.

SAUAIA, M.G.; OLIVEIRA, F.S.; TEDESCO, A.C.; SILVA,R.S Control of NO release by light irradiation from nitrosyl-ruthenium complexes containing polypyridil ligands. Inorganica Chimica Acta, v.355, p.191196, 2003a.

SAUAIA, M.G.; LIMA, R.G., TEDESCO, A.C., SILVA, R. S., Photoinduced no release by visible light irradiation from pyrazine-bridged nitrosyl ruthenium complexes, Journal of the American Chemical Society, v.125, p.14718-14719, 2003b. 
SCHMOOK, P.F.; MEINGASSNER, G.J.; BILLICH, A. Comparison of human skin or epidermis models with human and animal skin in in-vitro percutaneous absorption. International Journal of Pharmaceutics, v. 215, p. 51-56, 2001.

SCHWIETERT, C. W.; McCUE, J. P. Coordination compounds im medicina chemistry. Coordination Chemical Reviews v. 184, p. 67-89, 1999.

SCHRÖDER, M.; STEPHENSON, T. A. Ruthenium. In: WILKINSON, G. (ed.). Comprehensive Coordination Chemistry. The synthesis, reactions e applications of coordination compounds. 1.ed. Nova Iorque, Pergamon Press, 1987. v. 4, cap. 45,p. 279-518.

SEDDON, E. A.; SEDDON, K. R. The chemistry of ruthenium. Nova Iorque, Elsevier, 1984.

SHIMOKAWA, H. et al. Coronary artery spasm induced in arterosclerotic miniature swine. Science. v. 221, p. 550-62, 1983.

SHUKLA, R., RAJANI, M., BARTHWAL, M. K., SRIVASTAVA, N., DIKSHIT, M. Cerebrospinal fluid nitrite and malondialdehyde levels in patients with motor neuron disease. INTERNATIONAL JOURNAL OF NEUROSCIENCE v. 113 (8): p. 1043-1054, 2003

SILVA, R. S.; TFOUNI, E. Ruthenium(II) macrocyclic complexes with inert chloride and labile azines. Synthesis and properties of the macrociclic complexes

trans- 
chloro(azine)(1,4,8,11tetraazaciclotetradecane)ruthenium(II)trans-

[RuCl(cyclam)L] $]^{+}$Inorganic Chemistry., v. 31, p. 3313-24, 1992.

SILVA, R. S. et al. Structural properties of trans-chloro(4-acetylpyridine) (1, 4, 8, 11-tetraazaciclotetradecane)ruthenium(II) tetrafluorborate, trans[RuCl(cyclam)(4-acpy)](BF $\mathrm{BF}_{4}$, by X-ray diffraction and NMR spectroscopy. Inorganica Chimica Acta, v. 245, p. 215-20, 1992.

SNYDER, S. H.; BREDT, D. S. Biological roles of nitric oxide. Scientific American. v. 266,p. 28-35, 1992.

STAMLER, J.S.; SINGEL, D.J.; LOSCALZO, J. Biochemistry of nitric oxide and its redox-activated forms. Science, v. 258, p. 1898-902, 1992.

STOCHEL, G.; WANAT, A.; KULIS, E.; STASICKA, Z. Light and metal complexes in medicine, Coordination Chemical Reviews v. 171, p. 20320, 1998.

SUHONEN, M. et al., A, Chemical enhancement of percutaneous absorption in relation to stratum corneum structural alterations. J. Control. Rel. 59: 149-161, 1999

SZCZEPURA, L. F.; TAKEUCHI, K. J. Synthesis and characterization of novelcyclopentadienyl)nitrorutheniumcomplexes.InorganicChemistry v.29, p. 1772-1777, 1990.

SZNITOWSKA, M.; DABROWSKA,E.A.; JANICKI, S. Solubilizing 
potential of submicron emulsions and aqueous dispersions of lecithin. International Journal of Pharmaceutics. v 246 (1-2) p. 203-206, 2002

TFOUNI, E.; FORD, P. C. Thermal and photo-chemical properties of some trans-disubstituted tetraammineruthenium (II) complexes of aromatic nitrogen-heterocycles, trans-[Ru( $\left.\left.\mathrm{NH}_{3}\right)_{4} \mathrm{LL}^{\prime}\right]^{\mathrm{n}+}$. Inorganic Chemistry v.19, p. $72-6,1980$

TFOUNI, E.; KRIEGER, M.; MCGARVEY, B.R.; FRANCO, D.W. Structure, chemical and photochemical reactivity and biological activity of some ruthenium amine nitrosyl complexes. Coordination Chemical Reviews v.236(1-2), p. 57-69, 2003

TOGNIOLO, V.; SILVA, R. S.; TEDESCO, A. C. Photo-induced nitric oxide release from chlorobis(2,2 '-bipyridine)nitrosylruthenium(II) in aqueous solution. Inorganica Chimica Acta. v. 316, p. 7-12, 2001.

TOLEDO, J.C.; LOPES, L.G.D.; ALVES, A.A.; DA SILVA, L.P.; FRANCO, D.W. Release of NO by a nitrosyl complex upon activation by the mitochondrial reducing power. Journal of Inorganic Biochemistry v. 89 (3-4), p. 267-271, 2002.

TOMA, H.E.; SERRASQUEIRO, R.M.; ROCHA, R.C.; DEMETS, G.J.F.; WINNISCHOFER, H.; ARAKI, K.; RIBEIRO, P.E.A.; DONNICI, C.L. Photophysical and photoelectrochemical properties of the bis(2,2'bipyridine)(4,4'-dimethylthio-2,2'-bipyridine)ruthenium(II) complex. Journal of Photochemistry and Photobiology A-Chemistry, v. 135, p. 
185-191, 2000.

TOGANO, T.; KURODA, H.; NAGAO, N.; MAEKAWA, Y.; NISHIMURA, H.; HOWELL, F.S.; MUKAIDA, M. Synthesis, properties and molecular structure of trans-hydroxobis (2,2'-bipyridine)nitrosylruthenium(2+): influence of axial ligand on characteristics of nitrosyl moiety in trans$\left[\mathrm{Ru}(\mathrm{NO}) \mathrm{XL}_{4}\right]^{\mathrm{n}+}(\mathrm{X}=\mathrm{OH}, \mathrm{Cl} ; \mathrm{L}=\mathrm{py}, 1 / 2($ bpy $))$ type complexes. Inorganica Chimica Acta, v. 196, p. 57-63, 1992.

TOMA, H. E. et al. Photophysical and photoelectrochemical properties of the bis(2,2’-bipyridine)(4,4'-dimethylthio-2,2'-bipyridine)ruthenium(II) complex. J. Photoch. Photobio. A. v. 135, p. 185-191, 2000.

TORSONI, A.S.; DE BARROS, B.F.; TOLEDO, J.C.; HAUN, M.; KRIEGER, M.H.; TFOUNI, E.; FRANCO, D.W. Hypotensive properties and acute toxicity of trans-[Ru(NH3)(4)P(OEt)(3)(NO)](PF6)(3), a new nitric oxide donor. Nitric Oxide-Biology and Chemistry, v. 6 (3), p. 247254, 2002.

TRAYLOR, T. G.; SHARMA, V. S. Why NO? Biochemistry, v. 31, p. 28472455, 1992.

UEKAMA, K,; ADACHI, H.; IRIE, T.; YANO,T.; SAITA, M.; NODA, K; WALSH, J. L.; DURHAM, B. Trans isomers of ruthenium(II) complexes containing two bipyridine ligands. Inorganic Chemistry. v. 21, p. 329332, 1982. 
UEKAMA, K.; IMAI,T.; MAEDA, T.; IRIE, T.; HIRAYAMA, F.; OTAGIRI, M. Improvement of dissolution and suppository release characteristics of flurbiprofen by inclusion complexation with heptakis(2,6-di-O-methyl)-beta-cyclodextrin.Journal of Pharmaceutical $\begin{array}{llllll}\text { of } & \text { Science. } & \text { v. } & 74(8) & \text { p. } & \text { 841-5.1985 }\end{array}$

WALSH, J. L.; BULLOCK, R. M.; MEYER, T. J. Alkyl nitrite complexes of ruthenium prepared by acid-base chemistry at the bound nitrosyl group. Inorganic Chemistry, v. 19, p. 865-9, 1980.

WIERASZKO, A.; CLARKE, M.J.; LANG, D.R.; LOPES, L.G.F.; FRANCO, D.W. The influence of NO-containing ruthenium complexes on mouse hippocampal evoked potentials in vitro. Life Sciences, v. 68, p. 1535-44, 2001.

WINK, D.A.; GRISHAM, M.B.; MITCHELL, J.B.; FORD, P.C. Direct and indirect effects of nitric oxide in chemical reactions relevant to biology. In: PACKER, L. (ed.) Nitric Oxide. Part A: sources and detection of NO; NO synthase. Methods in Enzimology. Califórnia, Academic Press, v. 268, 1996. Cap. 3, p. 12-31

WORKS, C. F.; FORD, P. C. Photoreactivity of the ruthenium nitrosyl complexes, Ru(salen)(CL)(NO). Solvent effects on the back reaction of $\mathrm{NO}$ with the Lewis acid $\mathrm{Ru}^{\mathrm{III}}(\mathrm{salen})(\mathrm{Cl})$. Journal of the American Chemical Society, v.122, p. 7592-3, 2000. 
WORKS, C. F.; JOCHER,C.; FORD, P. C . Synthesis, characterization, and photophysical studies of some ruthenium salen nitrosyl compounds: Potential NO delivery agents and mechanistic insights in catalytic behavior. Abstracts of Papers of the American Chemical Society, v. 221, p. 712, 2001.

ZAMPIERI, R.C.L.; VON POELHSITZ, G., BATISTA, A.A.; NASCIMENTO, O.R.; ELLENA, J.; CASTELLANO, E.E. Syntheses, characterization and X-ray structures of the fac-[RuCl3(NO)(dppe)] and the trans-[RuCl(NO)(dppe)(2)](2+) species. Journal of Inorganic Biochemistry, v.92(1), (1): p.82-88, 2002. 